\title{
EVOLUÇÃO DA MORTALIDADE GERAL, INFANTIL E PROPORCIONAL NO BRASIL
}

\author{
João YUNES * \\ Vera Shirley Carvalho RONCHEZEL **
}

YUNES, J. \& RONCHEzel, V. S. C. - Evoluçāo da. mortalidade geral, infantil $e$ proporcional no Brasil. Rev. Saúde públ., S. Paulo, 8(supl.):3-48, 1974.

ReSUMo: Estudo da evolução da mortalidade geral, infantil e proporcional para o Brasil e Regiões Fisiográficas de 1941 a 1970. Nos ultimos 30 anos a redução de mortalidade geral para o Brasil foi de $47,5 \%$, tendo sido maior a queda na região Centro-Oeste. No último decenio observa-se o aumento do coeficiente em todas as regióes iniciando-se em diferentes periodos, sendo em parte devido ao aumento da mortalidade infantil. Ao se comparar a mortalidade geral do Brasil com a de países mais desenvolvidos, ela pode ser considerada elevada, uma vez que cerca de 42\% da população tem menos de 14 anos de idade, indicando nivel de saúde insatisfatório. Para a mortalidade infantil, em 30 anos houve uma redução de seu coeficiente em 46,2\%, tendo sido maior esta queda na região Centro-Oeste. No último decênio, observa-se um aumento deste coeficiente, sugerindo, portanto, uma piora do nivel de saúde e ao se comparar com outros paises é notória a diferença observada. Ao se comparar a mortalidade proporcional (percentagem do total de óbitos de crianças menores de 1 anol de 1940/1970, observa-se uma elevação de 16,3\%, sendo no último decênio o maior aumento para as regióes Centro-Oeste $(5 \%, 7 \%)$ e Sudeste (36,1\%). Ao se comparar os dados do Brasil com o Estado e Município mais desenvolvido ( $S \tilde{a}$ o $P$ Pulo), observa-se sempre que estes indicadores para o país como um todo apresentam-se mais elevados, sugerindo um pior nivel de saude. Entre os principais fatores condicionantes da piora do nivel de saúde do Brasil no último decênio, destaca-se o económico onde ocorre um aumento na concentração da distribuição de renda, declíneo do salário minimo real de $20 \%$, com conseqüente diminuição do poder aquisitivo da população assalariada. Acresce-se ainda, o aumento da população descoberta dos recursos de saneamento basico.

UnItermos: Mortalidade (Brasil)*. Niveis de Saude*, Estatistica vital*, Mortalidade infantil*; Mortalidade proporcional; Populaçáa brasileira.

\section{I N T R O D U C A O}

A evolução da mortalidade constitui um importante componente para análise e compreensão do crescimento populacional.
Os principais estudos feitos neste setor para a população brasileira foram realizados, principalmente, por Giorgio Mortara.

* Do Centro de Estudos de Dinâmica Populacional (CEDIP) da Faculdade de Saúde Pública da USP - Av. Dr. Arnaldo, 715 - São Paulo, SP - do Grupo de Pediatria Social da: Faculdade de Medicina da USP. Da Divisão de Epidemiologia da Secretaria do Estado da Saúde.

** Da Divisão de Epidemiologia da Secretarıa do Estado da Saúde - Av. São Luiz, 99 - São Paulo, SP - Brasil. 
YUNES, J. \& RONCHEZEL, V. S. C. - Evolução da mortalidade geral, infantil e proporcional no Brasil. Rev. Saúde públ., S. Paulo, 8(supl):3-48, 1974.

De 1870 a 1940 Mortara" estuda a mortalidade geral para o Brasil através dos censos demográficos do IBGE, tendo sido apresentado os dados em periodos quinquenais até 1920, conforme seguem:

$\begin{array}{cc}\text { Ano } & \begin{array}{c}\text { Mortalidade Geral } \\ \text { (por } 1000 \text { habitantes) }\end{array} \\ 1870-1875 & 31,12 \\ 1875-1880 & 30,19 \\ 1880-1885 & 29,10 \\ 1885-1890 & 28,00 \\ 1890-1895 & 26,84 \\ 1895-1900 & 25,71 \\ 1900-1905 & 24,61 \\ 1905-1910 & 23,61 \\ 1910-1915 & 22,69 \\ 1915-1920 & 21,87 \\ 1920-1940 & 24,94\end{array}$

Em relação à mortalidade infantil MoRTARA ${ }^{10}$ faz um cálculo aproximado deste coeficiente para o Brasil, no decênio anterior ao censo de 1950, aproveitando as tábuas de sobrevivência calculadas para o município de São Paulo (menor mortalidade) e para o município de Recife (maior mortalidade) nos anos de 1939 a 1941, obtendo a taxa de 171 óbitos de crianças menores de um ano por mil nascidos vivos.

Ao se continuar avaliar a evolução da mortalidade geral e infantil para o Brasil, é preciso conhecer a população, o número total de óbitos que ocorre, incluindose os de menores de um ano e o número de nascidos vivos. Embora se conheça em geral a estimativa da população, não se dispõe dos outros elementos, em consequiência das grandes falhas de registro de óbitos e principalmente do de nascimen. tos.
Como a partir de 1940 não contamos praticamente com estimativas destes coeficientes, baseados em séries históricas construídas através de cálculos anuais, julgamos fundamental que se avalie a evolução destes indicadores de saúde para o Brasil, em conjunto, baseado em dados das Capitais dos Estados.

Embora este tipo de análise não permita um conhecimento real da situação de saúde para o Brasil, julgamos válida esta metodologia para que se tenha uma avaliação global dos níveis de saúde. Portanto. sempre que se apresentem tabelas e gráficos especificando "Brasil" e "Regióes Fisiográficas" a situação se refere às Capitais dos Estados.

Como o sub-registro de óbitos é bem menor que o de nascimentos, analisar-se-á. também, a mortalidade proporcional de crianças menores de um ano de idade, constituindo um importante indicador quando o coeficiente de mortalidade infantil é calculado através de dados de precária confiabilidade.

\subsection{Objetivos}

1. Estudar a evolução da mortalidade geral, infantil e proporcional para o Brasil e comparar com as suas Regiōes Fisiográficas de 1941-1970.

2. Comparar a evolução de mortalidade geral, infantil e proporcional do Brasil com uma área mais desenvolvida, Estado de São Paulo e Município. Para esta área o estudo será a partir de 1918.

3. Estudar os fatores condicionantes da situação atual para a década 1960-1970.

\section{MATERIAL E METODOS}

A evolução dos coeficientes foi obtida através da obtenção de dados secundários de várias fontes: 
YUNES, J. \& RONCHEZEL, V. S. C. - Evolução da mortalidade geral, infantil e proporcional no Brasil. Rev. Saúde públ., S. Paulo, 8(supl.):3-48, 1974.

- Anuários Estatísticos do Brasil, dados brutos do I.B.G.E. e do Departamento Estadual de Estatística do Estado de São Paulo. Uma das dificuldades sérias encontradas para compor as regióes ou estudar o Brasil como um todo é que para determinados anos, várias Capitais não apresentavam seus dados publicados.

A composição das Regiões Fisiográficas do Brasil por Capitais de Estado e Territórios são as que se seguem:

Norte: Rio Branco, Porto Velho, Manaus, Boa Vista, Belém e Amapá. Para esta regiāo só existem dados para Belém e Manaus.
Nordeste: São Luiz, Terezina, Fortaleza, Natal, João Pessoa, Recife, Maceió, Aracajú e Salvador.

Centro-Oeste: Cuiabá, Goiânia e Brasília.

Sudeste: Niterói, Belo Horizonte, Vitória, São Paulo e Rio de Janeiro.

Sul: Curitiba, Florianópolis e Porto Alegre.

Para o cálculo do coeficiente de mortalidade geral, para o Brasil e Regiōes Fisiográficas estabeleceu-se a seguinte relação:
Coeficiente de mortalidade geral para o Brasil

N. ${ }^{\circ}$ total de óbitos das Capitais dos Estados População das Capitais dos Estados $\times 1000$

\author{
N.o total de óbitos das Capitais que compōem \\ a Região
}

População das Capitais que compõem a Região
Coeficiente de mortalidade geral por Região Fisiográfica ção da região, esta Capital. Este critério foi adotado também para os coeficientes de mortalidade infantil e mortalidade proporcional.

Para a avaliação da evolução da mortalidade geral excluiu-se, por falta de dados, Brasilia de 1960-1962; Rio de Janeiro 1963; Rio de Janeiro e Porto Alegre de 1964 a 1967; Rio de Janeiro e Florianópolis de 1968-1969 e Rio de Janeiro. São Paulo, Goiânia e Florianópolis em 1970.

A mortalidade infantil para o Brasil e Regiões Fisiográficas foi calculada através da seguinte relação:

$$
\text { atraves da seguinte relaçă }
$$
pital para o cálculo do coeficiente em determinado ano, excluia-se, da composi-

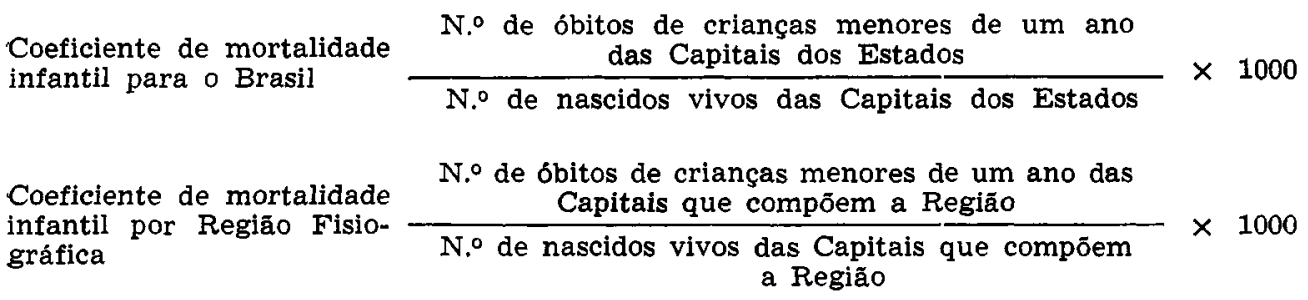


YUNES, J. \& RONCHEZEL, V. S. C. - Evolução da mortalidade geral, infantil e proporcional no Brasil. Rev. Saúde públ., S. Paulo, 8(supl.):3-48, 1974.

No cálculo do coeficiente de mortalidade infantil, nenhuma fonte dos dados consultada tinha o número de nascidos vivos por Capital. Para que o coeficiente de mortalidade infantil para o Brasil e para as Regiões Fisiográficas pudesse ser calculado, estimou-se o número de nascidos vivos de cada Capital através do valor apresentado pelo coeficiente de mortalidade infantil e pelo número de óbitos de crianças menores de um ano.
Para a avaliação da evolução da mortalidade infantil, exclui-se, por falta de dados, Brasília e Florianópolis de 19601962; Brasília e Rio de Janeiro em 1963; Rio de Janeiro e Porto Alegre de 19641967; Rio de Janeiro e Florianópolis de 1968-1969 e Rio de Janeiro, São Paulo, Florianópolis e Goiânia em 1970.

A mortalidade proporcional foi avaliada para o Brasil e para as Regióes Fisiográficas através da seguinte relação: Mortalidade proporcional
para o Brasil

Mortalidade proporcional por Região Fisiográfica

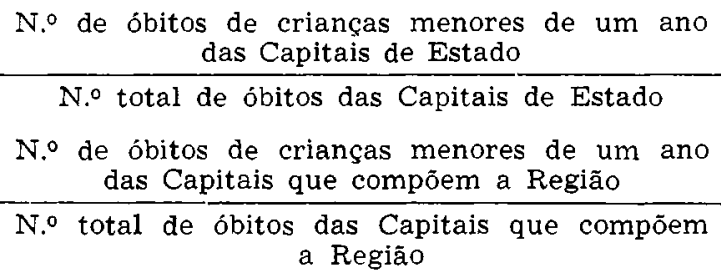

Para avaliação da evolução da mortalidade proporcional. excluiu-se, por falta de dados, Brasília de 1960-1962; Rio de Janeiro em 1963; Rio de Janeiro e Porto Alegre de 1964-1966; Rio de Janeiro, Porto Alegre e Curitiba em 1967; Florianópolis de 1968-1969; e Rio de Janeiro,
São Paulo, Florianópolis e Goiânia em 1970.

As diferenças percentuais dos coeficientes de mortalidade geral, infantil e proporcional foram obtidas calculando-se $o$ quociente da diferença dos coeficientes nos anos extremos da década sobre o coeficiente do ano extremo inicial vezes 100 .

Coeficiente do extremo final da década $=C_{F}$

Coeficiente do extremo inicial da década $=C_{I}$

Diferença percentual do coeficiente na década $=\mathrm{D}$

$$
D=\frac{C_{F}-C_{I}}{C_{I}} \times 100
$$

Tal método foi usado por se necessitar comparar as diferenças dos coeficientes dentro das décadas estudadas para cada Região Fisiográfica e dentro desta para as Capitais que a compõem.

\section{RESUltados E DISCUSSÃO}

\subsection{Evolução da mortalidade geral}

Ao se avaliar a evolução da mortali- dade geral para o Brasil, baseada em dados das Capitais, conforme Tabela $l^{*}$, observa-se que a tendência foi de queda, variando o coeficiente de 19,25 em 194] para 10,12 óbitos por mil em 1970, ou seja, houve uma redução de $47,5 \%$ em 30 anos.

Para o mesmo período (1941-1970), ao se estudar a evolução de mortalidade ge-

* As Tabelas de 1 a 35 encontram-se em Anexo. 
YUNES, J. \& RONCHEZEL, V. S. C. - Evoluçāo da mortalidade geral, infantil e proporcional no Brasil. Rev. Saúde públ., S. Paulo, 8(supl.):3-48, 1974.

ral por Região Fisiográfica, conforme Tabelas 2 a 6 , observa-se que a variação, para a região Norte, por mil habitantes, foi de: 22,45-7,81; região Nordeste 26,5311,41; região Centro-Oeste 27,97-7,94; Sudeste 16,65-10,67 e Região Sul 19,818,10 .

A redução se deu, pois, principalmente na região Centro-Oeste seguida das regiōes Norte, Sul, Nordeste e Sudeste (Tabela 8 ). Nota-se que a região que apresentou a maior redução, apresentava em 1941 o maior coeficiente, enquanto que o Sudeste que apresentou a menor redução tinha o menor coeficiente. Interessante é observar, ainda, o comportamento das outras regiōes e salientar que foge a essa tendência, o Nordeste, que apresentava o segundo maior coeficiente e sofreu a segunda menor redução, conforme se observa a seguir:

\begin{tabular}{lcc}
\multicolumn{1}{c}{ Região } & $\begin{array}{c}\text { Coeficiente } \\
(\%) \\
\text { em 1941 }\end{array}$ & $\begin{array}{c}\text { Reducão } \\
\% \\
(1941-1970)\end{array}$ \\
Centro-Oeste & 27,97 & 71,6 \\
Nordeste & 26,53 & 56,9 \\
Norte & 22,45 & 69,6 \\
Sul & 19,81 & 59,0 \\
Sudeste & 16,65 & 35,9
\end{tabular}

Ao se comparar a mortalidade geral do Brasil com as Regiões, observa-se, de acordo com a Figura 1, que a tendência à queda foi mais ou menos homogênea, havendo maiores flutuações, principalmente para a Região Norte e Nordeste, podendo se responsabilizar este fato, em parte, à qualidade do registro de dados. A curva de mortalidade geral do Brasil segue, em linhas gerais, os valores apresentados pela região Sul. A curva da região Sudeste encontra-se abaixo da do Brasil, apresentando os menores coeficientes; entretanto, no último decênio, observa-se elevação dos mesmos colocandose em situação semelhante a das demais regióes. Acima da curva do Brasil, encontram-se a da região Centro-Oeste para alguns anos, e a das regióes Norte e Nor- deste para todos os anos, indicando nível de saúde mais precário que a do Brasil como um todo, principalmente em relação à região Sudeste. Interessante observar a curva da regiấo Norte abaixo das regiões Nordeste e Centro-Oeste para quase todos os anos o que poderia ser explicado pela dificuldade de locomoção do interior para a Capital com pequena invasão de óbitos o que nos daria coeficientes representativos apenas das Capitais e não dos Estados como um todo, na região Norte.

Analisando-se o comportamento do coeficiente de mortalidade geral para o Brasil por décadas (Tabela 8), observa-se que a tendência à queda diminui $(24,9 \%$ de 1941 a 1950 e apenas $10,9 \%$ de 1960 a $1970)$.

Em relação à região Sudeste, observase comportamento semelhante ao Brasil no período 1941 a 1960. Interessante notar que no decênio seguinte $(1960$ a 1970$)$. a situação se inverte, isto é, ao invés de se observar uma redução no coeficiente. existe um nítido aumento de $10,1 \%$, ou seja, uma elevação no coeficiente de mortalidade geral, devido, em parte, ao aumento da mortalidade infantil como se mostrará adiante.

Para as demais regiōes, em geral, a tendência é diminuir o declínio da mortalidade na década 1950-1960, em relação à anterior, e aumentar na década seguinte. Observa-se, contudo, que a redução da mortalidade apresentada para a década de 1960-1970, embora seja, geralmente maior que na década imediatamente anterior, é em geral menor que na década de 1940-1950, fazendo exceção a região Nordeste, que apresentou nos últimos dez anos a maior redução no seu coeficiente de mortalidade geral desde 1941. Para a última década, a região Norte foi a que apresentou maior redução no seu coeficiente de mortalidade geral (Tabela 81 . Essa tendência é evidente, considerandose os anos extremos 1960-1970.

Nota-se, pela Figura 1, que todas as regiōes apresentam, dentro da década. 1960-1970, uma tendência ao aumento. 
YLNES, J. \& RONCHEZEL, V. S. C. - Evolusão da mortalidade geral, infantil e proporcional no Brasil. Rer. Saúle pribl., S. Paulo, 8(supl):3-48, 1974.

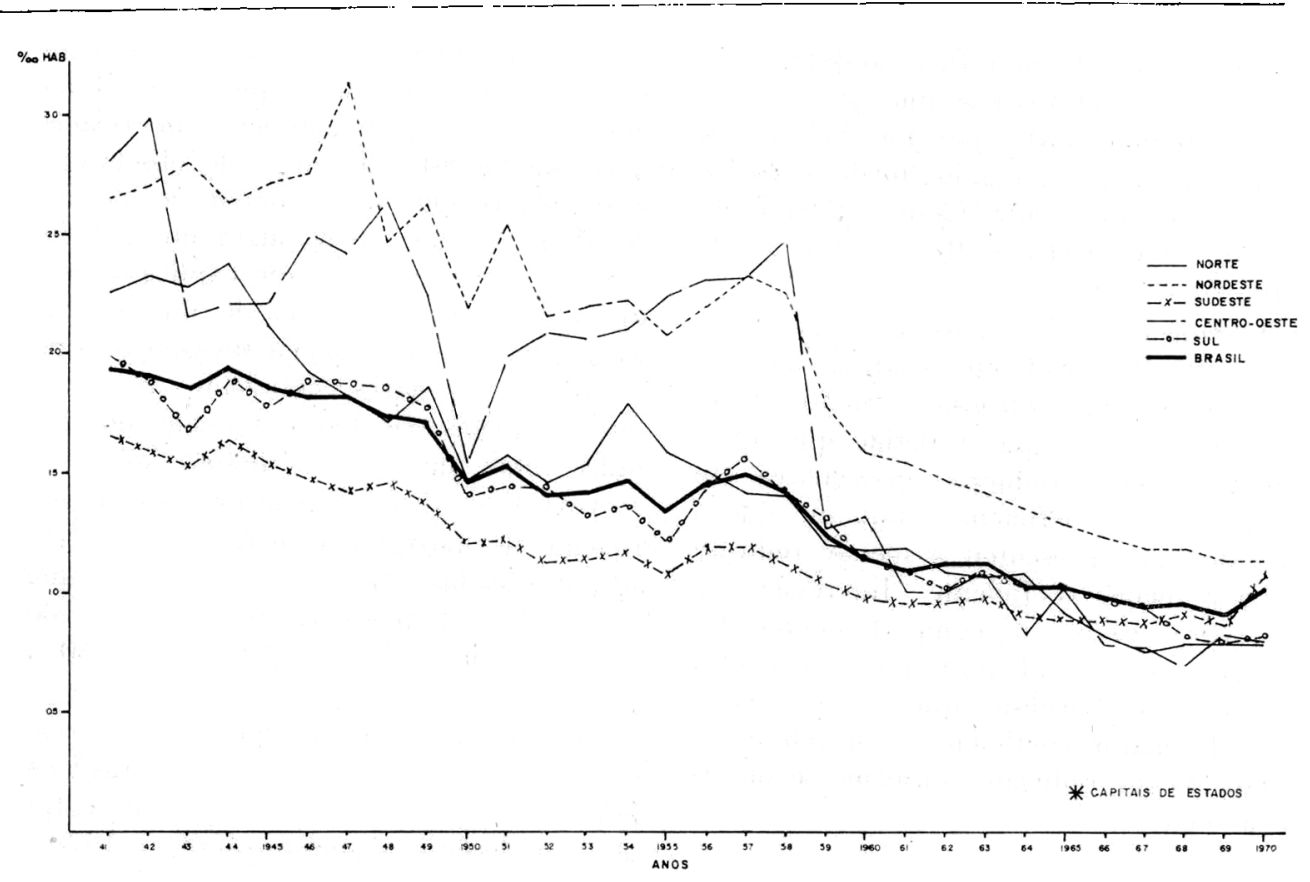

Fig. 1 - Evolução da mortalidade geral no Brasil e por regiôes fisiográficas * $1941-1970$.

que começa para a região Sudeste em 1965, para o Norte em 1967, Centro-Oeste em 1968 e no Nordeste e Sul em 1969.

Na regiäo Centro-Oeste, onde se observou o maior declínio da mortalidade Geral $(71,6 \%$ em 30 anos), a capital que mais contribuiu para esta queda foi Goiânia que em 1941 apresentava um coeficiente de 36,1 óbitos por mil habitantes e em 1969 o valor foi de 10,9 (Fig. 2).

A região Norte apresentou um declínio de $69,2 \%$ e, considerando-se as duas $\mathrm{Ca}$ pitais que forneceram dados para o nosso estudo, observa-se que em Belém houve um declínio de $67,5 \%$ (25,6\% em 1941 e $8.3 \%$ em 1970) enquanto que em Manaus o declínio foi de $40,3 \%(17,6 \%$ em 1941 e 10,7\% em 1970) (Fig. 3).

Na regiáo Sul o declínio foi de $59 \%$, sendo Florianópolis e Porto Alegre as Capitais que mais contribuiram. Para Florianópolis, a redução em 27 anos (1941-67) foi de $63,6 \%$ e para Porto Alegre, em 30 anos, esta queda foi de $62.2 \%$.
Em Curitiba houve uma redução de apenas $14,3 \%$, mas em todo o Brasil excluindo São Paulo foi a Capital que, em 1941, apresentou o menor coeficiente de mortalidade geral $(14,7 \%$ ) (Fig. 4).

A região Nordeste apresentou um dezlínio de $56,9 \%$. Em Aracajú esta queta foi de $69,0 \% \quad(23,6 \%$ em 1941 e $7.3 \%$ em 1970) e em Fortaleza e Maceió observou-se as menores reduções $(29,0 \%$ e $28,7 \%$ respectivamente) (Fig. 5 ).

Para o Sudeste, a redução foi de apenas $35,9 \%$ e Niterói e Rio de Janeiro foram as capitais que mais contribuiram para esta queda, tendo sido de $48,3 \%$ e $48,8 \%$ respectivamente (Fig. 6).

Nas outras regióes, a tendência observada foi que a Capital que possuia o maior coeficiente, em 1941, apresentava também maior declínio no decorrer dos 30 últimos anos, com exceção da região Nordeste e Sudoeste.

Por outro lado, ao se comparar os dados do Brasil com a área mais desenvol- 
YUNES, J. \& RONCHEZEL, V. S. C. - Evoluçăo da mortalidade geral, infantil e proporcional no Brasil. Rev. Saúde públ., S. Paulo, 8(supl.):3-48, 1974.

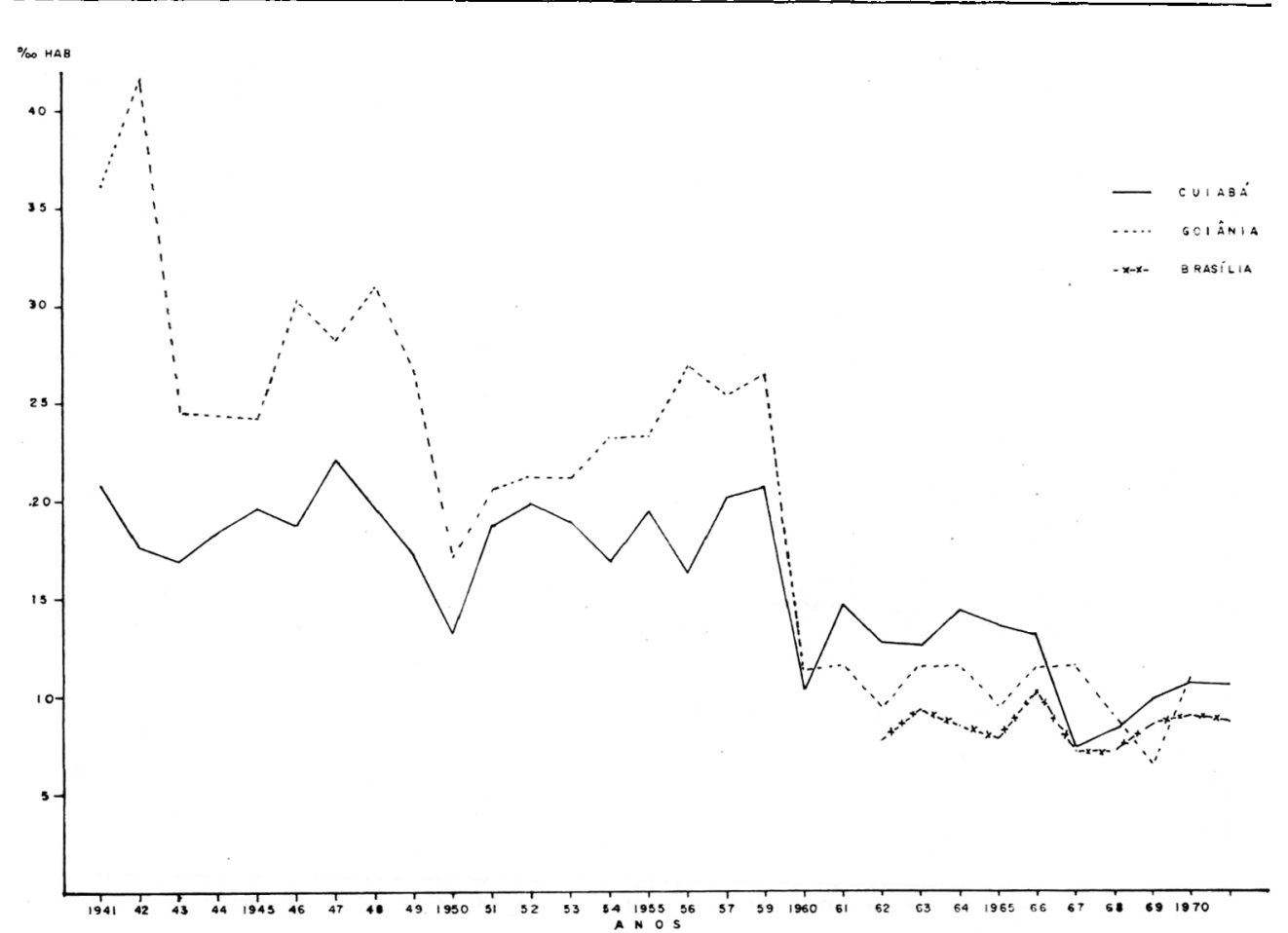

Fig. 2 - Evolução da mortalidade geral por capital na região centro-oeste - 1941-1970

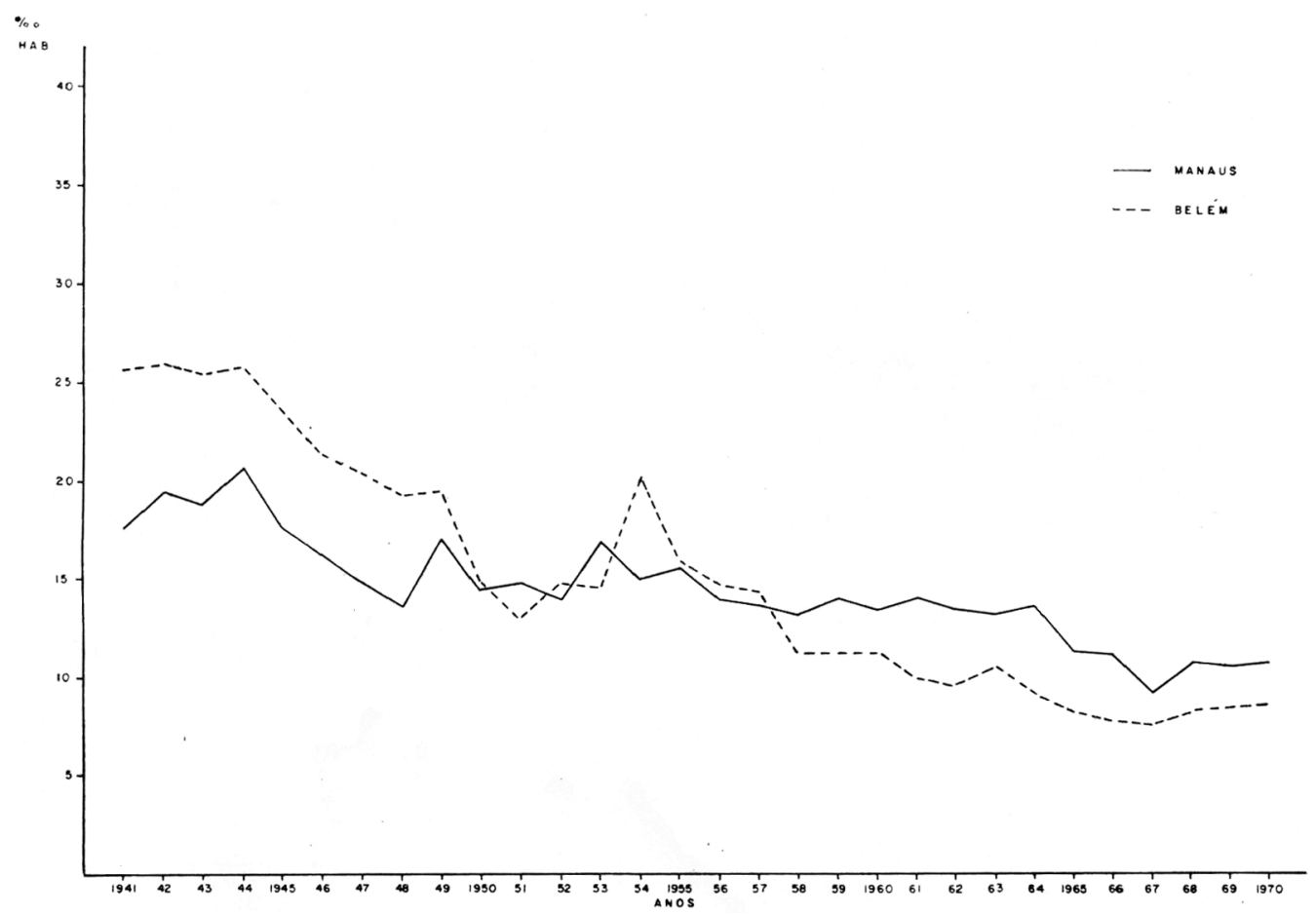

Fig. 3 - Evolução da mortalidade geral por capital na regiăo norte - 1941-1970. 
YUNES, J. \& RONCHEZEL, V. S. C. - Evoluçāo da mortalidade geral, infantil e proporcional no Brasil. Rev. Saúde públ., S. Paulo, 8(supl.):3-48, 1974.

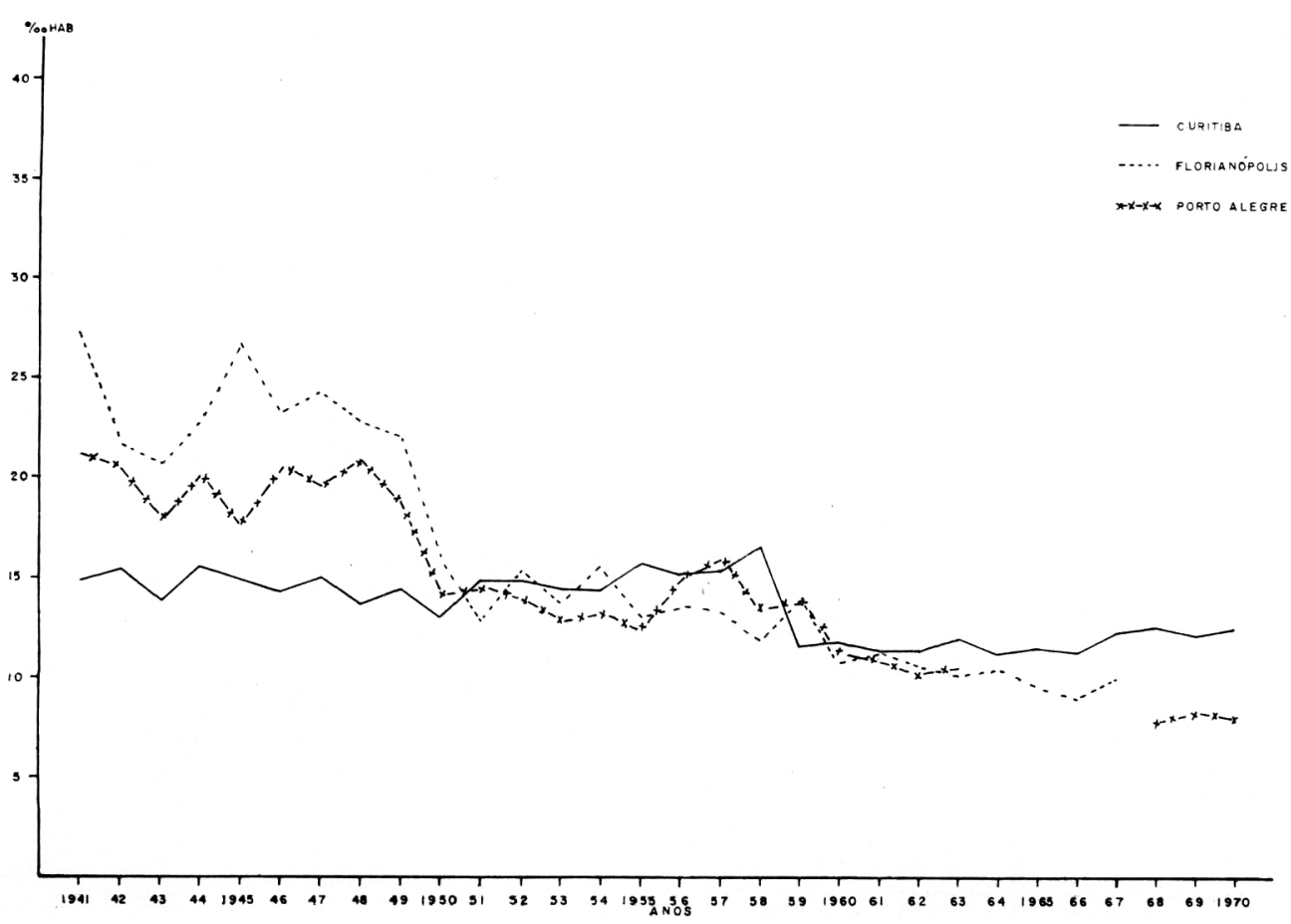

Fig. 4 - Evolução da mortalidade geral por capital na regiano sul - 1941-1970.

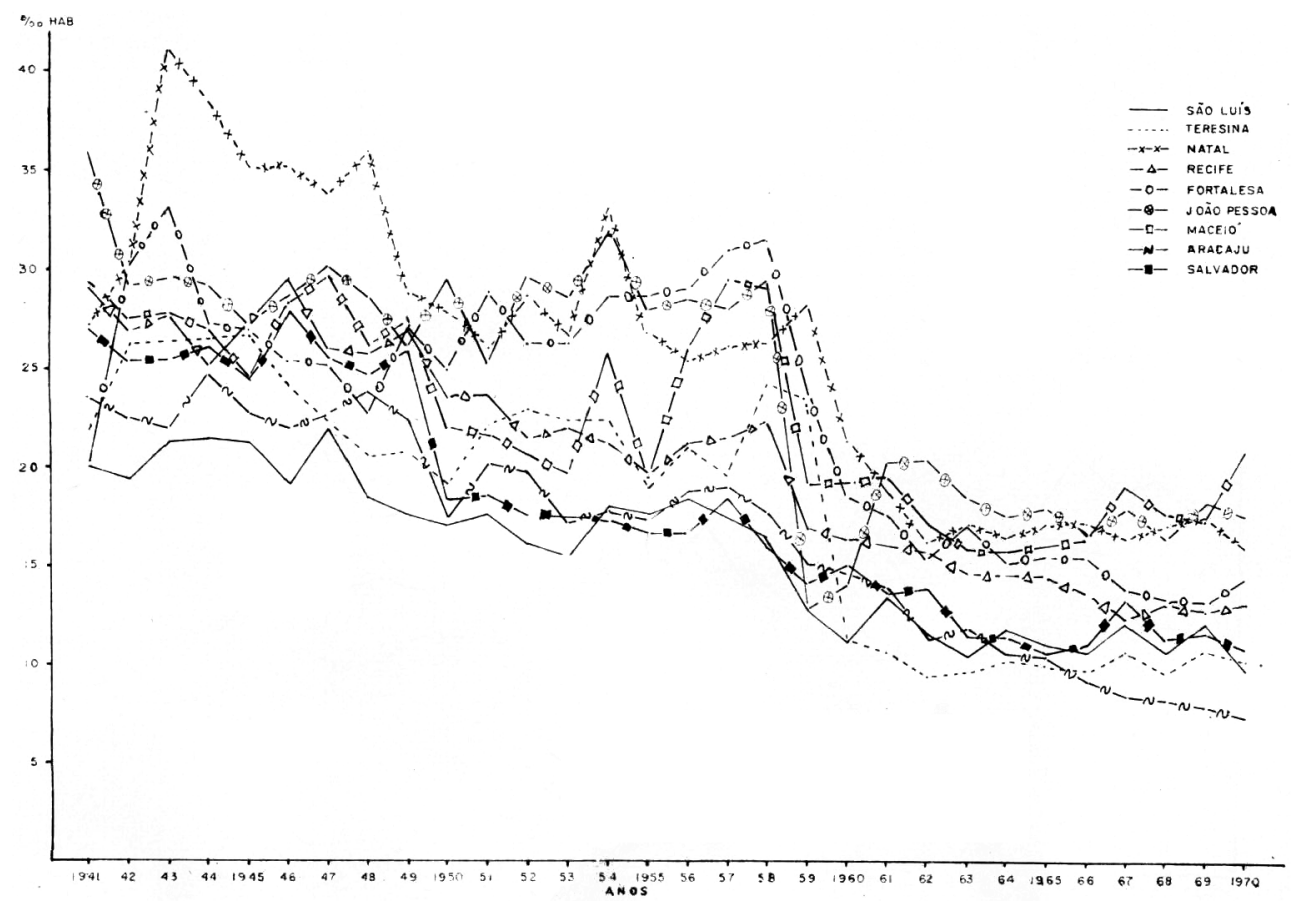

Fig. 5 - Evolução da mortalldade geral por capital na região nordeste - 1941-1970. 
YUNES, J. \& RONCHEZEL, V. S. C. - Evolucão da mortalidade geral, infantil e proporcional no Brasil. Rev. Saúde públ., S. Paulo, 8(supl.):3-48, 1974.

vida da região Sudeste e mesmo do país (o Estado e o município de São Paulo), como se observa na Figura 7, o coeficiente de mortalidade geral para o Brasil encontra-se mais elevado que o apresentado pelo Estado, e maior ainda em relação ao Município, sugerindo, portanto, pior nível de saúde. Nos 30 anos estudados a redução do coeficiente é maior no Estado de São Paulo $(55,6 \%)$ que no Brasil. O Município apresenta uma redução de $32,6 \%$. Analisando-se por décadas, observa-se para o Estado a mesma tendência que para o Brasil, ou seja, diminuição na redução do coeficiente. Para o municipio de São Paulo a redução, na década 50 a 60 , é menor em relação à anterior. Para a década 60 a 70 o coeficiente de mortalidade geral sofre um aumento de $12,0 \%$ em relação à década anterior $(\mathrm{Ta}$. bela 9 ).

Como para São Paulo existem dados desde 1918, analisou-se a tendência da mortalidade geral desde este ano até 1970 . Observa-se, conforme Tabela 7 que a mortalidade geral no município de São Paulo variou de 27,4 em 1918 para 9,3 óbitos por mil habitantes em 1969. Para o Estado esta variação foi de 16,9 em 1930 (somente a partir deste ano que os dados são disponíveis) para 7,9 por mil habitantes em 1970. A tendência à queda deu-se, portanto, tanto para o Estado como para o Município, conforme Figura 7 .

A mortalidade geral do município de São Paulo foi, praticamente, sempre menor que a do Estado de São Paulo, fazendo exceção a partir do ano de 1963, podendo ser explicado, em parte, dado ao grande aumento de mortalidade infantil verificada no Município neste decênio conforme se discutirá adiante.

A queda da mortalidade geral para o Brasil no último decênio foi mais lenta, apresentando coeficientes em torno de 10 óbitos por mil habitantes.

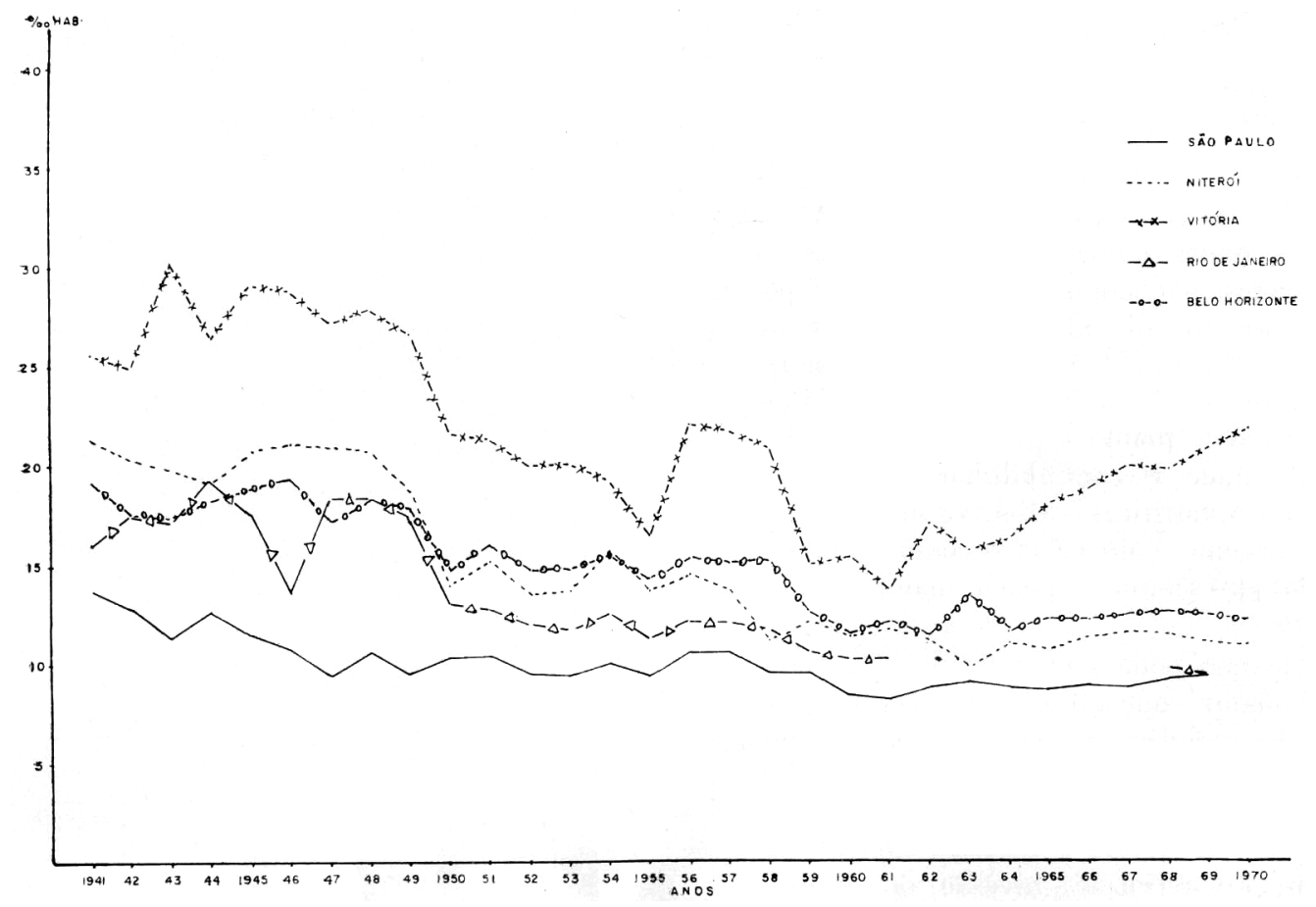

Fig. 6 - Evolução da mortalidade geral por capital na região sudeste - 1941-1970. 
Ao se comparar este coeficiente (10.1200) com os de outros países ${ }^{2}$. tais como: Estados Lnidos. 9.4/1000 habitantes (1970); Canadá, 7,3/1000 habitantes 1 1969); LRSS. 8.2/1000 habitantes (1970): Japão, 6.9/1000 habitantes: e Chile, 9.0/1000 habitantes (1969). ele pode ser considerado elevado. principalmente, por nossa população ser mais jorem. uma vez que $41.79 \%$ tem menos de 14 anos de idade ${ }^{13}$. indicando. ainda. um insatisfatório nível de saúde da população brasileira.

Consideramos válido analisar os dados dos coeficientes para as Capitais. uma rez que, como já foi mencionado anteriormente. não tínhamos dados para o Brasil como um todo.

Comparando-se nossos dados com os obtidos por estimativa ${ }^{13}$ para o Brasil nos diferentes decênios, conforme quadro 1 , temos o seguinte coeficiente de mortalidade geral por mil habitantes:

$\begin{array}{ccc}\text { Ano } & \begin{array}{c}\text { Brasil } \\ \text { (capitais) }\end{array} & \begin{array}{c}\text { Brasil } \\ \text { (estimativa) }\end{array} \\ 1940-1950 & 17,83 & 20,60 \\ 1950-1960 & 13,68 & 11.7 \\ 1960-1970 & 10,09 & 9,7\end{array}$

Não existe muita diferença entre os nossos dados baseados em capitais e os estimados, podendo-se inferir que eles podem ser considerados representativos da situação de saúde do Brasil como um todo. pelo menos na fase em que este País se encontra quanto à precariedade de disponibilidade e confiabilidade das informações estatísticas. Observa-se que, para o decênio 1940-1950. o coeficiente estimado apresentou-se pouco maior que os nossos.

Este fato pode ser explicado, em parte. pela maior concentração de recursos nas grandes cidades, fato este que não se modificou nos decênios seguintes. mas que devido a maiores facilidades de transporte comunicando o Interior com as $\mathrm{Ca}$ pitais, favoreceu a "invasão de óbitos",

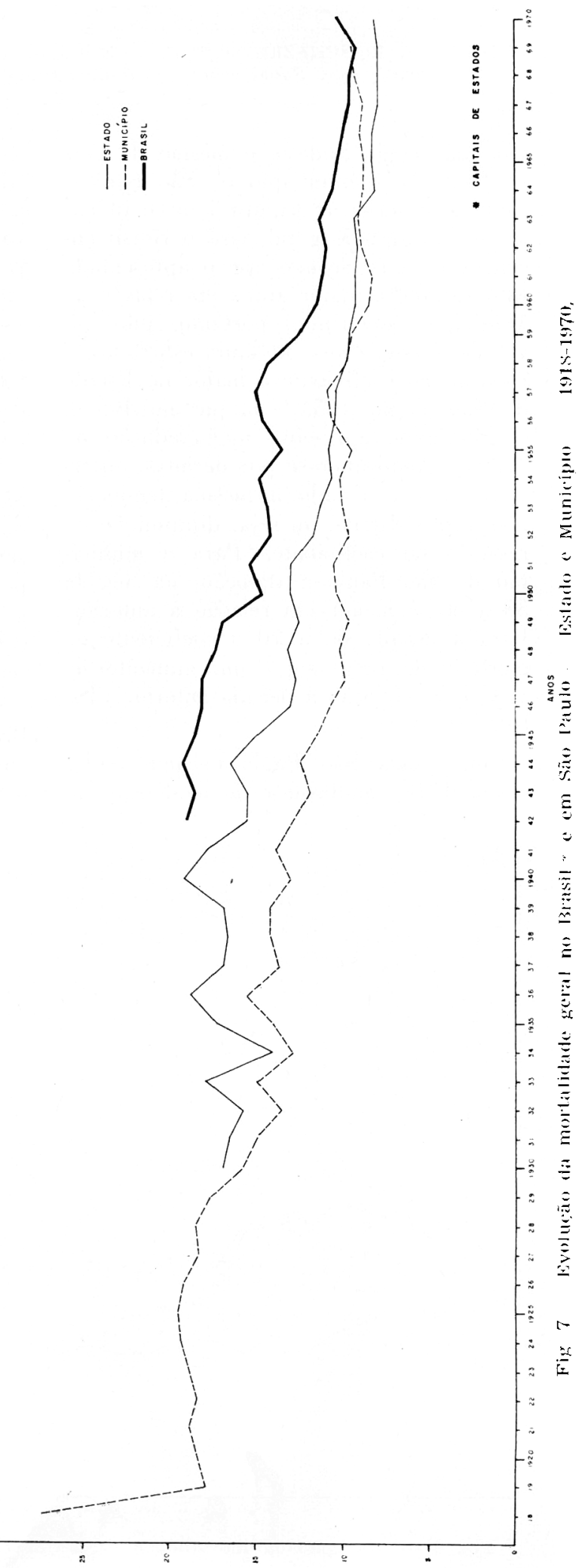


YUNES, J. \& RONCHEZEL, V. S. C. - Evolusão da mortalidade geral, infantil e proporcional no Brasil. Rev. Saúde públ., S. Paulo, 8(supl.):3-48, 1974.

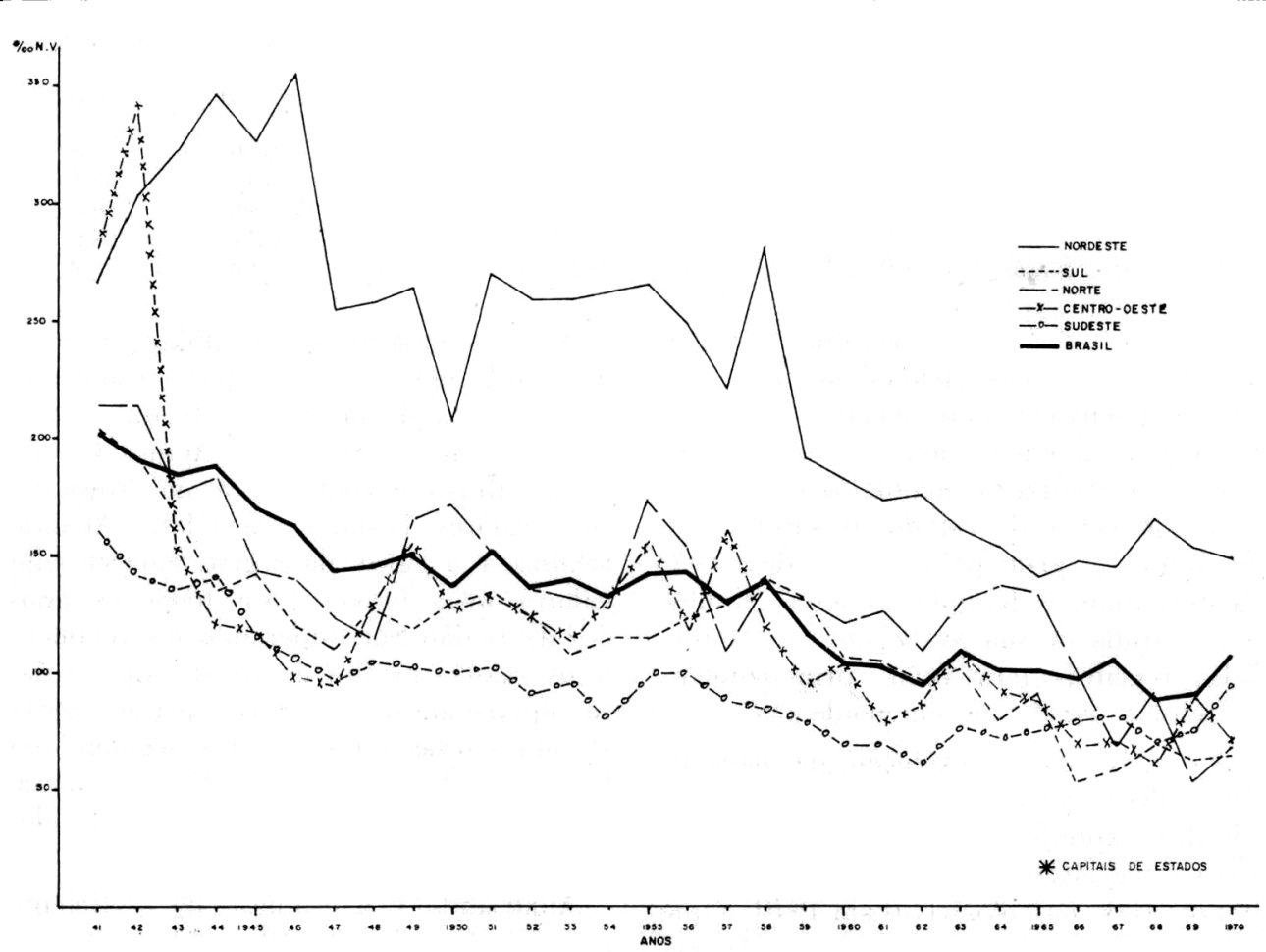

2: Fig. 8 - Evoluçāo da mortalidade infantil no Brasil e por regióes físiográficas * - 1941-1970.

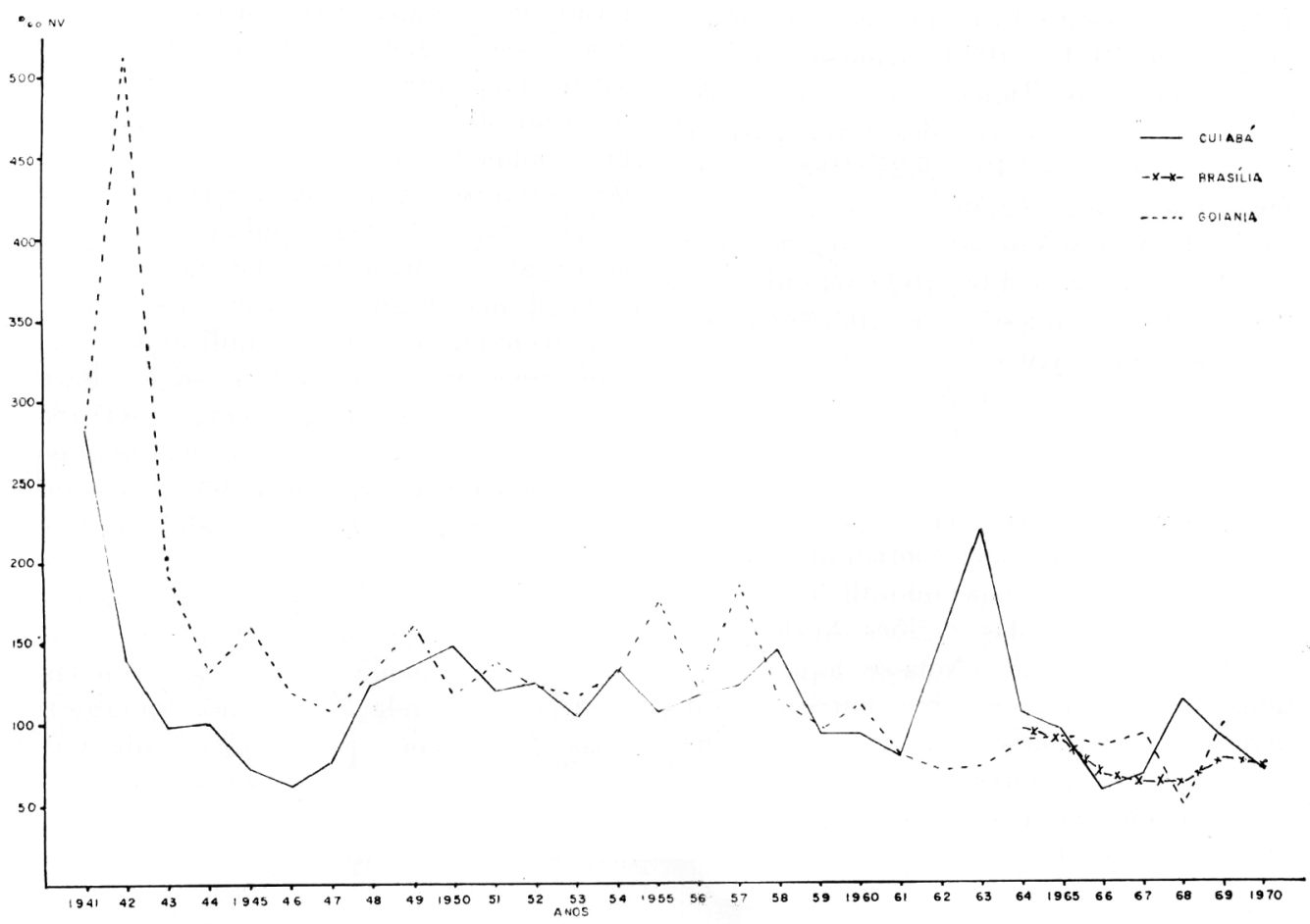

Fig. 9 - Evolução da mortalidade infantil por capital na região centro-oeste - 1941-1970. 
YUNES. J. \& RONCHEZEL, V. S. C. - Fvolução da mortalidade geral, infantil e proporcional no Brasil. Rev. Saúde plibl., S. Paulo, 8(supl.):3-48, 1974

uma vez que estes são registrados pelo local de ocorrência e não de procedência. aumentando, portanto, o coeficiente nas capitais à despeito dos maiores recursos.

\subsection{Evolução da mortalidade infantil}

Embora este coeficiente seja um dos melhores indicadores não só de saúde como de desenvolvimento social e econômico. a sua validade, para o nosso estudo, terá uma limitação maior, pois. dependendo da área de estudo, o sub-registro de óbitos e, principalmente, o de nascimentos ainda é bastante comum. Contudo, o estudo de sua avaliação, com as devidas ressalvas terá valor, principalmente, para o estudo de sua tendência.

Ao se avaliar a evolução da mortalidade infantil para o Brasil baseado em dados das Capitais, conforme Tabela 1, observa-se variação de 202.33 em 1941 para $108,68 / 1000$ nascidos vivos em 1970, o que dá uma redução percentual de $46,2 \%$ em 30 anos. A evolução da mortalidade infantil por Região Fisiográfica, durante o período de 1941 a 1970 variou, conforme se observa nas Tabelas de 2 a 6 de $213,93-67,05 / 1000$ nascidos vivos para a região Norte; 264,19-149,27/1000 nascidos vivos para a região Nordeste; 279,86$72,04 / 1000$ nascidos vivos na região Centro-Oeste; $159,93-94,66 / 1000$ nascidos vivos na região Sudeste e de 203,39-64,59/ 1000 nascidos vivos para a região Sul, tendo sido a redução de $68,6 \%, 43,4 \%$, $72,04 \%, 40,8 \%$ e $68,2 \%$ respectivamente.

Tal como acontece na mortalidade geral, a região que mais contribuiu para a redução da mortalidade infantil foi a Centro-Oeste seguida das regiões Norte, Sul, Vordeste e Sudeste. Nota-se aqui, também, que as regiōes que apresentavam maiores coeficientes em 1941 também apresentaram maiores reduçōes, fugindo à essa tendência o Nordeste, conforme se ohserva a seguir:

\begin{tabular}{lcc}
\multicolumn{1}{c}{ Região } & $\begin{array}{c}\text { Coeficiente } \\
\text { em } 1941\end{array}$ & $\begin{array}{c}\text { Redução } \\
\text { \% }\end{array}$ \\
Centro-Oeste & $27941-1970$ \\
Nordeste & 264,19 & 74,3 \\
Norte & 213,93 & 43,4 \\
Sul & 203,39 & 68,6 \\
Sudeste & 159,93 & 68,2 \\
& & 40,8
\end{tabular}

Ao se comparar a mortalidade infantil do Brasil com as regiōes que o compõem, verifica-se conforme Figura 8, que a tendência geral é a de queda. Acima da curva do Brasil encontra-se a do Nordeste, com valores bastante elevados. Abaixo, localiza-se a curva da região Sudeste com valores mais baixos para todos os anos e a da região Sul, superando discretamente os valores médios do Brasil, apenas para alguns anos. As outras regiōes apresentam curvas cujos valores seguem, em linhas gerais, a curva do Brasil estando a região Sudeste e Sul sempre com valores mais baixos.

Analisando-se a evolução do coeficiente por décadas (Tabela 10), observa-se que para o Brasil há uma diminuição da redução de década para década (19411960) sendo que no periodo 1960-1970 ocorre uma inversão, isto é, verifica-se um aumento de $3,3 \%$ significando, portanto, aumento do coeficiente de mortalidade infantil. A mesma tendência é observada para a região Sudeste considerada a mais desenvolvida, onde o coeficiente na última década apresenta um aumento percentual de $39,9 \%$, indicando, portanto, uma piora no nível de saúde. Para as demais regióes a tendência observada é a diminuição da queda no período 1950-1960 em relação ao anterior, voltando a aumentar na década seguinte (1960. 1970). Para este último período, excluindo-se a região Sudeste, onde houve aumento, o Nordeste foi a região onde se observou a menor redução do coeficiente $(18,6 \%$ em relação à década anterior $)$. Essas diminuições do coeficiente observadas na última década só é verdade considerando-se os dois extremos (1960-1970). Pela Figura 8 entretanto, notamos que 
YUNES, J. \& RONCHEZEL, V. S. C. - Evoluçāo da mortalidade geral, infantil e proporcional no Brasil. Rev. Saúde públ., S. Paulo, 8(supl.):3-48, 1974.

em todas as regiões há, a partir de um dado ano dentro desta década, uma tendência ao aumento do seu coeficiente, sendo que na região Sudeste a elevação se verifica a partir de 1962, no Nordeste a partir de 1965, no Sul em 1966, no Centro-Oeste em 1968 e no Norte a partir de 1969.

$\mathrm{Na}$ região Centro-Oeste que apresentou a maior redução percentual do coeficiente $(72,04 \%$ em 30 anos), a capital que mais contribuiu foi Cuiabá com uma redução de $75,0 \%$ (282,7\% em 1941 e $70,2 \%$ em 1970). Vale salientar que tal redução não progressiva tendo apresentado oscilações durante todo o período. podendo tal fato em parte ser devido à precariedade dos dados. Para Goiânia se observa a mesma tendência e a redução do seu coeficiente foi de $55,8 \%(278,8 \%$ em 1941 e 123,1\%o em 1970). Brasília de 1964 (ano a partir do qual existem dados) até 1970 apresentou uma diminuição percentual de $23,0 \%$. Vale salientar que apesar dessa queda observada, considerando-se os coeficientes dos anos 1964 e 1970, existe a partir de 1967 uma nítida tendência ao aumento $(61,3 \%$ nascidos vivos em 1967 para 72,3\% nascidos vivos em 1970) (Fig. 9).

Das capitais que forneceram dados para o nosso estudo, na região Norte a que mais contribuiu para a queda do coeficiente $(68,6 \%$ em 30 anos) foi Manaus $(302,9 \%$ em 1941 e $80,4 \%$ em 1970). Belém sofreu redução de $69,2 \% \quad(189,6 \%$ em 1941 e 60,3\% em 1970). Estudandose mais detalhadamente a última década, observa-se que há uma tendência ao aumento que em Manaus se dá a partir de 1967 e em Belém a partir de 1969 (Fig. 10).

Na região Sul a redução foi de $68,2 \%$ nos 30 anos. Florianópolis, que apresentava em 1941 o coeficiente de 303,7/1000, em 1967 era de 28,5/1000 sofrendo uma redução percentual de $90,6 \%$. Em Curitiba a redução foi de $33,2 \% \quad(124,2 \%$ em 1941 e 82,9\% em 1970) e em Porto
Alegre a redução foi de $78,5 \%$ (230,3\% em 1941 e 49,4\% em 1970). Na última década, observa-se para Curitiba uma tendência ao aumento que começa em 1966. Faltam alguns dados para Porto Alegre e Florianópolis, não sendo possível analisar com detalhes o comportamento do seu coeficiente no período citado (Fig. 11).

No Nordeste, a capital que mais contribuiu para a redução do coeficiente de mortalidade infantil foi Aracaju, que apresentou uma redução percentual de $86,73 \%$ $(243,5 \%$ em 1941 e $32,3 \%$ em 1970$)$.

Interessante observar uma queda maior de $100 \%$ entre 1968 e 1970 . Terezina que apresentava o maior coeficiente do Nordeste em $1941(501,1 \%$ ) sofreu uma redução de $84,13 \%$ em 30 anos, apresentando em 1970 o coeficiente de 79.5/ 1000. Em 1942 seu coeficiente era 634,5/ 1000 nascidos vivos e depois de 1968 sua queda foi de quase $70 \%$.

A menor queda se verificou em Fortaleza $(12,67 \%)$ que em 1941 apresentava um coeficiente de 209,1/1000 (o menor do Nordeste) e em 1970 seu valor é $182,6 / 1000$.

São Luiz apresenta uma redução de $59,96 \%$ tendo tido a curva mais baixa. A partir de 1965 seu coeficiente começa a aumentar e, entre 1965 e $1970(59,2 \%$ e $92,4 \%$ respectivamente), este aumento é de $56,0 \%$. Para Natal, o aumento se dá a partir de 1968. Curioso observar em 1953 um coeficiente de mortalidade infantil igual a 605,8/1000 nascidos vivos.

João Pessoa tem o seu menor coeficiente em 1959 (112,2\% nascidos vivos) tendo sofrido nesta década (1960-1970) um aumento percentual de $31,0 \%$.

Recife sofre uma redução de $29,8 \%$ nos 30 anos, entretanto, no período de 1964 (125,6\% nascidos vivos) a 1970 $(205,7 \%$ nascidos vivos $)$ o seu coeficiente aumenta $63,7 \%$. Maceió contribuiu com uma redução de $60,3 \%$. Salvador sofre redução de $64,9 \%$, sendo que até 1965 seu coeficiente sofre flutuaçōes e, a 
YUNES, J. \& RONCHEZEL, V. S. C. - Evolusão da mortalidade geral, infantil e proporcional no Brasil. Rev. Saúde públ., S. Paulo, 8(supl.):3-48, 1974.

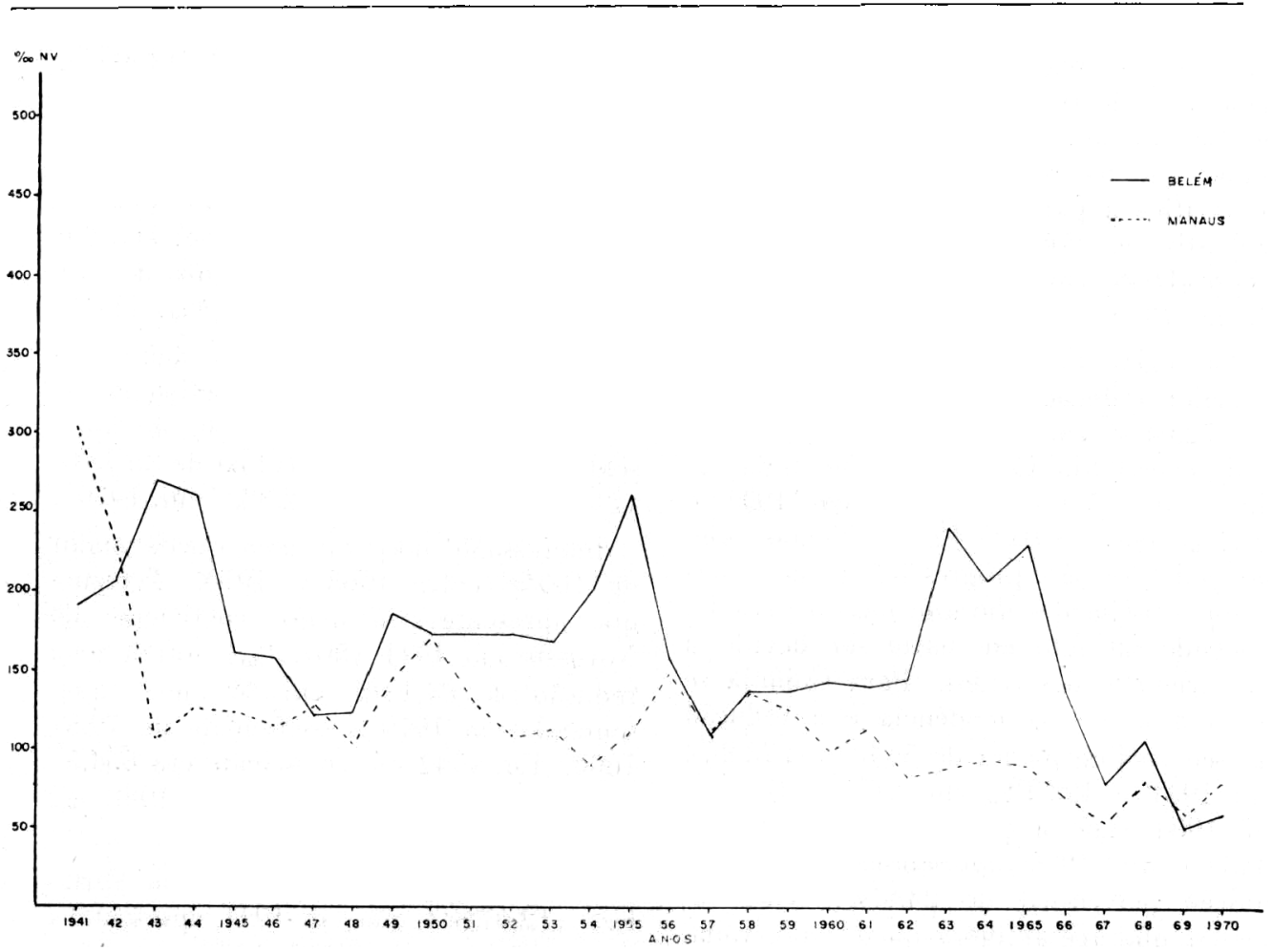

Fig. 10 - Evolução da mortalidade infantil por capital na região nurte - 1941-1970.

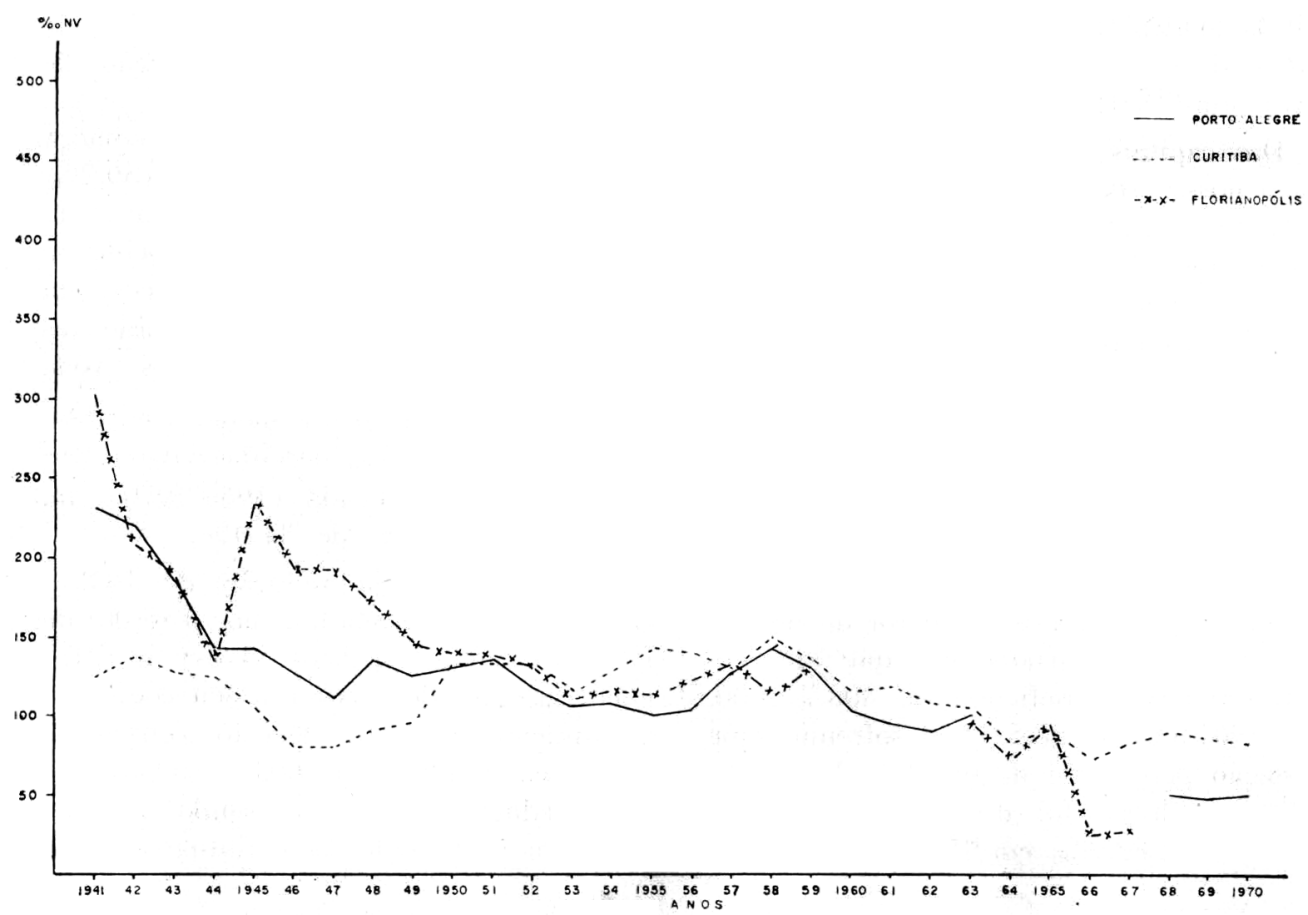

Fig. 11 - Evolução da mortalidade infantil por capital na região sul - 1941-1970. 


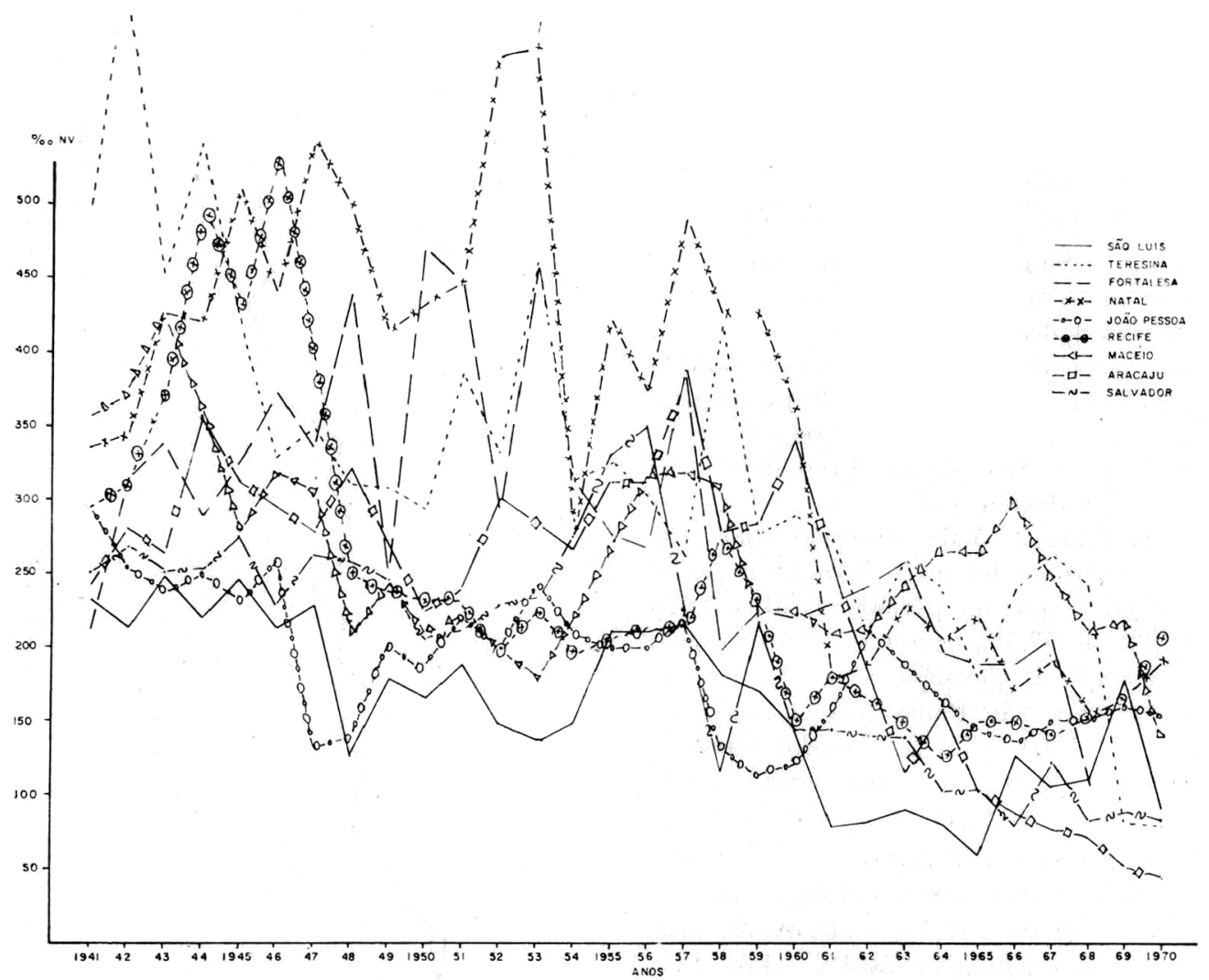

Fig. 12 - Evolução da mortalidade infantil por capital na região nordeste - 1941-1970.

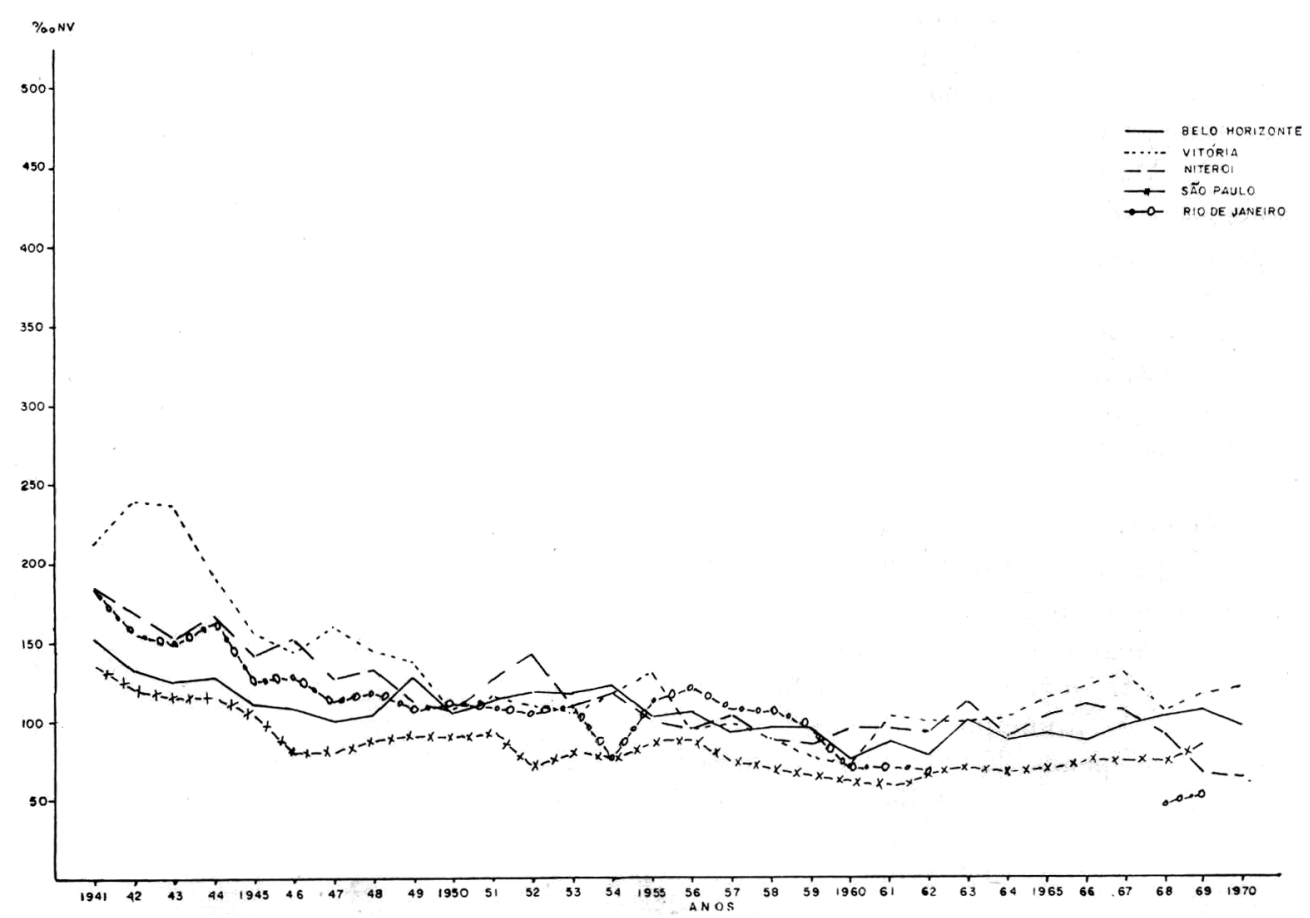

Fig. 13 - Evolução da mortalidade infantil por capital na região sudeste - 1941-1970. 
partir daí. mostra tendência ao aumento

tendo se verificado até 1970 uma elevação percentual de $8.1 \%$ (Fig. 12 ).

Para o Sudeste, região que apresenton a menor redução do coeficiente nos 30 anos estudados; o Rio de Janeiro sofreu uma variação de $71,0 \%$, tendo faltado dados para rários anos da última década. Em Niterói a redução foi de $65,4{ }^{\prime} c$. Belo Horizonte e São Paulo apresentaram as menores reduçoes $136.5 \%$ e $38.0 \%$ respectivamente). Vale observar que em Belo Horizonte há uma elevação a partir de 1960 e que no período 1960 a 1970 $\left(74.2^{\circ}\right.$ e $97,4_{00}^{\circ}$ nascidos vivos respec(iramente) a elevação percentual é de $31.2 \%$. Em São Paulo essa elevação começa em 1964 (67.7\% nascidos vivos) e até $1969\left(83,8_{\% 0}^{\circ}\right.$ nascidos vivos) sendo essa subida de $23.7 \%$.

Em Vitória, a redução foi de $42.4 \%$ entretanto. entre $1960 \quad 77.9^{\circ} \%$ nascidos viros) e 1970 (121. cou $^{\prime}$ ) observa-se uma elevação percentual de $56,4{ }^{\prime} \mathrm{C}$ (Fig. 13).

Ao se comparar os dados do Brasil com a área mais desenvolvida do País, Estado e Município de São Paulo, verifica-se, conforme a Figura 14, que a curva do Brasil apresenta-se acima para todos os anos comparada com as curvas do Estado e do Município de São Paulo, indicando pior nível de saúde.

Dada a disponibilidade de dados para São Paulo, observa-se conforme Tabela 7 , que o coeficiente da mortalidade infantil variou de 222.7 em 1918 para 83,8/1000 nascidos vivos em 1969; para o município de São Paulo e para o Estado esta variação foi $187,6 \mathrm{em} 1921$ para 81,4/ 1000 nascidos vivos em 1970.

Ao se observar a Tabela 11 , nota-se que nos 30 anos estudados a redução do coeficiente é maior para o Estado de São Paulo que para o Brasil $(55,3 \%$ e $46,2 \%)$ sendo que o Município apresentou uma redução de apenas $37,9 \%$, observando-se aqui a mesma tendência da mortalidade geral.

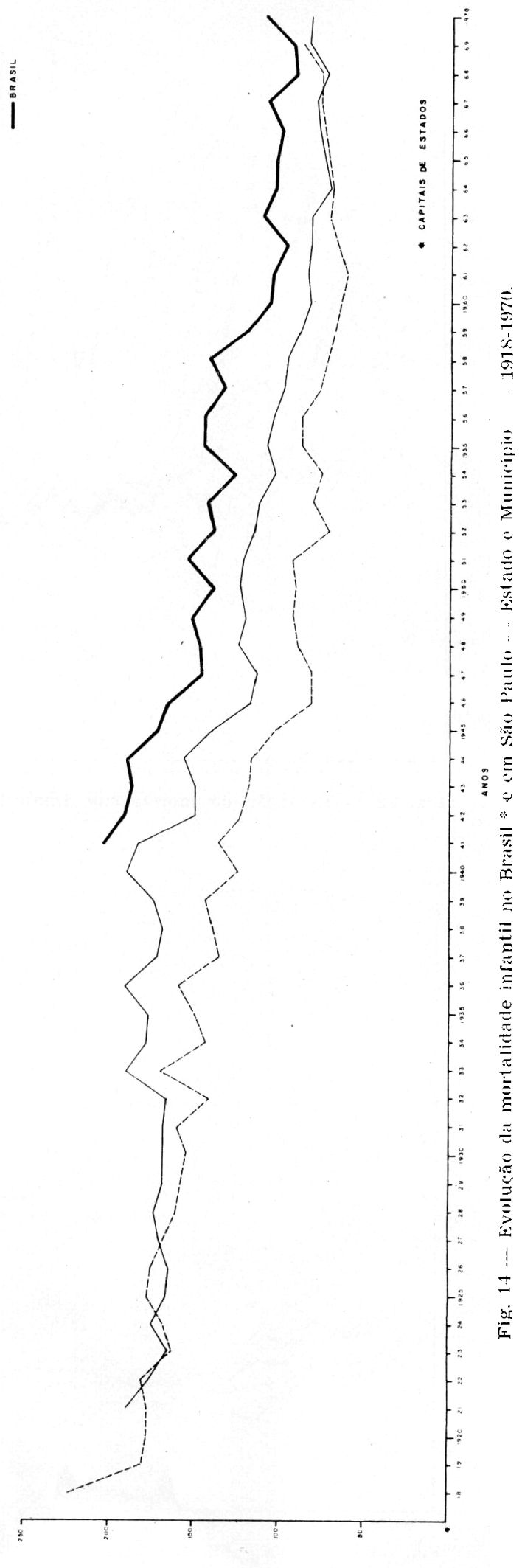


YUNES, J. \& RONCHEZEL, V. S. C. - Evolução da mortalidade geral, infantil e proporcional no Brasil. Rev. Saũde públ., S. Paulo, 8(supl.):3-48, 1974.

Analisando-se por década observa-se para o município de São Paulo a mesma tendência que a do Brasil e da região Sudeste, ou seja, diminuição na redução do coeficiente de mortalidade infantil, na década 1950-1960 em relação à anterior e aumento do coeficiente, na proporção de $32,2 \%$ na década 1960-1970, maior portanto, que para o Brasil como um todo $(3,3 \%)$. Para o Estado não chega a haver aumento do coeficiente na última década, considerando-se somente os anos extremos 1960-1970, mas a redução é de apenas $1,3 \%$ (Tabela 11).

Ao se observar a Figura 15, ou seja, o comportamerito do coeficiente dentro da última década, nota-se que ele começa a aumentar para o município a partir de 1961 e para o Estado em 1964. Sendo essa a região mais desenvolvida do País e quiçá da América Latina, indica portanto, uma piora do nível de saúde, uma vez que os dados de registro civil são considerados bastante satisfatórios.

Para o último decênio, a mortalidade infantil do Brasil, baseada em dados das Capitais, ainda é alto, estando em torno de 105 óbitos/1000 nascidos vivos. Ao se comparar com outros países é notória a diferença observada, por exemplo, com os

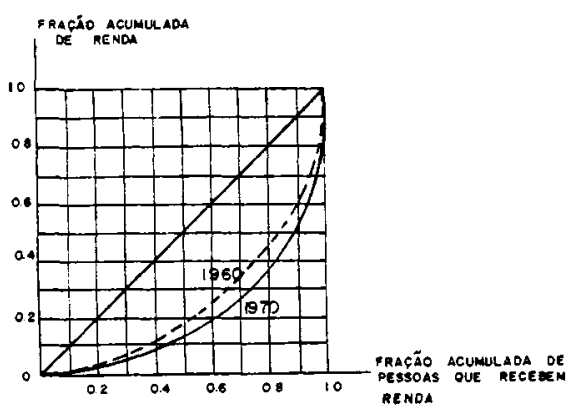

Fonte: HOFFMAN \& DUARTE ${ }^{\circ}$.

Fig. 15 - Curvas de Lorenz da distribuição da renda no Brasil, em 1960 e 1970 . valores encontrados para os países mais desenvolvidos ${ }^{2}$, que são os que se seguem:

$\begin{array}{ll}\text { URSS } & \begin{array}{l}24,4 / 1000 \\ (1970)\end{array} \\ \text { EE.Lit. }- & 19,8 / 1000 \text { nascidos vivos } \\ & (1970) \\ \text { CANADÁ }- & 19,3 / 1000 \text { nascidos vivos } \\ & (1969) \\ \text { JAPÃO }- & 15.3 / 1000 \text { nascidos vivos } \\ & (1969)\end{array}$

Interessante também comparar com o Chile ${ }^{10}$, por ser um País da América Latina com hoas estatísticas vitais, em que o valor encontrado foi de $91.6 / 1000$ nascidos vivos em 1969.

Os nossos dados foram baseados nas capitais dos Estados mas, como se observou em relação à mortalidade geral. podemos considerá-los representativos da situação de saúde para o Brasil. Comparando-os com os dados obtidos por estimativa temos os seguintes coeficientes por mil habitantes, no período de 1941-1970 (YUNes ${ }^{13}$ ) :

$\begin{array}{lcc}\text { Ano } & \begin{array}{c}\text { Brasil } \\ \text { (capitais) }\end{array} & \begin{array}{c}\text { Brasil } \\ \text { (estimativas) }\end{array} \\ & 163,97 & 171,00 * \\ 61-1950 & 105,23 & 120,00 * \\ 70 & 108,68 & 103,4\end{array}$

Observa-se que os dados baseados em Capitais e em estimativa não são tão diferentes. A maior mortalidade verificada para o Brasil, baseada em estimativas na década de 1940-1950 e no ano de 1960. pode ser explicada, em parte, pela maior concentração de recursos nas grandes cidades onde já se espera encontrar melhor nível de saúde. Vale ressaltar que a invasão de óbitos de menores de um ano é menor que a de óbitos totais, dado talvez à menor possibilidade de locomoção. Para o ano de 1970, a mortalidade estimada apresenta-se menor que a por nós calculada e, algumas hipóteses podem 
YLNES, J. \& RONCHEZEL, V. S. C. - Evoluçāo da mortalidade geral, infantıl e proporcional no Brasil. Rev. Saúde públ., S. Paulo, 8(supl):3-48, 1974.

ser lançadas: a primeira é que o método utilizado na estimativa é diferente. Baseando-se em OYA ${ }^{11}$ e SANTos ${ }^{12}$ obtevese primeiro o número de nascidos vivos entre $01 / 09 / 69$ a $01 / 09 / 70$ e que foi igual a 3.265 .629 (N). Para calcular a população que sobreviveu no mesmo período calculou-se o número de crianças entre 0 e 1 ano de idade em $01 / 09 / 70$ corrigindo-o para sub enumeração no censo e idade ignorada e que foi iqual:

$$
\mathrm{P}_{\mathrm{o}}=2.979 .311
$$

Calculou-se, ainda, o número de óbitos de menores de um ano entre os que nasceram de $01 / 09 / 69$ a $01 / 09 / 70$.

$$
\lambda-P_{0}=\varnothing \text {. }
$$

\section{$3.265 .629-2.979 .314=286.315$}

Para estimar o número total de óbitos de menores de um ano $\left(D_{0}\right)$ entre $01 / 09 / 69$ a $01 / 09 / 70$ usou-se o fator de separação $\mathrm{t}_{0}=0.1521$ (uma vez que morreram neste período, crianças com menos de um ano mas que nasceram antes deste, a proporção calculada destes óbitos é de $15,21 \%$ ).

$$
\begin{aligned}
D_{0}=\frac{D_{\circ}^{\prime}}{1-t_{0}} & =\frac{286.315}{0.8479}= \\
=D_{0} & =337.675
\end{aligned}
$$

$O$ coeficiente de $\mathbf{M}_{1}$ é portanto:

$$
\begin{aligned}
& \mathrm{M}_{0}=\frac{\mathrm{D}_{\circ}}{\mathrm{N}}=0.10340= \\
& =103,4 / 1000 \text { nascidos vivos. }
\end{aligned}
$$

Outra hipótese é que realmente tenha aumentado nas Capitais o coeficiente devido a maior posibilidade de locomoção, facilidades de transporte, consequientemente favorecendo a invasão.

\subsection{Evoluçäo da mortalidade proporcional}

Como foi mencionada anteriormente. embora o coeficiente de mortalidade infantil seja um dos indicadores mais usados para se medir o nível de saúde $\mathrm{e}$ avaliar o estágio de desenvolvimento social e econômico. seu uso em nosso meio apresenta uma limitação séria, pois. o sub-registro, principalmente o de nascimentos, é ainda bastante comum em algumas regiões do Brasil. Para eliminar este fator, utilizaremos a taxa de mortalidade proporcional que é calculada somente utizando-se o número de óbitos. cujo sub-registro é menor.

Ao se avaliar a mortalidade proporcional (percentagem do total de óbitos de crianças menores de um ano) para o Brasil, observa-se, conforme a Tahela 1 . que esta taxa variou de $27.80 \%$ em 1941 para $32.32 \%$ em 1970 , o que significa um aumento percentual de $16,3 \%$.

Ao se estudar esta taxa ano a ano, conforme a Figura IC, verifica-se uma tendência ao aumento. indicando uma piora do nível de saúde e/ou melhora do registro de dados.

Analisando-se por décadas (Tabela 12), observa-se que a taxa só apresentou redução entre 1941-50. Nas décadas seguintes houve aumento sendo que no período $1960-70$ este foi de $10.7 \%$ devido, principalmente. a elevação sofrida pela taxa a partir de 1965.

Ao se estudar a evolução da mortalidade proporcional por regiōes Fisiográficas (Tabelas 2 a 6 ) para o mesmo periodo considerado (1941-1970), constata-se que ela variou de $18,57 \%$ a $27,73 \%$ para a região Norte; $42,28 \%$ a $36,37 \%$ para a região Nordeste; $30,84 \%$ a $42,19 \%$ para a região Centro-Oeste; $21,11 \%$ a $28,30 \%$ para a região Sudeste e de 23,55 a $22,28 \%$ para a Região Sul, o que sig. nifica diferenças percentuais com aumentos para as regiões: Norte $(49,3 \%)$, Centro-Oeste $(36.8 \%)$ e Sudeste $(34.1 \%)$, 
YUNES, J \& RONCHFZEL, V. S. C. - Evolução da mortalidade geral, infantil e proporciona. no Brasil. Rev. Saúde pübl., S. Paulo, 8(supl.):3-48, 1974.

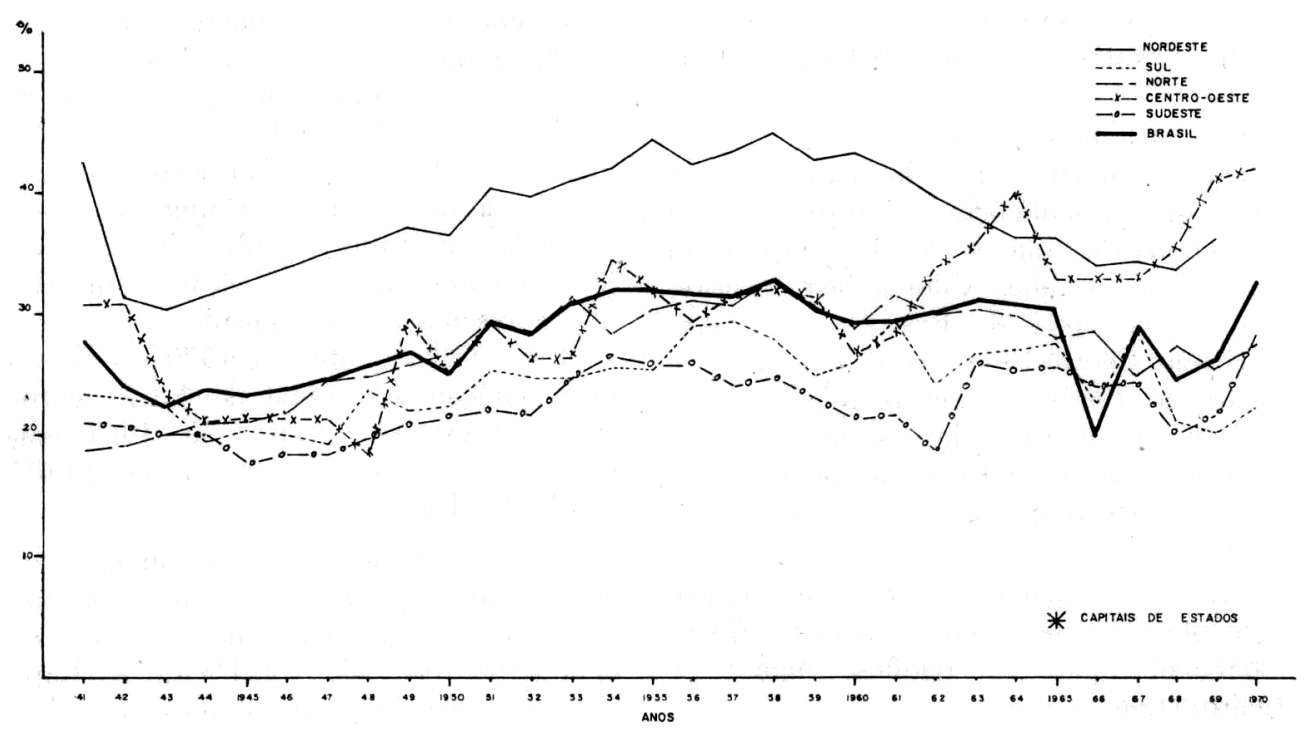

Fig. 16 - Evolução da mortalidade proporcional no Brasil e por regiōes fisiográficas * $1941-1970$

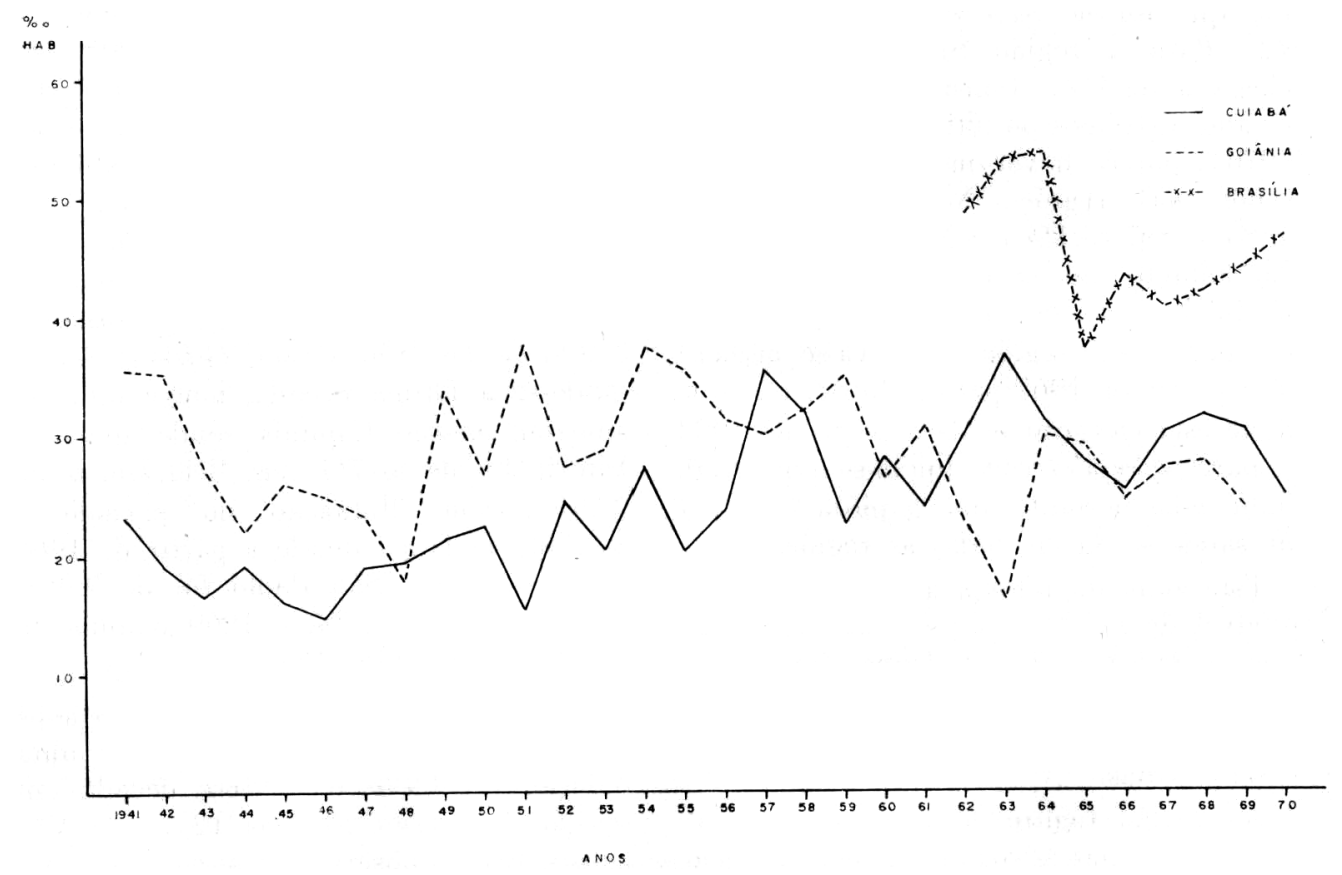

Fig. 17 - Evolução da mortalidade proporcional por capital na região centro-oeste 1941-1970. 
ILNES, J. \& RONCHEZEL, V. S. C. - Evolução da mortalidade geral, infantil e proporcional no Brasil. Rev. Saüde pribl., S. Paulo, 8(supl.):3-48, 1974.

e queda nas taxas para as regiōes: Nordeste $(14,0 \%)$ e Sul $(5,4 \%)$ (Tabela 12).

Comparando-se a mortalidade proporcional do Brasil com as Regiōes Fisiográficas que o compõem, conforme Figura 16, observa-se que o Nordeste apresenta para todos os anos valores bem maiores que os da curva do Brasil e que, para a região Centro-Oeste, isto se verifica a partir de 1962. As outras regióes apresentam, em quase todos os anos, valores menores que os do Brasil, sendo a da região Sudeste a que apresenta as menores taxas.

Para o último decênio observa-se aumento desta taxa para o Brasil e, principalmente, para as regiōes: Sudeste e Centro-Oeste.

Analisando-se por decênio, verifica-se que na região Centro-Oeste, tal como acontece no Brasil como um todo, a queda observada entre 1941-50 desaparece. dando lugar ao aumento no último decênio que foi de $57,7 \%$, conforme tabela 12. Para a região Sudeste o aumento chega a $32,4 \%$. Considerando-se apenas os anos extremos do último decênio (19601970), parece haver melhora do nível de saúde nas regiões Norte (redução de $4,9 \%)$, Sul $(3,1 \%)$ e Nordeste $(16,3 \%)$. No entanto, ao se analisar o comportamento da taxa de mortalidade proporcional para essas regiões, observa-se aumento a partir de 1967 para a Norte, na Nordeste esta elevação se dá a partir de 1968 e para a regiâo Sul, inicia-se em 1969 , indicando, portanto, que a piora do nível de saúde se dá em todas as regiōes.

Este aumento reforça a hipótese de que o nível de saúde está piorando, uma vez que os registros de estatística vital nestas áreas são considerados melhores em relação às outras, bem como, são regiões mais desenvolvidas.

$\mathrm{Na}$ região Centro-Oeste onde se observou nos 30 anos o maior aumento percentual da taxa de mortalidade proporcional, observa-se que tal aumento foi mais acentuado na última década $(57,7 \%$ ) e dentro desta, no período de 1965 a 1970. Em Cuiabá e Goiânia há aumento da taxa de 1941-1970 sendo tal aumento de $7,0 \%$ e $13,6 \%$, respectivamente. Na primeira Capital, observa-se uma tendência à queda na última década e na segunda um aumento que é de $54,5 \%$. Brasília. que apresenta dados somente a partir de $1962(48,61 \%)$, sofre até $1970(46,59 \%)$ uma redução percentual de $4,2 \%$; entretanto, observa-se a partir de 1967 uma tendência ao aumento que é de $11,6 \%$ até 1970 (Fig. 17).

Na região Sudeste, onde o aumento nos 30 anos foi de $34,1 \%$, a elevação foi mais acentuada na última década e dentro desta a partir de $1968(36,1 \%)$. As Capitais que sofreram redução nos seus coeficientes de mortalidade proporcional no período 1941-1970 foram Niterói $11,0 \%$ ) e Rio de Janeiro $(23,2 \%)$. Entretanto. observa-se para Niterói, na última década uma elevação de $15,0 \%$ a partir de 1966, quando apresentava taxa igual a $15,82 \%$ até 1970 quando sua taxa era $18,19 \%$. No Rio de Janeiro faltam dados para alguns anos da última década. Considerando-se os anos 1960-1969 a redução foi de 18,4\%. Nas demais Capitais, houve aumento da mortalidade proporcional nos 30 anos estudados, sendo que em Vitória foi de $82,30 \%$, em Belo Horizonte $31,6 \%$ e em São Paulo 24,5\%. Analisando-se a última década, houve também aumento nessas Capitais sendo que em Vitória foi de $52,7 \%$, em Belo Horizonte $22,9 \%$, com flutuação no período e aumento mais acentuado a partir de 1966 $(16,7 \%)$ e em São Paulo foi de $3.9 \%$, sendo que entre 1968 e 1969 o aumento foi de $8,9 \%$ (Fig. 18).

No Norte, onde o aumento nos 30 anos (1941-1970) foi de 49,3\%, houve uma redução de $4,9 \%$ na última década em relação à anterior (Tabela 12). Em Manaus e Belém, observou-se aumento no período 1941-1970 sendo que em Manaus esta elevação foi de $72.5 \%$ e em Belém 
YENES, J. \& RONCHEZEL, V. S. C. - Evolusãa da mortalidade geral, infantil e proporcional no Brasil. Rev. Saúde públ, S. Paulo, 8(supl.):3-48, 1974.

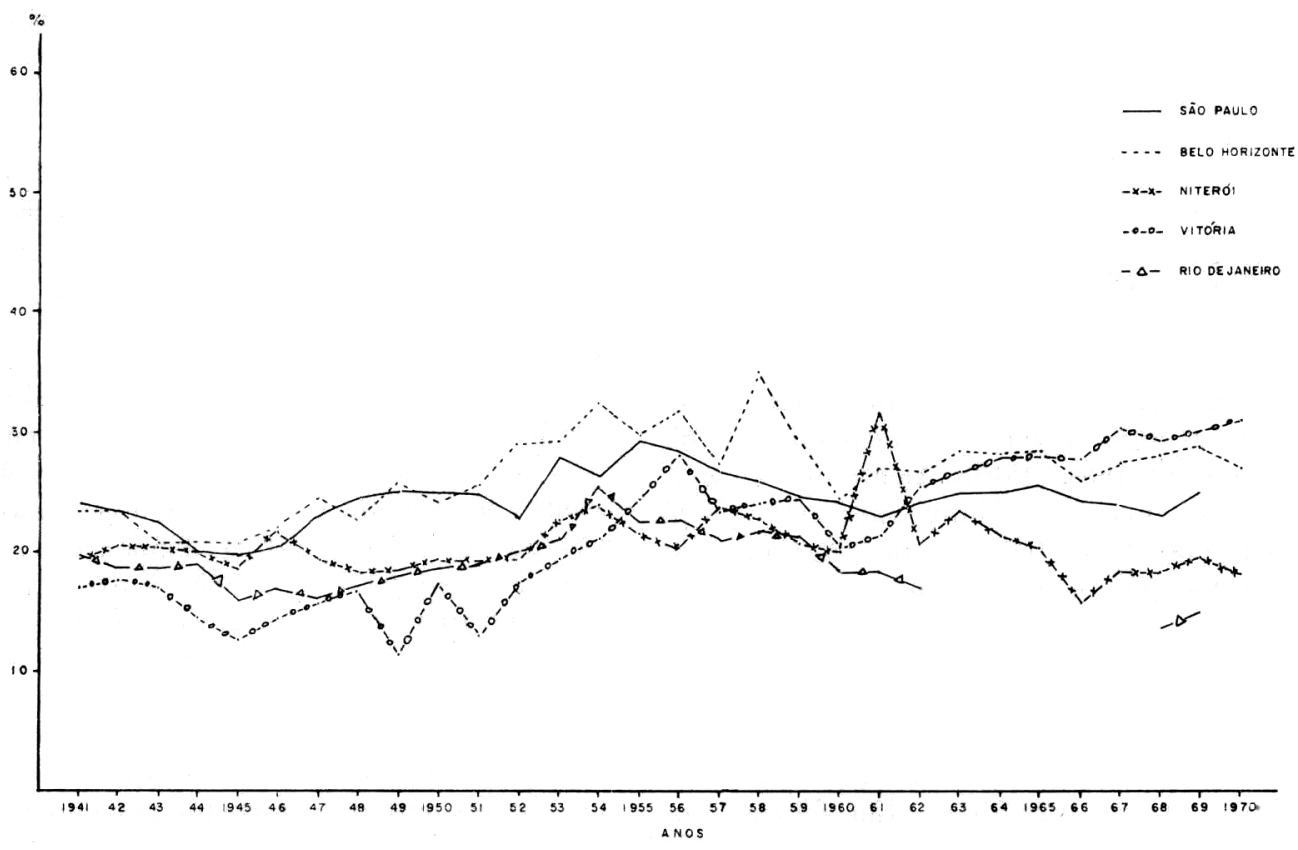

Fig. 18 -. Evolução da mortalidade proporcional por capital na região sudeste — 1941-1970.

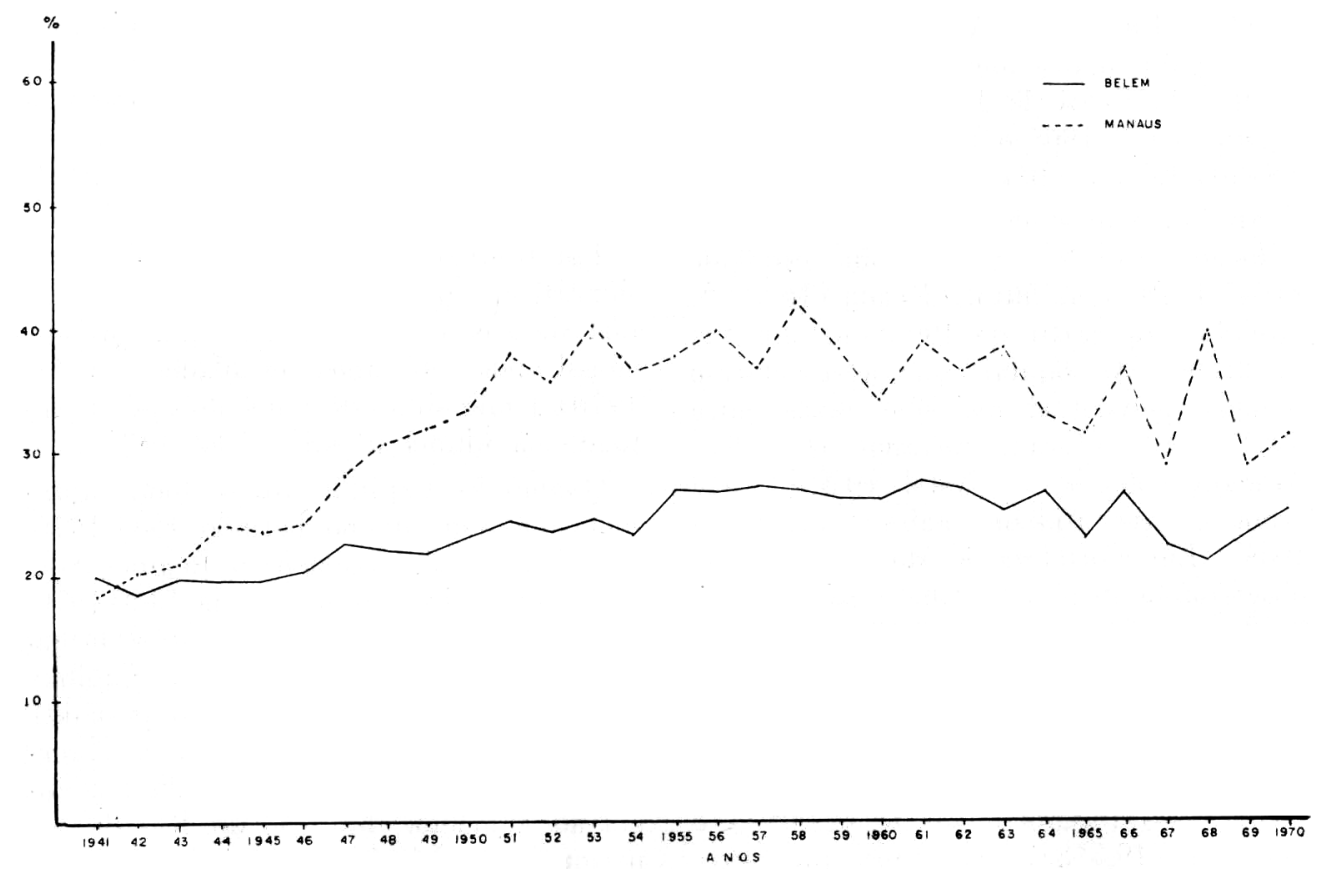

Fig. 19 - Evolução da mortalidade proporcional por capital na região norte - 1941-1970. 
YLNES, J. \& RONCHEZEL, V. S. C. - Evolução da mortalldade geral, infantil e proporciona] no Brasil. Rev. Saúde públ., S. Paulo, 8(supl.):3-48, 1974.

de $37,1 \%$. Vale salientar que em 1941 os valores das taxas de mortalidade proporcional eram próximos $(18,42 \%$ e $18,65 \%$ respectivamente). Ambas as Capitais sofrem, na última década, pequena queda nas taxas $(7,8 \%$ e $3,3 \%$ respectivamente) sendo que dentro deste período, a partir de 1968, há aumento em Belém de $19,3 \%$ e em Manaus de $8,7 \%$, a partir de 1967 (Fig. 19).

No Sul a mortalidade proporcional sofreu redução percentual de $5,4 \%$ nos últimos 30 anos. Porto Alegre foi a capital que mais contribuiu para esta queda sofrendo uma redução de $22,2 \%$. Em Florianópolis a redução foi de apenas $0,7 \%$ e em Curitiba houve um aumento de $26,6 \%$. Na década de 1960-1970, todas as Capitais sofreram queda no valor de suas taxas (para a Região Sul a redução percentual foi de $3,1 \%$ ), sendo maior em Porto Alegre $(23,5 \%)$. Em Florianópolis esta redução foi de 15,3\% até $1967 \mathrm{e}$ em Curitiba foi apenas $3,0 \%$. Interessante notar que nesta década há a partir de 1966, para Curitiba, um aumento de 20,2\%. Em Porto Alegre, onde faltam dados para alguns anos, o aumento entre 1969 e 1970 foi de 10,5\% e em Florianópolis, entre 1966 e 1967, a elevação observada foi de $9,9 \%$ (Fig. 20).

No Nordeste, onde se observou a maior redução $(14,0 \%)$ no período estudado (1941-1970) e na última década $(16,3 \%)$, observa-se a partir de 1968 um aumento de $8,1 \%$. As capitais que apresentaram redução percentual nas suas taxas entre 1941 e 1970 foram Salvador $(63,4 \%)$, Aracajú $(59,6 \%)$ e Natal $(0,5 \%)$ que eram as que tinham maiores taxas em 1941. Em Fortaleza e Maceió onde se observou também uma alta taxa de mortalidade proporcional $(35,62 \%$ e $31,03 \%$ respectivamente), verificou-se aumento percentual de $30,0 \%$. Nas demais capitais também deu-se um aumento que foi em ordem decrescente: São Luiz $(37,2 \%)$, João Pessoa $(33,3 \%)$, Recife $(23,0 \%)$ e Terezina $(19,5 \%)$. São Luiz que apresentou o maior aumento percentual tinha, em 1941, a menor taxa de mortalidade proporcional da região $(21,92 \%)$. Para a década 1960-1970, todas as Capitais com exceção de João Pessoa onde se observou um aumento percentual de $1,6 \%$ e em Terezina onde não houve variação, apresentaram redução que foi maior em Aracajú $(62,7 \%)$ seguida por Recife $(21,0 \%)$ e São Luiz $(5,9 \%)$. Dentro desta década todas as Capitais, com exceção de João Pessoa, que apresenta flutuação da mortalidade proporcional em todo o período, e Aracajú que tende à queda, apresentam a partir de um determinado ano, uma nítida tendência ao aumento; em 1967, para São Luiz, Recife e Terezina, em 1968 para Fortaleza e Maceió e em 1969 para Salvador e Natal. Esta tendência foi maior para São Luiz $(77,8 \%)$ e menor para Natal $(7,8 \%)$. As demais capitais apresentam nos citados períodos aumentos percentuais de suas taxas, conforme se segue: $\mathrm{Ma}$ ceió $(26,6 \%)$, Terezina $(12,6 \%)$, Recife $(9,5 \%)$, Salvador $(8,6 \%)$ e Fortaleza $(7,6 \%)$. Observa-se que em geral, como já se esperava, as capitais que apresentaram as menores reduçôes na década 1960-1970 foram as que apresentaram os maiores aumentos a partir de um determinado momento deste período (Fig. 21).

Em resumo a maioria das Regióes Fisiográficas apresentam aumento percentual da sua taxa de mortalidade proporcional nos 30 anos estudados (19411970) tendo sido este aumento mais acentuado na última década (1960-1970).

Quanto às Capitais, quase todas apresentaram aumento no período 1941-1970, inclusive as que compóem as Regiōes Nordeste e Sul. Dentro da década 1960-1970, apesar de muitas capitais apresentarem redução (no Nordeste todas as Capitais sofreram queda da sua taxa no período) a partir de um determinado ano, observa-se em todas as capitais nítida tendência ao aumento. Exceção ao Rio de Janeiro (onde há falta de dados para o período $1963-1967$ e para o ano 1970 , não 
YUNES, J. \& RONCHEZEL, V. S. C. - Evolução da mortalldade geral, infantil e proporcional no Brasil. Rev. Saúde públ., S. Paulo, 8(supl.):3-48, 1974.

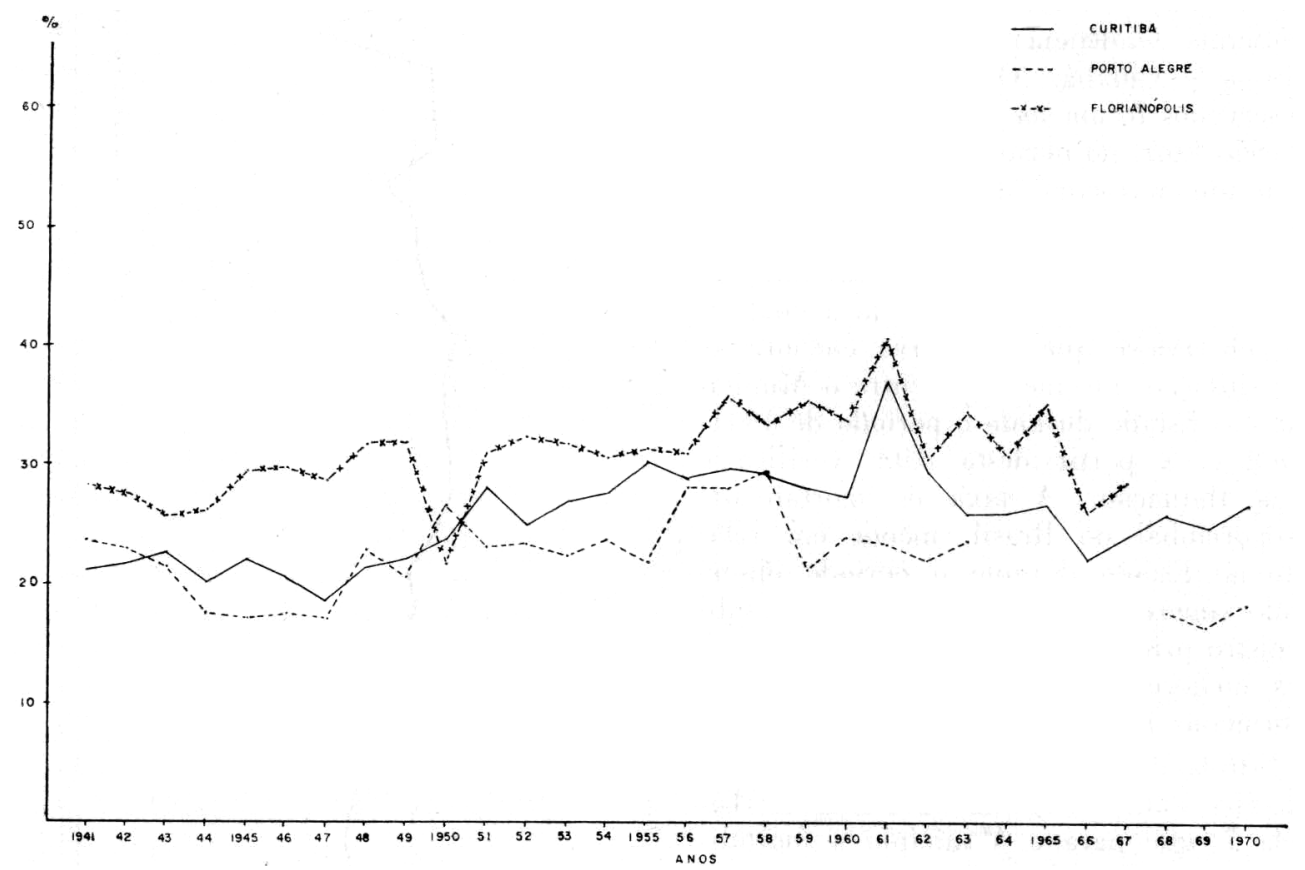

Fig. 20 - Evolucão da mortalidade proporcional por capital na região sul - 1941-1970.

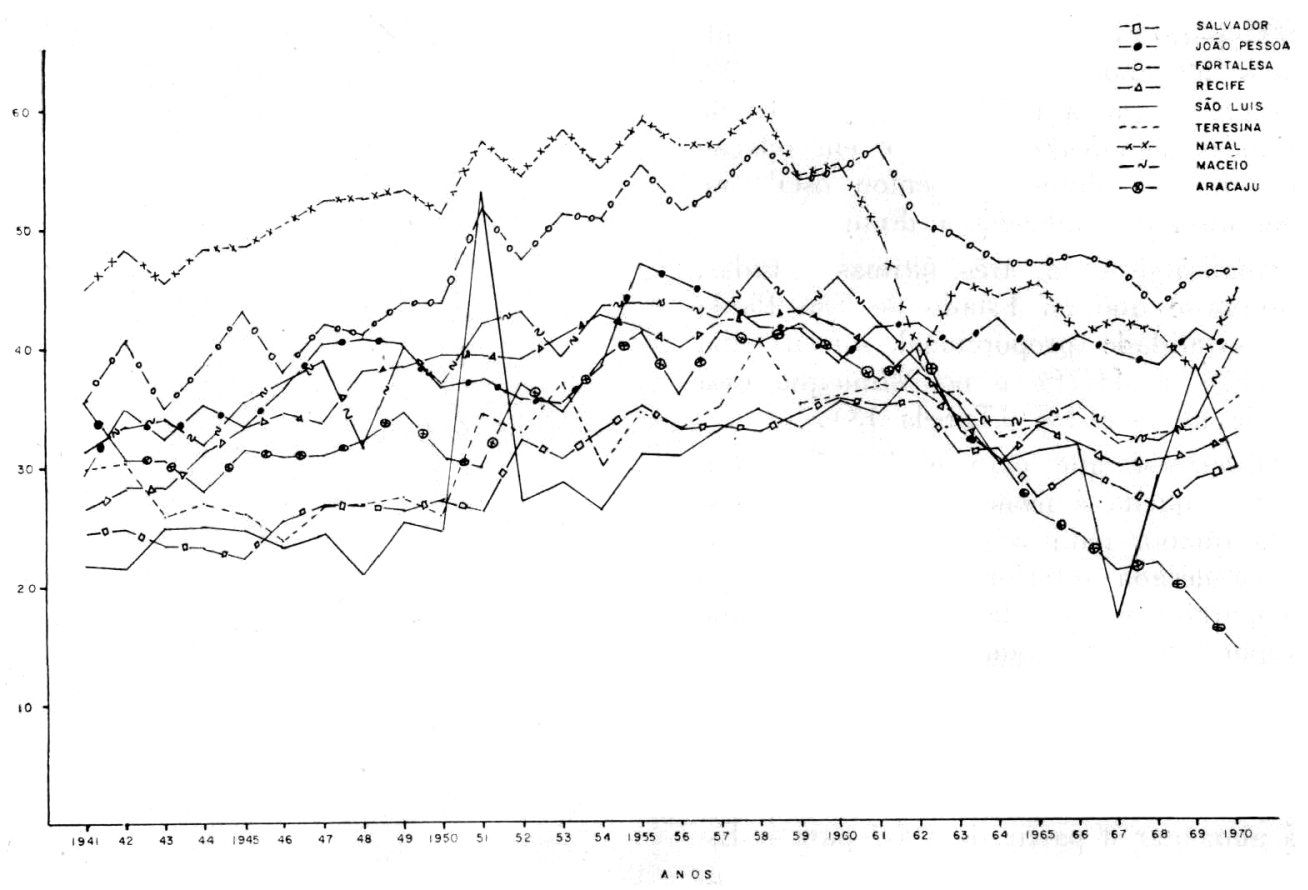

Fig. 21 - Evolução da mortalidade proporcional por capital na regiăo nordeste - 1941-1970. 
tendo sido possivel. portanto. identificar nenhuma tendência) e a Aracaju. João Pessoa e Cuiahá. Os maiores aumentos observados foram na Região Nordeste. onde São Luiz. no período de 1967-1970. sofreu um acréscimo de $77.8 \%$ e Maceió. no período $1968-1970$, de $26.6 \%$.

Ao se comparar a taxa de mortalidade proporcional de São Paulo com a do Brasil. observa-se que sua curva encontra-se em situação intermediária entre o Município e o Estado durante o período de 1941 1962 e. a partir desta data, verifica-se uma flutuação. A taxa de mortalidade proporcional do Brasil, menor em relação ao Estado durante o período observado sugere como um dos fatores o subregistro principalmente de óbitos de crianças menores de um ano como foi anteriormente mencionado (Fig. 22 ).

Estudando-se a evolução desta taxa para São Paulo, constata-se, conforme Tabela 7. que para o Município a mortalidade proporcional variou de $26,8 \% \mathrm{em}$ 1918 para 24,9\%/ em 1969. e para o Estado esta variação foi de $32,0 \%$ em 1921 para $27.0 \%$. Portanto. para os últimos 52 anos, conforme a Figura 22. observa-se que a proporção de óbitos de crianças menores de um ano em relação ao total de óbitos apresentou oscilação. com discreta tendência a diminuição.

Analisando-se as três últimas décadas, observa-se que no Estado de São Paulo a mortaljdade proporcional sofreu uma redução de $11,7 \%$ e no Município essa queda foi de $9,1 \%$ (Tabela 13 ).

Observa-se que para o decênio 1960 1970 a queda é menor tanto para o Estado quanto para o Município em relação à década anterior. Ao se analisar o comportamento da taxa de mortalidade proporcional de crianças menores de um ano nessa última década. verifica-se que apesar de haver redução, considerando-se os anos extremos 1960-1970 (Estado) e 1960-1969 (Município) esta taxa começa aumentar a partir de 1967 para o Estado, e para o Município em 1968 (Fig. 22 ! .

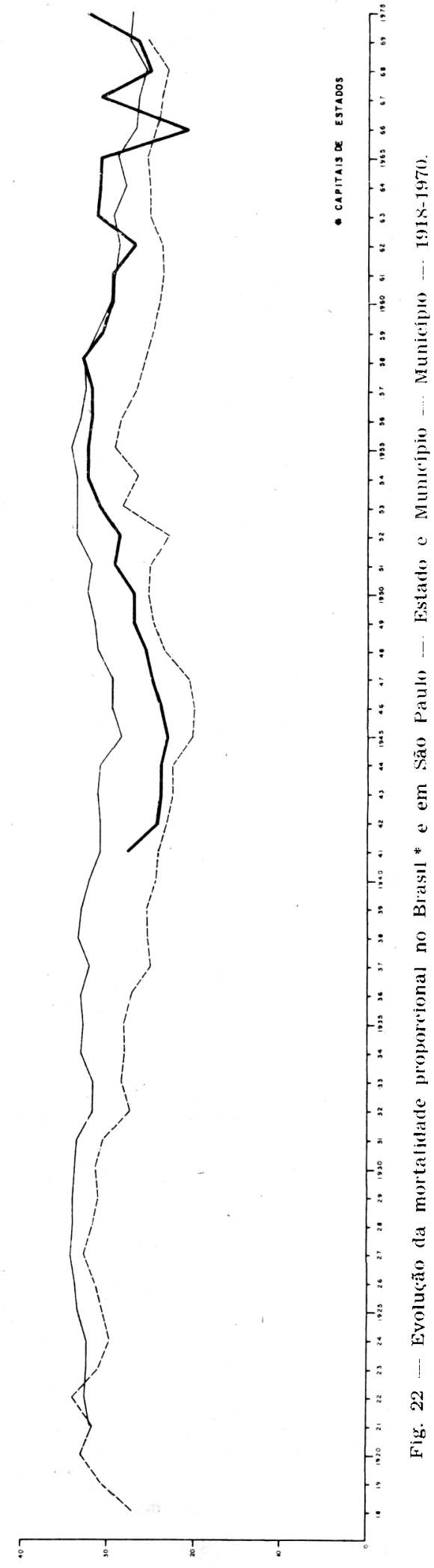


YLNES, J \& RONCHEZEL, V. S. C. - Eroluço da mortalidade geral, infantil e proporcanal no Brasil. Roi Saúde públ.. S. Paulo, 8(supl):3-48, 1974

A evolução dos coeficientes de mortalidade geral, infantil e da taxa de mortalidade proporcional encontra-se nas $\mathrm{Ta}$ belas 14 a 35 .

\subsection{Fatores condicionantes da situação atual}

Estes fatores serão avaliados em relacão ao comportamento dos indicadores de saúde utilizados em nosso trabalho, principalmente nos últimos 10 anos. dado a maior disponibilidade de dados.

Entre os fatores setoriais mais importantes. destaca-se o econômico. É sabido que o PIB (Produto Interno Bruto) no Brasil alcançou. em 1972, o valor de Cr\$ $232.256,00$, ou seja, LS $\$ 38,709.00$, correspondendo a uma renda "per capita" de US\$ 403.00, que embora tenha aumentado no último decênio é considerada ainda limitada.

Em relação à distribuição de renda, houve uma mudança entre 1960 e 1970. Segundo Fish LOW ${ }^{3}$, em $1960,3,1 \%$ da população economicamente ativa concentrava cerca de $27,0 \%$ do total da renda e em 1970 a mesma proporção de população passou a concentrar $33.1 \%$. Este autor. baseando seus cálculos em dados dos censos de 1960 e 1970 , concluiu que a concentração de riquezas aumentou no decênio considerado. Segundo este estudo, a política adotada entre 1964 e 1967 de restrição de aumento salarial a fim de diminuir a inflação fez com que o salário mínimo real tivesse declinado de $20 \%$. Fishlow afirma que esta situação é consequiência inevitável do rápido crescimento.

Segundo Montoro " "a CEPAL, em documento recente, afirma que o ponto fraco do atual desenvolvimento brasileiro é a perda do poder aquisitivo da população assalariada. E o Presidente da República, em seu corajoso discurso da Escola Superior de Guerra, afirmou: A Economia talvez vá bem, mas o povo vai mal". HOFFMANY \& DUARTE ${ }^{5}$, comparando a distribuição de renda no Brasil entre 1960 e 1970. citam em seu trabalho várias conclusões importantes conforme se seguem:

-O grau de concentração da renda é maior nas regiões Nordeste e Leste. mas difere pouco do grau de concentração do País como um todo. $\mathrm{O}$ aumento no grau de concentração da distribuição da renda foi mais acentuado nas regiôes industrializadas, de modo que em 1970 as diferenças entre os índices do Nordeste e do Sul apresentam-se menos acentuadas que no inicio da década anterior.

0 perfil da distribuição da renda pessoal no Brasil apresenta em 1970 marcadas descontinuidades. Metade da população das pessoas remuneradas recebe $13,7 \%$ da renda total, e $10.0 \%$ da população apropria-se de quase metade da renda total. Finalmente, a cúpula da distrihuição da renda constitui-se de $5.0 \%$ das pessoas remuneradas, que detém $36 \%$ da renda sendo esta população, a base estável do mercado de bens duráveis de consumo, uma base restrita cujas necessidades moldaram e ainda moldam muitas das

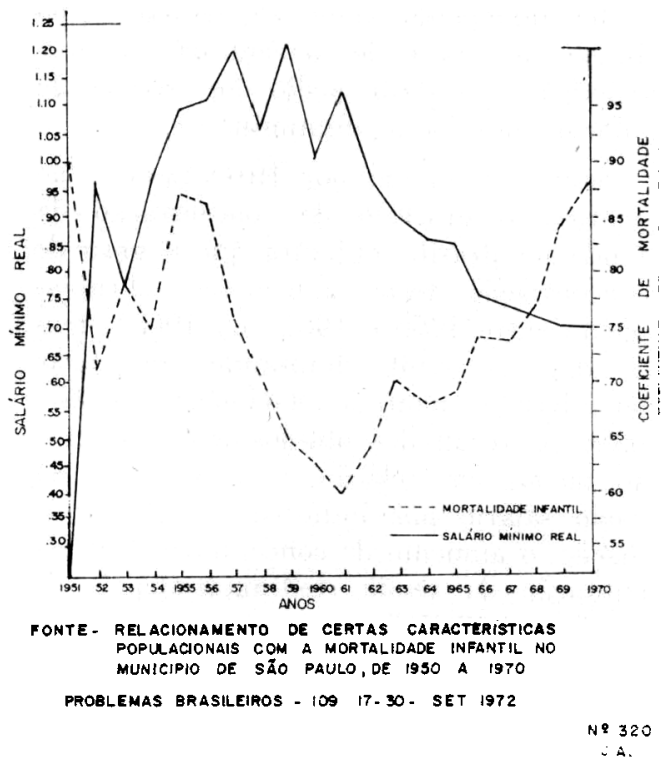

Fig. 23 - Mortalidade infantil (coeficientes por 1000 nascidos vivos) e salário minimo real munciípio de São Paulo. 
YLNES, J. \& RONCHEZEL, V. S. C. - Evolução da mortalidade geral, infantil e proporcional no Brasil. Rev. Saúde públ., S. Paulo, 8(supl.):3-48, 1974.

características do processo de industrialização do Brasil". Esses autores comparam os perfis de distribuição da renda em 1960 e 1970. que é ilustrada, na Figura 15 , pelas curvas de Lorenz. onde se observa a concentração da renda no referido decênio.

Estudos realizados por HoFfuANX * (1973) demonstram que na indústria o grupo constituído pelos $40 \%$ dos empregados com salários mais baixos teve sua participação na renda total reduzida de $20 \%$, em 1967. para $17,5 \%$ em 1971. aproximadamente. Ao mesmo tempo, a participação dos $5 \%$ com salários mais altos aumentou de $22 \%$ para $25 \%$. No setor urbano, como um todo (indústria, comércio e serviço), o grupo constituído pelos $40 \%$ dos empregados com salários mais baixos teve sua participação na renda total reduzida em cerca de $19 \%$, em 1967, para 16\%, em 1971. Ao mesmo tempo, a participação dos $5 \%$ com salários mais altos aumentou de $23 \%$ para $26.5 \%$.

Embora o valor do salário real médio tenha aumentado, como ao mesmo tempo aumentou o grau de concentração da distribuição, o salário médio dos estratos de salário mais haixo diminuiu.

Simoxsex citado por HofFmaxy 4 "ao analisar o processo de concentração da renda no Brasil, conjetura que o grau de concentração teria aumentado abruptamente entre 1966 e 1967 (ou 1968), tendo daí por diante diminuido um pouco. ou talvez se mantido estacionário. Entretanto os resultados obtidos mostram que, ao menos em relação à renda recebida como salário nas indústrias de transformação, o aumento de concentração na distribuição da renda continuou depois de 1967 (ou 1968)".

Hofrmany ${ }^{*}$ explica o aumento do grau de concentração da renda no Brasil no decênio 1960-1970. principalmente nos setores secundário e terciário dentro do "modelo" de desenvolvimento brasileiro, ressaltando que vários aspectos da políti- ca econômica governamental estão diretamente ligados ao aumento da concentração. Segundo este mesmo autor o valor do salário mínimo real caiu drasticamente durante o período: "Levando em consideração a criação do $13 .^{\circ}$ salário em 1962, um índice do valor do salário mínimo real médio na Guanabara, tendo por hase o triênio 1959-1961 igual a 100, caiu para 87 nos triênios 1962-1964 e para 80 e 75 nos triênios 1965-1967 e 19681970. respectivamente no biênio 19711972 o valor desse índice é 76".

Para o municipio de São Paulo, como se verificou anteriormente, os dados de estatística de saúde são de melhor qualidade e observou-se o aumento da mortalidade infantil a partir de 1961. Estudo interessante realizado por $\mathrm{LESER}^{6}$ aponta. como fator importante a ser levado em consideração no aumento da mortalidade infantil, o referente à capacidade aquisitiva da população e concluiu que na década de 1960 o salário mínimo real sofreu severa redução, conforme demonstra a Figura 23. Segundo este autor, "é compreensível que, com a redução da capacidade aquisitiva, mormente nas classes menos favorecidas, sejam prejudicadas, quantitativa e, principalmente, qualitativamente. as condições de alimentação da população. Por outro lado, é fato comprovado que a desnutrição, além de poder constituir causa direta de morte, representa fator predisponente e agravante de doenças infecciosas, aumentando substancialmente os coeficientes da morbidade e de fatalidade das mesmas".

Entre outros fatores extra-setoriais responsáveis pelo nível de saúde no Brasil podemos citar: " $\mathrm{O}$ analfabetismo da ordem de $32 \%$ (1970) e a subalimentação (disponibilidade média de cal/dia: 2.690 e de proteínas totais: $66,3 \mathrm{~g} / \mathrm{dia}^{1}{ }^{1}$, quando o recomendado é em torno de $3.200 \mathrm{col}$, e de 104 a $120 \mathrm{~g} /$ dia de proteínas.

Observa-se também grande deficit de saneamento básico, pois "dos $3.950 \mathrm{mu}$ - 
YUNES, J. \& RONCHEZEL, V. S. C. - Evoluçāo da mortaltdade geral, infantil e proporcional no Brasil. Rev. Saúde públ., S. Paulo, 8(supl.):3-48, 1974.

nicípios existentes em $1969,43,3 \%$ não têm abastecimento de água e $59,3 \%$ não têm esgoto. Embora a maior deficiência se verifique na área rural, a situação na área urbana é ainda bastante precária, pois $45 \%$ dos domicílios não têm abastecimento de água servida pela rede geral e $70,2 \%$ não possuem instalações sanitárias ligadas também à rede geral". ${ }^{1}$
Ainda se acrescenta o aumento da população descoberta dos recursos de saneamento básico, devido à grande migração rural-urbana observada no último decênio.

A par dos indicadores extra-setoriais pode-se citar ainda "insuficiente integração do Setor Saúde na Política Nacional de Desenvolvimento Econômico e Social" ${ }^{1}$.

YUNES, J. \& RONCHEzEL, V. S. C. - [Trends in general, infant and proportional mortality in Brazil]. Rev. Saúde públ., S. Paulo, 8(supl.):3-48, 1974.

SUMMARY: Study of the evolution of general mortality, infant mortality rate and mortality ratio in Brazil and phisiographical regions. During the last 30 years the reduction of general mortality in Brazil was $47.5 \%$ and the biggest fall was noticed in the West-Center Region. In the last 10 years the rise of the rate in all Regions was observed starting in different years. This fact is due to the increase of infant mortality. When one compares general mortality in Brazil with that of developed countries, it can be considered high since 42\% of the population in 14 years old, showing an insatisfactory health level. During the period of 30 years there was a reduction of the infant mortality rate to $46.2 \%$. In the last 10 years a rising rate is observed, showing that the health level is worse and when we compare it with other countries the noticed difference is relevant. When we evaluate the proportional mortality $1 \%$ of the total deaths of children with less than 1 year) from 1940 to 1970 is remarkable on increasing of $16.3 \%$. In the last 10 years it was higher in the west-center region (57.7\%) and South west $(36.1 \%)$. When we compare the data of Brazil with the most developed State and City of Brazil (São Paulo) we always see that these health indicators present itself as being higher in the country as a whole, refleting a worse health level. Among the principal conditionant reasons of the worsening health level in Brazil during the last ten years appears the economical one where the income distribution concentration increases, the real minimum wages fall by $20 \%$. Consequently the worker's possibility of acquising wealth decreases. Adding to this, the increasing of the population without environmental health is growing.

UNITERMS: Mortality; Infant mortality; Brazil; Population, Brazilian.

\section{REFERENCIAS BIBLIOGRAFICAS}

1. BRASIL. Ministério da Saúde. Diretrizes gerais para a politica de Saude materno infantil: documento preliminar. Rio de Janeiro, 1973. p. 1-20.

2. DEMOGRAPHIC YEARBOOK, 1970 (United Nations). New York, 1971.

3. FISHLOW, A. - Brazilian size distribution of income. Amer. Econ. Rev., 62: 391-402, 1972 .
4. HOFFMANN, R. - Consideração sobre a evolução recente da distribuição da renda no Brasil. Piracicaba, Escola Superior de Agricultura Luiz de Queiroz, USP, 1973. (Sérle Pesquisa 19)

5. HOFFMANN, R. \& DUARTE, J. C. - A distribuiçăo da renda no Brasil. Rev. Adm. Emp., Rio de Janeiro, 12(2): 46-66, 1972 . 
YUNES, J. \& RONCHEZEL, V. S. C. - Evolução da mortalidade geral, infantil e proporcional no Brasil. Rev. Saúde puibl., S. Paulo, 8(supl.):3-48, 1974.

6. LESER, W. - Relacionamento de certas caracteristicas populacionais com a mortalidade infantil no municipio de Sāo Pauio de 1950 a 1970 . Probl. bras., $10(109): 17-30,1972$

7. MONTORO, A. - Três rumos para o desenvolvimento brasileiro. Brasilia D.F., 1971. p. 19. [Discurso pronunciado no senado Federal em 29-4-71.]

8. MORTARA, G. - Estimativa do número de b́bitos e da taxa de mortalidade geral para 0 Brasil (1950). In: INSTITUTO BRASILEIRO DE GEOGRAFIA E ESTATISTICA. Pesquisa sobre a mortalidade no Brasil: :. $^{\circ}$ série. Rlo de Janeiro, 1956. p. 56-7. (Estudos de Estatistica Teórica e Aplicada. Estatistica Demográfica, 20).

9. MORTARA, G. - Estudos sobre a utilização do censo demográfico para a reconstrucão das estatísticas do movimento da população do Brasil. VI Sinopse da dinâmica da população do Brasil nos últimos cem anos. Rev. bras. Estat., 2: 267-76, 1941.

10. MORTARA, G. - Ligeiras consideraçôes sobre a mortalidade infantil no Brasil. In: INSTITUTO BRASILEIRO DE GEOGRAFIA E ESTATISTICA. Contribuição para o estudo da demografia do Brasil. Rio de Janeiro, 1961. p. 113-6.

11. OYA, D. R. T. - Estudo da distribuicão do fator de separação $f x^{t}$ na tábua de sobrevivência - São Paulo, 1970. [Dissertação de Mestrado - Faculdade de Saúde Pública da USP].

12. SANTOS, J. L. F, - Projeção da população brasilelra 1970-2000. Rev. Saúde públ., S. Paulo (supl.), junho, 1974.

13. YUNES, J. - The population of Brazil. Rev. Saúde públ., S. Paulo, 6:393404, 1972. 
YUNES, J. \& RONCHEZEL, V. S. C. - Evolução da mortalidade geral, infantil e proporcional no Brasil. Rev. Saude puibl., S. Paulo, 8(supl.):3-48, 1974.

\section{A N E X O}

TA B E L A 1

Brasil * Evolução da mortalidade geral, infantil e proporcional - 1941-1970

\begin{tabular}{c|c|c|c}
\hline Ano & $\begin{array}{c}\text { Mortalidade } \\
\text { geral } \\
\text { (por mil } \\
\text { habitantes) }\end{array}$ & $\begin{array}{c}\text { Mortalidade } \\
\text { infantil } \\
\text { (por mil } \\
\text { nascidos } \\
\text { vivos) }\end{array}$ & $\begin{array}{c}\text { Mortalidade } \\
\text { proporcio- } \\
\text { nal ** }\end{array}$ \\
\hline
\end{tabular}

\begin{tabular}{rrrl}
1941 & 19,25 & 202,33 & 27,80 \\
1942 & 18,96 & 190,21 & 24,12 \\
1943 & 18,54 & 185,25 & 23,56 \\
1944 & 19,29 & 188,55 & 23,71 \\
1945 & 18,46 & 170,20 & 22,98 \\
1946 & 18,15 & 162,71 & 23,77 \\
1947 & 18,14 & 142,90 & 24,54 \\
1948 & 17,36 & 145,42 & 25,50 \\
1949 & 17,02 & 149,59 & 26,67 \\
1950 & 14,45 & 136,64 & 26,67 \\
1951 & 15,21 & 151,48 & 28,92 \\
1952 & 13,92 & 137,19 & 28,36 \\
1953 & 14,14 & 139,99 & 30,55 \\
1954 & 14,60 & 124,88 & 31,99 \\
1955 & 13,26 & 144,05 & 32,11 \\
1956 & 14,42 & 142,59 & 31,77 \\
1957 & 14,79 & 131,33 & 31,50 \\
1958 & 14,20 & 139,95 & 32,70 \\
1959 & 12,36 & 118,65 & 30,26 \\
1960 & 11,36 & 105,23 & 29,20 \\
1961 & 10,96 & 102,64 & 29,36 \\
1962 & 10,78 & 94,61 & 26,59 \\
1963 & 11,16 & 109,42 & 31,04 \\
1964 & 10,48 & 102,41 & 30,64 \\
1965 & 10,23 & 101,07 & 30,41 \\
1966 & 9,87 & 98,03 & 20,18 \\
1967 & 9,52 & 105,88 & 28,80 \\
1968 & 9,44 & 89,62 & 24,67 \\
1969 & 9,18 & 91,21 & 26,44 \\
1970 & 10,12 & 108,68 & 32,32 \\
& & & \\
\hline & & & \\
\hline
\end{tabular}

\section{* Capitals de Estados}

* n. ${ }^{\circ}$ de óbitos de menores de 1 ano: n.० total de óbitos $\times 100$

Fontes: Departamento de Estatística do Estado de Săo Paulo (DEE)

Fundação Instituto Brasileiro de Geografia e Estatística (IBGE)

Anuárlo Estatístico do Brasil (IBGE), Rio de Janeiro - 1950-1972
T A B E L A 2

Brasil-Norte * - Evolução da mortalidade geral, infantil e proporcional - 1941-1970

\begin{tabular}{|c|c|c|c|}
\hline Ano & $\begin{array}{l}\text { Mortalidade } \\
\text { geral } \\
\text { (por mil } \\
\text { habitantes) }\end{array}$ & $\begin{array}{l}\text { Mortalidade } \\
\text { infantil } \\
\text { (por mil } \\
\text { nascidos } \\
\text { vivos) }\end{array}$ & $\begin{array}{l}\text { Mortalidade } \\
\text { proporcio- } \\
\text { nal ** }\end{array}$ \\
\hline
\end{tabular}

\begin{tabular}{rrrr}
1941 & 22,45 & 213,93 & 18,57 \\
1942 & 23,24 & 213,98 & 19,10 \\
1943 & 22,67 & 177,21 & 20,14 \\
1944 & 23,74 & 183,72 & 21,09 \\
1945 & 21,05 & 143,13 & 20,95 \\
1946 & 19,21 & 139,37 & 21,57 \\
1947 & 18,18 & 123,00 & 24,36 \\
1948 & 17,06 & 113,54 & 24,80 \\
1949 & 18,53 & 165,18 & 25,56 \\
1950 & 14,59 & 171,60 & 26,81 \\
1951 & 15,66 & 151,11 & 29,46 \\
1952 & 14,43 & 136,52 & 28,22 \\
1953 & 15,40 & 132,43 & 31,19 \\
1954 & 17,88 & 126,34 & 28,48 \\
1955 & 15,77 & 173,34 & 30,22 \\
1956 & 14,96 & 153,41 & 30,96 \\
1957 & 14,16 & 109,69 & 30,75 \\
1958 & 13,92 & 136,16 & 32,98 \\
1959 & 12,02 & 132,11 & 30,71 \\
1960 & 11,73 & 122,04 & 29,15 \\
1961 & 11,86 & 127,03 & 31,84 \\
1962 & 10,85 & 110,37 & 30,13 \\
1963 & 10,62 & 132,47 & 30,50 \\
1964 & 10,84 & 137,84 & 30,02 \\
1965 & 9,24 & 134,32 & 28,16 \\
1966 & 8,14 & 100,90 & 28,71 \\
1967 & 7,46 & 68,30 & 24,96 \\
1968 & 7,82 & 92,19 & 27,31 \\
1969 & 7,87 & 55,57 & 25,75 \\
1970 & 7,81 & 67,05 & 27,73 \\
& & & \\
\hline & & & \\
\hline & & &
\end{tabular}

- Capitais de Estados

** n.o de óbitos de menores de 1 ano: n. ${ }^{\circ}$ total de óbitos $\times 100$

Fontes: DEE

IBGE

Anuário Estatístico do Brasil (IBGE), Rio de Janeiro - 1950-1972 
YUNES, J. \& RONCHEZEL, V. S. C. - Evolução da mortalidade geral, infantil e proporcional no Brasil. Rev. Saúde públ., S. Paulo, 8(supl.):3-48, 1974.

TA B E L A 3

Brasil-Nordeste * - Evolução da mortalidade geral, infantil e proporcional - 1941-1970

\begin{tabular}{l|c|c|c}
\hline & $\begin{array}{c}\text { Mortalidade } \\
\text { geral } \\
\text { (por mil } \\
\text { habitantes) }\end{array}$ & $\begin{array}{c}\text { Mortalidade } \\
\text { infantil } \\
\text { (por mil } \\
\text { nascidos } \\
\text { vivos) }\end{array}$ & $\begin{array}{c}\text { Mortalidade } \\
\text { proporcio- } \\
\text { nal ** }\end{array}$ \\
\hline & & & \\
1941 & 26,53 & 264,19 & 42,28 \\
1942 & 27,02 & 301,24 & 31,46 \\
1943 & 28,03 & 322,41 & 30,21 \\
1944 & 26,42 & 346,54 & 31,46 \\
1945 & 27,00 & 326,57 & 32,58 \\
1946 & 27,54 & 356,23 & 33,52 \\
1947 & 31,39 & 255,12 & 35,17 \\
1948 & 24,65 & 257,85 & 35,64 \\
1949 & 26,14 & 264,44 & 37,15 \\
1950 & 21,88 & 206,85 & 36,38 \\
1951 & 25,32 & 270,30 & 40,49 \\
1952 & 21,57 & 260,73 & 39,58 \\
1953 & 21,87 & 260,33 & 41,14 \\
1954 & 22,19 & 262,99 & 42,15 \\
1955 & 20,86 & 266,99 & 44,21 \\
1956 & 21,91 & 249,31 & 42,22 \\
1957 & 23,12 & 220,96 & 43,44 \\
1958 & 22,51 & 282,96 & 44,99 \\
1959 & 17,80 & 193,83 & 42,55 \\
1960 & 15,91 & 183,59 & 43,46 \\
1961 & 15,38 & 174,60 & 42,13 \\
1962 & 14,74 & 176,83 & 39,61 \\
1963 & 14,11 & 162,26 & 38,14 \\
1964 & 13,44 & 154,90 & 36,19 \\
1965 & 12,90 & 142,05 & 36,29 \\
1966 & 12,39 & 148,53 & 33,96 \\
1967 & 11,86 & 146,26 & 34,48 \\
1968 & 11,82 & 167,51 & 33,64 \\
1969 & 11,30 & 155,22 & 36,28 \\
1970 & 11,41 & 149,27 & 36,37 \\
& & & \\
\hline & & \multicolumn{3}{c}{} \\
\hline
\end{tabular}

* Capitais de Estados

** n. ${ }^{\circ}$ de 6 bitos de menores de 1 ano: n. ${ }^{\circ}$ total de óbitos $\times 100$

Fontes: DEE

IBGE

Anuário Estatístico do Brasil (IBGE), Rio de Janeiro - 1950-1972
T A B E I A 4

Brasil-Centro-Oeste * Evolução da mortalidade geral, infantil e proporcional - 1941-1970

\begin{tabular}{|c|c|c|c|}
\hline Ano & $\begin{array}{l}\text { Mortalidade } \\
\text { geral } \\
\text { (por mil } \\
\text { habitantes) }\end{array}$ & $\begin{array}{c}\text { Mortalidade } \\
\text { infantil } \\
\text { (por mil } \\
\text { nascidos } \\
\text { vivos) }\end{array}$ & $\begin{array}{l}\text { Mortalidade } \\
\text { proporcio- } \\
\text { nal ** }\end{array}$ \\
\hline 1941 & 27,97 & 279,86 & 30,84 \\
\hline 1942 & 29,80 & 340,95 & 30,52 \\
\hline 1943 & 21,30 & 154,53 & 23,25 \\
\hline 1944 & 22,05 & 118,90 & 20,88 \\
\hline 1945 & 22,22 & 116,88 & 21,20 \\
\hline 1946 & 24,86 & 96,37 & 21,34 \\
\hline 1947 & 24,21 & 93,65 & 21,47 \\
\hline 1948 & 26,40 & 130,21 & 18,43 \\
\hline 1949 & 22,36 & 155,09 & 29,31 \\
\hline 1950 & 15,36 & 126,77 & 25,13 \\
\hline 1951 & 19,91 & 133,79 & 29,08 \\
\hline 1952 & 20,83 & 124,05 & 26,34 \\
\hline 1953 & 20,51 & 113,45 & 26,35 \\
\hline 1954 & 20,93 & 131,30 & 34,43 \\
\hline 1955 & 22,34 & 157,39 & 31,93 \\
\hline 1956 & 23,03 & 118,55 & 29,51 \\
\hline 1957 & 23,29 & 161,21 & 31,37 \\
\hline 1958 & 24,70 & 119,02 & 31,92 \\
\hline 1959 & 11,09 & 95,55 & 31,28 \\
\hline 1960 & 11,57 & 104,11 & 26,75 \\
\hline 1961 & 9,99 & 78,50 & 28,43 \\
\hline 1962 & 10,06 & 85,50 & 33,83 \\
\hline 1963 & 10,87 & 107,76 & 35,60 \\
\hline 1964 & 8,44 & 92,51 & 40,48 \\
\hline 1965 & 10,17 & 89,00 & 32,97 \\
\hline 1966 & 7,83 & 70,57 & 33,07 \\
\hline 1967 & 7,63 & 70,61 & 33,12 \\
\hline 1968 & 6,83 & 62,01 & 35,40 \\
\hline 1969 & 8,23 & 91,85 & 41,35 \\
\hline 1970 & 7,94 & 72,04 & 42,19 \\
\hline
\end{tabular}

* Capitais de Estados

* n.o de óbitos de menores de 1 ano: $n .^{\circ}$ total de óbitos $\times 100$

Fontes: DEE

IBGE

Anuário Estatístico do Brasil (IBGE), Rio de Janeiro - 1950-1972 
YUNES, J. \& RONCHEZEL, V. S. C. - Evolução da mortalidade geral, infantil e proporcional no Brasil. Rev. Saúde públ., S. Paulo, 8(supl.):3-48, 1974.

TA B E L A 5

Brasil-Sudeste * - Evoluçāo da mortalidade geral, infantil e proporcional — 1941-1970

\begin{tabular}{c|c|c|c}
\hline Ano & $\begin{array}{c}\text { Mortalidade } \\
\text { geral } \\
\text { (por mil } \\
\text { habitantes) }\end{array}$ & $\begin{array}{c}\text { Mortalidade } \\
\text { infantil } \\
\text { (por mil } \\
\text { nascidos } \\
\text { vivos) }\end{array}$ & $\begin{array}{c}\text { Mortalidade } \\
\text { proporcio- } \\
\text { nal ** }\end{array}$ \\
\hline
\end{tabular}

\begin{tabular}{rrrl}
1941 & 16,65 & 159,93 & 21,11 \\
1942 & 15,80 & 140,69 & 20,49 \\
1943 & 15,24 & 135,37 & 20,04 \\
1944 & 16,40 & 139,84 & 20,13 \\
1945 & 15,31 & 115,33 & 17,72 \\
1946 & 14,72 & 105,48 & 18,37 \\
1947 & 14,15 & 97,45 & 18,49 \\
1948 & 14,55 & 102,61 & 19,78 \\
1949 & 13,73 & 102,04 & 20,74 \\
1950 & 11,98 & 99,86 & 21,40 \\
1951 & 12,10 & 100,95 & 21,89 \\
1952 & 11,19 & 89,36 & 21,74 \\
1953 & 11,37 & 95,24 & 24,73 \\
1954 & 11,68 & 79,63 & 26,23 \\
1955 & 10,71 & 97,74 & 25,84 \\
1956 & 11,77 & 100,72 & 25,73 \\
1957 & 11,80 & 89,04 & 23,91 \\
1958 & 11,12 & 84,75 & 24,63 \\
1959 & 10,31 & 79,97 & 23,06 \\
1960 & 9,69 & 67,66 & 21,37 \\
1961 & 9,57 & 68,13 & 21,75 \\
1962 & $\mathbf{9 , 5 6}$ & 60,00 & 18,71 \\
1963 & 9,66 & 77,17 & 25,72 \\
1964 & 8,95 & 72,45 & 25,43 \\
1965 & 8,83 & 75,42 & 25,80 \\
1966 & 8,88 & 78,40 & 24,15 \\
1967 & 8,64 & 81,63 & 24,38 \\
1968 & $\mathbf{9}, 07$ & 69,63 & 20,05 \\
1969 & 8,74 & 74,97 & 21,67 \\
1970 & 10,67 & 94,66 & 28,30 \\
& & & \\
\hline
\end{tabular}

* Capitaís de Estados

** n.0 de óbitos de menores de 1 ano: n.0 total de óbitos $\times 100$

Fontes: DEE

IBGE

Anuário Estatístico do Brasil (IBGE), Rio de Janeiro - 1950-1972
T A B E L A 6

Brasil-Sul * Evolução da mortalidade geral, infantil e proporcional - 1941-1970

\begin{tabular}{|c|c|c|c|}
\hline Ano & $\begin{array}{l}\text { Mortalidade } \\
\text { geral } \\
\text { (por mil } \\
\text { habitantes) }\end{array}$ & $\begin{array}{l}\text { Mortalidade } \\
\text { infantil } \\
\text { (por mil } \\
\text { nascidos } \\
\text { vivos) }\end{array}$ & $\begin{array}{l}\text { Mortalidade } \\
\text { proporcio- } \\
\text { nal ** }\end{array}$ \\
\hline 1941 & 19,81 & 203,39 & 23,55 \\
\hline 1942 & 18,90 & 191,60 & 23,11 \\
\hline 1943 & 16,83 & 166,88 & 22,25 \\
\hline 1944 & 18,82 & 135,21 & 19,54 \\
\hline 1945 & 17,74 & 142,45 & 20,27 \\
\hline 1946 & 18,84 & 119,49 & 19,91 \\
\hline 1947 & 18,62 & 110,16 & 19,20 \\
\hline 1948 & 18,44 & 126,16 & 23,69 \\
\hline 1949 & 17,66 & 118,02 & 22,18 \\
\hline 1950 & 14,02 & 130,64 & 22,23 \\
\hline 1951 & 14,36 & 134,91 & 25,38 \\
\hline 1952 & 14,29 & 124,71 & 24,71 \\
\hline 1953 & 13,29 & 108,93 & 24,71 \\
\hline 1954 & 13,71 & 114,34 & 25,57 \\
\hline 1955 & 12,29 & 114,82 & 25,34 \\
\hline 1956 & 14,70 & 122,57 & 28,99 \\
\hline 1957 & 15,45 & 128,85 & 29,37 \\
\hline 1958 & 14,20 & 139,63 & 28,06 \\
\hline 1959 & 12,92 & 132,45 & 25,10 \\
\hline 1960 & 11,34 & 107,72 & 25,88 \\
\hline 1961 & 10,84 & 104,80 & 29,44 \\
\hline 1962 & 10,27 & 96,83 & 24,25 \\
\hline 1963 & 10,60 & 101,20 & 26,56 \\
\hline 1964 & 10,15 & 79,59 & 26,86 \\
\hline 1965 & 10,10 & 90,96 & 27,54 \\
\hline 1966 & 9,61 & 53,89 & 22,67 \\
\hline 1967 & 9,48 & 58,12 & 28,54 \\
\hline 1968 & 8,20 & 68,18 & 21,50 \\
\hline 1969 & 8,02 & 63,33 & 20,49 \\
\hline 1970 & 8,10 & 64,59 & 22,28 \\
\hline
\end{tabular}

* Capitais de Estados

** n.o de óbitos de menores de 1 ano: n.o total de óbitos $\times 100$

Fontes: DEE

IBGE

Anuárlo Estatístico do Brasil (IBGE), Rio de Janeiro - 1950-1972 
YUNES, J. \& RONCHEZEL, V. S. C. - Evolução da mortalldade geral, infantil e proporcional no Brasil. Rev. Saúde puibl., S. Paulo, 8(supl.):3-48, 1974.

\section{T A B ELA 7}

São Paulo - Estado e Município - Evolucão da mortalidade geral, infantjl e proporcional 1918-1970

\begin{tabular}{|c|c|c|c|c|c|c|}
\hline \multicolumn{4}{|c|}{ Estado } & \multicolumn{3}{|c|}{ Município } \\
\hline Ano & $\begin{array}{c}\text { Mortalldade } \\
\text { geral } \\
\text { (por mil } \\
\text { habitantes) }\end{array}$ & $\begin{array}{c}\text { Mortalidade } \\
\text { infantil } \\
\text { (por mil } \\
\text { nascidos } \\
\text { vivos) }\end{array}$ & $\begin{array}{c}\text { Mortalidade } \\
\text { proporcio- } \\
\text { nal * }\end{array}$ & $\begin{array}{c}\text { Mortalidade } \\
\text { geral } \\
\text { (por mil } \\
\text { habitantes) }\end{array}$ & $\begin{array}{l}\text { Mortalidade } \\
\text { infantil } \\
\text { (por mil } \\
\text { nascidos } \\
\text { vivos) }\end{array}$ & $\begin{array}{c}\text { Mortalidade } \\
\text { proporcio- } \\
\text { nal * }\end{array}$ \\
\hline 1918 & $\ldots$ & $\ldots$ & $\ldots$ & 27,4 & 222,7 & 26,8 \\
\hline 1919 & $\ldots$ & $\ldots$ & $\ldots$ & 17,9 & 180,4 & 30,6 \\
\hline 1920 & $\ldots$ & $\ldots$ & $\ldots$ & 18,4 & 176,3 & 32,9 \\
\hline 1921 & $\ldots$ & 187,6 & 32,0 & 18,8 & 176,4 & 31,8 \\
\hline 1922 & $\ldots$ & 174,8 & 32,6 & 18,4 & 179,3 & 34,0 \\
\hline 1923 & $\ldots$ & 165,6 & 32,5 & 18,9 & 163,7 & 31,0 \\
\hline 1924 & $\cdots$ & 175,9 & 32,3 & 19,4 & 168,0 & 29,6 \\
\hline 1925 & $\cdots$ & 168,2 & 33,2 & 19,5 & 176,4 & 30,7 \\
\hline 1926 & $\cdots$ & 162,6 & 33,7 & 19,1 & 174,3 & 32,2 \\
\hline 1927 & $\cdots$ & 168,3 & 34,3 & 18,4 & 166,8 & 32,8 \\
\hline 1928 & $\cdots$ & 171,9 & 33,9 & 18,4 & 160,2 & 30,5 \\
\hline 1929 & $\ldots$ & 166,9 & 34,0 & 17,6 & 156,3 & 30,8 \\
\hline 1930 & 16,9 & 167,9 & 33,7 & 15,6 & 152,6 & 31,2 \\
\hline 1931 & 16,6 & 168,3 & 33,3 & 15,0 & 160,5 & 30,4 \\
\hline 1932 & 15,7 & 163,8 & 31,5 & 13,5 & 140,8 & 27,7 \\
\hline 1933 & 17,9 & 184,0 & 31,7 & 14,8 & 169,2 & 28,4 \\
\hline 1934 & 16,8 & 177,7 & 32,9 & 12,9 & 141,3 & 28,0 \\
\hline 1935 & 17,1 & 174,9 & 32,6 & 14,0 & 141,8 & 28,1 \\
\hline 1936 & 18,6 & 188,5 & 33,0 & 15,4 & 157,8 & 27,4 \\
\hline 1987 & 16,8 & 171,5 & 32,1 & 27,4 & 222,7 & 26,8 \\
\hline 1938 & 16,7 & 166,5 & 33,2 & 17,9 & 108,4 & 30,6 \\
\hline 1989 & 16,9 & 170,8 & 32,9 & 18,4 & 176,3 & 32,9 \\
\hline 1940 & 19,2 & 187,5 & 31,9 & 18,8 & 176,4 & 31,8 \\
\hline 1941 & 17,8 & 182,4 & 30,6 & 18,4 & 179,3 & 34,0 \\
\hline 1942 & 15,6 & 149,1 & 30,6 & 18,9 & 163,7 & 31,0 \\
\hline 1943 & 15,4 & 147,7 & 31,1 & 19,4 & 168,0 & 29,6 \\
\hline 1944 & 16,5 & 155,0 & 30,5 & 19,5 & 176,4 & 30,7 \\
\hline 1945 & 15,0 & 138,5 & 28,3 & 19,1 & 174,3 & 32,2 \\
\hline 1946 & 12,9 & 115,8 & 29,2 & 18,4 & 166,8 & 32,8 \\
\hline 1947 & 12,6 & 112,1 & 29,2 & 18,4 & 160,2 & $\mathbf{3 0 , 5}$ \\
\hline 1948 & 13,2 & 123,6 & 31,1 & 17,6 & 156,3 & 30,8 \\
\hline 1949 & 12,5 & 119,1 & 31,4 & 15,6 & 152,6 & 31,2 \\
\hline 1950 & 12,8 & 122,4 & 32,0 & 15,0 & 160,5 & 30,4 \\
\hline 1951 & 12,8 & 119,7 & 31,7 & 13,5 & 140,8 & 27,7 \\
\hline 1952 & 11,6 & 114,0 & 33,3 & 14,8 & 169,2 & 28,4 \\
\hline 1953 & 11,2 & 111,2 & 33,2 & 12,9 & 141,3 & 28,0 \\
\hline 1954 & 10,5 & 102,2 & 33,2 & 14,0 & 147,8 & 28,1 \\
\hline 1955 & 10,7 & 107,4 & 34,0 & 15,4 & $\mathbf{1 5 7 , 8}$ & 27,4 \\
\hline 1956 & 10,4 & 103,8 & 32,9 & 13,7 & 134,4 & 24,9 \\
\hline 1957 & 10,2 & 96,4 & 32,2 & 14,1 & 138,2 & 25,2 \\
\hline 1958 & 9,7 & 95,1 & 32,7 & 9,7 & 69,2 & 25,8 \\
\hline 1959 & 9,5 & 88,0 & 30,9 & 9,3 & 65,8 & 24,6 \\
\hline 1960 & 9,1 & 82,0 & 29,2 & 8,3 & 62,9 & 24,0 \\
\hline
\end{tabular}

- n.o de óbitos de menores de um ano: n.0 total de óbitos $\times 100$ 
YUNES, J. \& RONCHEZEL, V. S. C. - Evolução da mortalidade geral, infantil e proporcional no Brasil. Rev. Saúde públ., S. Paulo, 8(supl.):3-48, 1974.

TABELA 7 (continuação)

\begin{tabular}{|c|c|c|c|c|c|c|}
\hline \multicolumn{4}{|c|}{ Estado } & \multicolumn{3}{|c|}{ Município } \\
\hline Ano & $\begin{array}{c}\text { Mortalidade } \\
\text { geral } \\
\text { (por mil } \\
\text { habitantes) }\end{array}$ & $\begin{array}{l}\text { Mortalidade } \\
\text { infantil } \\
\text { (por mil } \\
\text { naseidos } \\
\text { vivos) }\end{array}$ & $\begin{array}{l}\text { Mortalidade } \\
\text { proporcio- } \\
\text { nal * }\end{array}$ & $\begin{array}{l}\text { Mortalidade } \\
\text { geral } \\
\text { (por mil } \\
\text { habitantes) }\end{array}$ & $\begin{array}{l}\text { Mortalidade } \\
\text { infantil } \\
\text { (por mil } \\
\text { nascidos } \\
\text { vivos) }\end{array}$ & $\begin{array}{c}\text { Mortalidade } \\
\text { proporcio- } \\
\text { nal * }\end{array}$ \\
\hline 1961 & 9,1 & 83,2 & 29,0 & 8,1 & 60,2 & 23,2 \\
\hline 1962 & 9,0 & 81,0 & 28,2 & 8,7 & 64,4 & 23,7 \\
\hline 1963 & 9,1 & 82,3 & 29,1 & 9,0 & 69,9 & 25,1 \\
\hline 1964 & 8,0 & 71,8 & 27,8 & 8,7 & 67,7 & 24,9 \\
\hline 1965 & 8,1 & 73,9 & 28,6 & 8,6 & 69,4 & 25,4 \\
\hline 1966 & 8,1 & 76,8 & 26,8 & 8,8 & 73,8 & 24,2 \\
\hline 1967 & 7,9 & 78,9 & 26,2 & 8,7 & 74,4 & 23,8 \\
\hline 1968 & 7,8 & 72,4 & 25,2 & 8,1 & 75,1 & 22,9 \\
\hline 1969 & 7,9 & 84,1 & 27,3 & 9,3 & 83,8 & 24,9 \\
\hline 1970 & 7,9 & 81,4 & 27,0 & $\ldots$ & $\ldots$ & $\ldots$ \\
\hline
\end{tabular}

* n.o de óbitos de menores de um ano: n. ${ }^{\circ}$ total de 6 bitos $\times 100$

Fontes: IBGE

Anuário Estatístico do Brasil (IBGE). Rio de Janeiro - 1950-1972

TAB E L A 8

Mortalidade geral* - Diferença percentual do coeficiente para o Brasil e regiões físiográficas - 1941-1970

\begin{tabular}{|c|c|c|c|c|c|c|}
\hline Ano & Brasil & $\begin{array}{l}\text { Centro- } \\
\text { Oeste }\end{array}$ & Norte & Sul & Nordeste & Sudeste \\
\hline $1941-1950$ & $-24,9$ & $-45,1$ & $-35,0$ & $-29,2$ & $-17,5$ & $-28,0$ \\
\hline $1950-1960$ & $-21,4$ & $-24,7$ & $-19,6$ & $-19,1$ & $-27,3$ & $-19,1$ \\
\hline $1960-1970$ & $-10,9$ & $-31,4$ & $-33,4$ & $-28,6$ & $-28,3$ & $+10,1$ \\
\hline $1941-1970$ & $-47,5$ & $-71,6$ & $-69,6$ & $-59,0$ & $-56,9$ & $-35,9$ \\
\hline
\end{tabular}

* por mil habitantes 
YUNES, J. \& RONCHEZEL, V. S. C. - Evolução da mortalidade geral, infantil e proporcional no Brasil. Rev. Saude públ., S. Paulo, 8(supl.):3-48, 1974.

TABELA 9

Mortalidade geral * - Diferença percentual do coeficiente para o Brasil e São Paulo (Estado e Municipio)

\begin{tabular}{l|c|c|c}
\hline Ano & Brasil & $\begin{array}{c}\text { São Paulo } \\
\text { (Estado) }\end{array}$ & $\begin{array}{c}\text { São Paulo } \\
\text { (Municipio) }\end{array}$ \\
\hline $1941-1950$ & $-24,9$ & $-28,1$ & $-26,8$ \\
$1950-1960$ & $-21,4$ & $-28,9$ & $-17,9$ \\
$1960-1970$ & $-10,9$ & $-13,2$ & $+12,0$ \\
$1941-1970$ & $-47,5$ & $-55,6$ & $-32,6$ \\
\hline
\end{tabular}

* por mil habitantes

TABEL 10

Mortalidade infantil * - Diferença percentual do coeficiente para o Brasil e regióes fisiográficas - 1941-1970

\begin{tabular}{c|c|c|c|c|c|c}
\hline Ano & Brasil & $\begin{array}{c}\text { Centro- } \\
\text { Oeste }\end{array}$ & Norte & Sul & Nordeste & Sudeste \\
\hline $1941-1950$ & $-32,5$ & $-54,7$ & $-19,8$ & $-35,8$ & $-21,7$ & $-37,6$ \\
$1950-1960$ & $-23,0$ & $-17,9$ & $-28,9$ & $-17,5$ & $-11,2$ & $-32,2$ \\
$1960-1970$ & $+3,3$ & $-30,8$ & $-45,1$ & $-40,0$ & $-18,6$ & $+39,9$ \\
$1941-1970$ & $-46,2$ & $-72,04$ & $-68,6$ & $-68,2$ & $-43,4$ & $-40,8$ \\
\hline
\end{tabular}

* por mil nascidos vivos

TABELA 11

Mortalidade infantil * - Diferenca percentual do coeficiente para o Brasil e São Paulo (Estado e Município)

\begin{tabular}{l|c|c|c}
\hline Ano & Brasil & $\begin{array}{c}\text { São Paulo } \\
\text { (Estado) }\end{array}$ & $\begin{array}{c}\text { São Paulo } \\
\text { (Municipio) }\end{array}$ \\
\hline $1941-1950$ & $-32,5$ & $-32,9$ & $-33,6$ \\
$1950-1960$ & $-23,0$ & $-32,6$ & $-29,9$ \\
$1960-1970$ & $+3,3$ & $-1,3$ & $+32,2$ \\
$1941-1970$ & $-46,2$ & $-55,3$ & $+37,9$ \\
\hline
\end{tabular}

* por mil nascidos vivos 
YUNES, J. \&ONCHEZEL, V. S. C. - Evolução da mortalidade geral, infantil e proporcional no Brasil. Rev. Saúde públ., S. Paulo, 8(supl.):3-48, 1974.

TABELA 12

Diferença percentual da mortalidade proporcional * para o Brasil e regiões fisiográficas 1941-1970

\begin{tabular}{|c|c|c|c|c|c|c|}
\hline Ano & Brasil & Norte & Nordeste & $\begin{array}{l}\text { Centro- } \\
\text { Oeste }\end{array}$ & Sudeste & Sul \\
\hline $1941-1950$ & $-4,1$ & $+44,4$ & $-14,0$ & $-18,5$ & $+1,4$ & $-5,6$ \\
\hline $1950-1960$ & $+9,5$ & $+8,7$ & $+19,5$ & $+6,4$ & $-0,1$ & $+3,4$ \\
\hline $1960-1970$ & $+10,7$ & $-4,9$ & $-16,3$ & +57.7 & $+32,4$ & $-3,1$ \\
\hline $1941-1970$ & $+16,3$ & $+49,3$ & $-14,0$ & $+36,8$ & $+34,1$ & $-5,4$ \\
\hline
\end{tabular}

- percentagem dos óbitos de crianças menores de um ano sobre o total de óbitos.

TABELA 13

Mortalidade proporcional " Diferença percentual do coeficiente para o Brasil e São Paulo (Estado e Município)

\begin{tabular}{c|c|c|c}
\hline Ano & Brasil & $\begin{array}{c}\text { São Paulo } \\
\text { (Estado) }\end{array}$ & $\begin{array}{c}\text { São Paulo } \\
\text { (Municipio) }\end{array}$ \\
\hline $1941-1950$ & $-4,1$ & $+4,6$ & $-10,6$ \\
$1950-1960$ & $+9,5$ & $-8,9$ & $-3,1$ \\
$1960-1970$ & $+10,7$ & $-7,5$ & $-9,1$ \\
$1941-1970$ & $+16,3$ & $-11,7$ & $-9,8$ \\
\hline
\end{tabular}

* percentagem dos óbitos de crianças menores de um ano sobre o total de óbitos. 
YUNES, J. \& RONCHEZEL, V. S. C. - Evolução da mortalidade geral, infantil e proporcional no Brasil. Rev. Saúde públ., S. Paulo, 8(supl.):3-48, 1974.

TA B E L A 14

Regiāo Norte - Belém - Evolução da mortalidade proporcional, mortalidade geral e mortalidade infantil - 1941-1970

\begin{tabular}{c|c|c|c} 
Ano & $\begin{array}{c}\text { Mortalidade } \\
\text { proporcio- } \\
\text { nal * }\end{array}$ & $\begin{array}{c}\text { Mortalidade } \\
\text { geral } \\
\text { (por mil } \\
\text { nabitantes) }\end{array}$ & $\begin{array}{c}\text { Mortalidade } \\
\text { infantil } \\
\text { (por mil } \\
\text { nascidos } \\
\text { vivos) }\end{array}$ \\
\hline
\end{tabular}

1941

1942

1943

1944

1945

1946

1947

1948

1949

1950

1951

1952

1953

1954

1955

1956

1957

1958

1959

1960

1961

1962

1963

1964

1965

1966

1967

1968

1969

1970

18,65
18,56
19,69
19,56
19,59
20,35
22,60
22,24
22,22
23,02
24,55
23,73
24,71
23,51
27,01
26,85
27,40
26,99
26,43
26,42
27,82
27,19
25,77
26,99
23,39
27,13
22,73
21,42
23,79
25,56

18,65

18,56

19,56

22,60

22,24

23,02

24,71

23,51

26,85

26,43

26,42

27,19

25,77

26,99

27,13

22,73

23,79

25,56
25,6

25,7

25,2

25,8

23,1

21,3

20,3

19,3

19,5

14,7

16,2

14,7

14,6

20,3

15,9

15,6

14,5

14,6

11,2

11,1

11,2

10,0

9,8

10,4

9,1

8,2

7,7

7,8

8,2

8,3
189,6

206,1

267,4

260,8

159,6

158,0

120,0

121,6

184,7

172,0

171,9

177,4

168,7

200,0

263,6

158,5

109,7

137,9

138,8

142,9

140,3

144,4

239,3

207,6

229,9

139,8

80,1

107,3

52,5

60,3
T A B E L A 15

Região Norte - Manaus - Evolução da mortalidade proporcional, mortalidade geral e mortalidade infantil - 1941-1970

\begin{tabular}{|c|c|c|c|}
\hline Ano & $\begin{array}{c}\text { Mortalidade } \\
\text { proporcio- } \\
\text { nal }{ }^{*}\end{array}$ & $\begin{array}{l}\text { Mortalidade } \\
\text { geral } \\
\text { (por mil } \\
\text { habitantes) }\end{array}$ & $\begin{array}{l}\text { Mortalidade } \\
\text { infantil } \\
\text { (por mil } \\
\text { nascidos } \\
\text { vivos) }\end{array}$ \\
\hline
\end{tabular}

1942

1943

1944

1945

1946

1947

1948

1949

1950

1951

1952

1953

1954

1955

1956

1957

1958

1959

1960

1961

1962

1963

1964

1965

1966

1967

1968

1969

1970

18,42

20,21

21,08

24,12

23,77

24,16

28,20

30,64

32,13

33,57

38,07

35,81

40,30

36,50

37,86

38,65

36,90

42,19

38,51

34,45

39,15

35,31

38,67

35,30

36,78

31,61

29,24

36,98

29,22

31,78

\section{7,6}

17,6

19,4
18,7

20,5

17,8

15,9

14,8

13.5

16,9

14,4

14,8

14,0

16,7

15,0

15,5

13,9

13,6

13,0

13,9

13,1

13,9

13,2

13,2

13,6

11,4

10,1

9,1

10,8

10,5

10,7

302,9

230,9

106,3

124,5

121,8

115,0

128,7

102,3

144,4

171,1

130,8

108,6

111,7

91,4

109,6

147,3

109,7

134,5

124,6

100,2

113,2

83,7

87,5

95,2

90,9

70,2

56,0

81,3

60,7

80,4
* no de óbitos de menores de um ano n. total de óbitos $\times 100$

Fontes: IBGE

Anuário Estatístico do Brasil (IBGE). Rto de Janeiro. 1950-1972.
* n.o de óbitos de menores de um ano n.o total de óbitos $\times 100$

Fontes: IBGE

Anuário Estatístico do Brasil (IBGE). Rlo de Janeiro. 1950-1972. 
YUNES, J. \& RONCHEZEL, V. S. C. - Evolução da mortalidade geral, infantil e proporcional no Brasil. Rev. Saúde públ., S. Paulo, 8(supl.):3-48, 1974.

TA B E L A 16

Região Nordeste - Aracaju - Evolução da mortalidade proporcional, mortalidade geral e mortalidade infantil - 1941-1970

\begin{tabular}{|c|c|c|c|}
\hline Ano & $\begin{array}{c}\text { Mortalidade } \\
\text { proporcio- } \\
\text { nal * }\end{array}$ & $\begin{array}{c}\text { Mortalldade } \\
\text { geral } \\
\text { (por mil } \\
\text { habitantes) }\end{array}$ & $\begin{array}{l}\text { Mortalidade } \\
\text { infantil } \\
\text { (por mil } \\
\text { nascidos } \\
\text { vivos) }\end{array}$ \\
\hline
\end{tabular}

\begin{tabular}{lrrr}
1941 & 35,87 & 23,6 & 243,5 \\
1942 & 30,87 & 22,5 & 281,4 \\
1943 & 30,70 & 22,0 & 263,8 \\
1944 & 28,03 & 24,6 & 351,9 \\
1945 & 31,49 & 22,8 & 310,8 \\
1946 & 30,99 & 22,0 & 293,5 \\
1947 & 31,08 & 22,7 & 277,7 \\
1948 & 31,95 & 23,9 & 320,4 \\
1949 & 34,76 & 22,4 & 270,6 \\
1950 & 31,11 & 17,4 & 225,9 \\
1951 & 30,00 & 20,1 & 239,9 \\
1952 & 37,04 & 19,7 & 30,11 \\
1953 & 34,72 & 17,1 & 232,0 \\
1954 & 38,87 & 17,8 & 267,8 \\
1955 & 41,59 & 17,3 & 311,7 \\
1956 & 35,94 & 18,8 & 313,0 \\
1957 & 41,38 & 19,1 & 385,0 \\
1958 & 40,36 & 17,7 & 272,8 \\
1959 & 41,83 & 15,0 & 277,7 \\
1960 & 38,84 & 14,2 & 343,0 \\
1961 & 37,18 & 13,9 & 253,5 \\
1962 & 39,80 & 11,6 & 185,6 \\
1963 & 32,80 & 11,8 & 114,3 \\
1964 & 30,58 & 10,5 & 162,2 \\
1965 & 25,95 & 10,4 & 101,9 \\
1966 & 24,43 & 9,1 & 86,5 \\
1967 & 21,16 & 8,3 & 77,7 \\
1968 & 21,82 & 8,1 & 71,9 \\
1969 & 18,14 & 7,8 & 52,3 \\
1970 & 14,49 & 7,3 & 32,3 \\
& & & \\
\hline & & &
\end{tabular}

* n.o de óbitos de menores de um ano n. ${ }^{\circ}$ total de óbitos $\times 100$

Fontes: IBGE

Anuário Estatístico do Brasil (IBGE). Rlo de Janeiro. 1950-1972.
T A B E L A 17

Região Nordeste - Fortaleza - Evolução da mortalidade proporcional, mortalidade geral e mortalidade infantil - 1941-1970

\begin{tabular}{|c|c|c|c|}
\hline Ano & $\begin{array}{l}\text { Mortalidade } \\
\text { proporcio- } \\
\text { nal * }\end{array}$ & $\begin{array}{c}\text { Mortalidade } \\
\text { geral } \\
\text { (por mil } \\
\text { habitantes) }\end{array}$ & $\begin{array}{l}\text { Mortalidade } \\
\text { infantil } \\
\text { (por mil } \\
\text { nascidos } \\
\text { vivos) }\end{array}$ \\
\hline
\end{tabular}

\begin{tabular}{llll}
1941 & 35,62 & 20,0 & 209,1 \\
1942 & 40,55 & 30,0 & 312,6 \\
1943 & 35,02 & 33,1 & 336,7 \\
1944 & 38,74 & 27,2 & 290,3 \\
1945 & 39,71 & 26,9 & 325,6 \\
1946 & 37,97 & 25,4 & 371,9 \\
1947 & 41,92 & 25,2 & 336,2 \\
1948 & 41,17 & 22,8 & 438,6 \\
1949 & 43,64 & 26,8 & 306,8 \\
1950 & 43,82 & 24,9 & 252,7 \\
1951 & 51,57 & 28,7 & 469,1 \\
1952 & 47,23 & 26,2 & 447,1 \\
1953 & 51,12 & 26,6 & 291,3 \\
1954 & 50,75 & 28,5 & 460,5 \\
1955 & 55,30 & 28,6 & 315,5 \\
1956 & 51,30 & 28,9 & 278,5 \\
1957 & 53,36 & 30,9 & 269,5 \\
1958 & 56,75 & 31,4 & 385,5 \\
1959 & 54,06 & 23,5 & 197,8 \\
1960 & 54,84 & 18,4 & 224,8 \\
1961 & 56,74 & 17,6 & 220,0 \\
1962 & 50,32 & 15,5 & 231,3 \\
1963 & 49,23 & 17,1 & 241,4 \\
1964 & 46,84 & 15,1 & 260,8 \\
1965 & 46,84 & 15,4 & 196,7 \\
1966 & 47,33 & 15,4 & 188,9 \\
1967 & 46,48 & 13,7 & 207,8 \\
1968 & 43,04 & 13,0 & 229,2 \\
1969 & 46,10 & 13,2 & 190,7 \\
1970 & 46,32 & 14,2 & 182,6 \\
& & & \\
\hline
\end{tabular}

* n.o de óbitos de menores de um ano n. ${ }^{\circ}$ total de óbitos $\times 100$

Fontes: IBGE

Anuário Estatístico do Brasil (IBGE). Rio de Janeiro. 1950-1972. 
YUNES, J. \& RONCHEZEL, V. S. C. - Evoluçāo da mortalidade geral, infantil e proporcional no Brasil. Rev. Saúde públ., S. Paulo, 8(supl.):3-48, 1974.

T A B E L A 18

Região Nordeste - João Pessoa - Evolução da mortalidade proporcional, mortalidade geral e mortalidade infantil - 1941-1970

\begin{tabular}{c|c|c|c}
\hline Ano & $\begin{array}{c}\text { Mortalidade } \\
\text { proporcio- } \\
\text { nal * }\end{array}$ & $\begin{array}{c}\text { Mortalidade } \\
\text { geral } \\
\text { (por mil } \\
\text { habitantes) }\end{array}$ & $\begin{array}{c}\text { Mortalidade } \\
\text { infantil } \\
\text { (por mil } \\
\text { nascidos } \\
\text { vivos) }\end{array}$ \\
\hline
\end{tabular}

\begin{tabular}{llll}
1941 & 29,43 & 35,8 & 295,1 \\
1942 & 34,87 & 29,6 & 252,4 \\
1943 & 32,44 & 29,2 & 237,5 \\
1944 & 35,38 & 27,2 & 247,4 \\
1945 & 33,37 & 28,7 & 229,0 \\
1946 & 36,53 & 30,1 & 257,2 \\
1947 & 40,54 & 28,5 & 131,5 \\
1948 & 40,75 & 26,1 & 137,5 \\
1949 & 40,34 & 29,4 & 201,0 \\
1950 & 36,57 & 25,2 & 185,8 \\
1951 & 37,43 & 29,6 & 220,0 \\
1952 & 35,70 & 28,5 & 199,5 \\
1953 & 35,02 & 31,8 & 242,8 \\
1954 & 38,51 & 27,9 & 209,0 \\
1955 & 46,68 & 28,4 & 201,0 \\
1956 & 45,48 & 28,0 & 200,8 \\
1957 & 43,87 & 29,4 & 216,5 \\
1958 & 41,43 & 22,6 & 131,4 \\
1959 & 41,46 & 12,7 & 112,2 \\
1960 & 38,61 & 14,0 & 119,0 \\
1961 & 41,74 & 20,2 & 157,9 \\
1962 & 41,88 & 20,3 & 212,8 \\
1963 & 39,79 & 18,4 & 185,2 \\
1964 & 42,40 & 17,5 & 163,7 \\
1965 & 39,00 & 17,9 & 145,1 \\
1966 & 40,72 & 16,6 & 137,3 \\
1967 & 39,06 & 17,9 & 150,4 \\
1968 & 38,47 & 16,4 & 152,0 \\
1969 & 41,36 & 18,1 & 160,6 \\
1970 & 39,23 & 17,5 & 156,0 \\
& & & \\
\hline & & &
\end{tabular}

* n.o de óbitos de menores de um ano total de óbitos $\times 100$

Fontes: IBGE

Anuário Estatístico do Brasil (IBGE). Rlo de Janeiro. 1950-1972.
TA B E L A 19

Região Nordeste - Maceió - Evolução da mortalidade proporcional, mortalidade geral e mortalidade infantil - 1941-1970

\begin{tabular}{c|c|c|c}
\hline Ano & $\begin{array}{c}\text { Mortalidade } \\
\text { proporcio- } \\
\text { nal * }\end{array}$ & $\begin{array}{c}\text { Mortalidade } \\
\text { geral } \\
\text { (por mil } \\
\text { habitantes) }\end{array}$ & $\begin{array}{c}\text { Mortalidade } \\
\text { infantil } \\
\text { (por mil } \\
\text { nascidos } \\
\text { vivos) }\end{array}$ \\
\hline
\end{tabular}

\begin{tabular}{llll}
1941 & 31,03 & 29,2 & 355,4 \\
1942 & 35,05 & 27,3 & 368,6 \\
1943 & 34,03 & 27,2 & 422,7 \\
1944 & 31,87 & 27,0 & 359,0 \\
1945 & 35,91 & 24,5 & 279,2 \\
1946 & 37,02 & 28,2 & 317,4 \\
1947 & 38,94 & 29,6 & 304,0 \\
1948 & 31,62 & 26,2 & 210,5 \\
1949 & 39,95 & 27,2 & 242,3 \\
1950 & 37,00 & 22,0 & 210,8 \\
1951 & 41,82 & 21,7 & 219,5 \\
1952 & 43,11 & 20,6 & 194,4 \\
1953 & 39,26 & 19,7 & 181,2 \\
1954 & 43,50 & 25,6 & 219,5 \\
1955 & 43,74 & 19,5 & 267,6 \\
1956 & 43,57 & 25,8 & 316,8 \\
1957 & 42,09 & 29,4 & 318,7 \\
1958 & 46,61 & 29,0 & 310,5 \\
1959 & 42,74 & 19,1 & 223,2 \\
1960 & 45,83 & 19,2 & 225,9 \\
1961 & 41,71 & 19,4 & 210,7 \\
1962 & 38,93 & 17,1 & 391,3 \\
1963 & 33,91 & 15,8 & 243,7 \\
1964 & 33,70 & 15,5 & 266,9 \\
1965 & 33,92 & 16,0 & 266,2 \\
1966 & 35,59 & 16,2 & 300,5 \\
1967 & 32,43 & 17,7 & 247,1 \\
1968 & 31,93 & 16,6 & 213,6 \\
1969 & 34,05 & 17,3 & 219,7 \\
1970 & 40,43 & 20,8 & 141,0 \\
& & & \\
\hline
\end{tabular}

* n.o de óbitos de menores de um ano n. total de óbitos $\times 100$

Fontes: IBGE

Anuário Estatístico do Brasil (IBGE). Rio de Janeiro. 1950-1972. 
YUNES, J. \& RONCHEZEL, V. S. C. - Evolução da mortalidade geral, infantil e proporcional no Brasil.' Rev. Saúde públ., S. Paulo, 8(supl.):3-48, 1974.

T A B E I A 20

Região Nordeste - Natal - Evolução da mortalidade proporcional, mortalidade geral e mortalidade infantil - 1941-1970

\begin{tabular}{c|c|c|c} 
Ano & $\begin{array}{c}\text { Mortalidade } \\
\text { proporcio- } \\
\text { nal * }\end{array}$ & $\begin{array}{c}\text { Mortalidade } \\
\text { geral } \\
\text { (por mil } \\
\text { habitantes) }\end{array}$ & $\begin{array}{c}\text { Mortalidade } \\
\text { infantil } \\
\text { (por mil } \\
\text { nascidos } \\
\text { vivos) }\end{array}$ \\
\hline
\end{tabular}

\begin{tabular}{llll}
1941 & 45,04 & 27,2 & 334,8 \\
1942 & 48,39 & 30,3 & 342,1 \\
1943 & 45,74 & 41,0 & 424,6 \\
1944 & 48,32 & 38,4 & 418,2 \\
1945 & 48,67 & 35,1 & 509,7 \\
1946 & 50,34 & 33,8 & 439,2 \\
1947 & 52,29 & 35,9 & 541,1 \\
1948 & 52,55 & 28,7 & 500,2 \\
1949 & 53,30 & 27,8 & 414,2 \\
1950 & 51,36 & 26,0 & 432,9 \\
1951 & 57,43 & 28,6 & 446,8 \\
1952 & 54,36 & 26,6 & 598,8 \\
1953 & 58,39 & 33,0 & 605,8 \\
1954 & 55,12 & 26,8 & 278,5 \\
1955 & 59,15 & 25,4 & 422,3 \\
1956 & 57,10 & 26,1 & 371,7 \\
1957 & 56,85 & 26,2 & 489,8 \\
1958 & 60,22 & 28,1 & 427,9 \\
1959 & 54,54 & 21,3 & 426,8 \\
1960 & 55,44 & 18,9 & 363,4 \\
1961 & 49,65 & 16,1 & 179,0 \\
1962 & 41,97 & 17,2 & 187,3 \\
1963 & 48,68 & 16,4 & 227,5 \\
1964 & 47,45 & 17,0 & 208,1 \\
1965 & 48,71 & 17,1 & 223,5 \\
1966 & 44,11 & 16,4 & 169,6 \\
1967 & 45,66 & 17,0 & 192,9 \\
1968 & 44,35 & 14,6 & 158,0 \\
1969 & 41,57 & 17,4 & 169,3 \\
1970 & 44,81 & 15,9 & 176,8 \\
& & & \\
\hline & & & \\
\hline
\end{tabular}

* n.o de óbitos de menores de um ano n. ${ }^{\circ}$ total de óbitos $\times 100$

Fontes: IBGE

Anuário Estatístico do Brasil (IBGE). Rlo de Janeiro. 1950-1972.
TA B E L A 21

Regiăo Nordeste - Recife - Evolução da mortalidade proporcional, mortalidade geral e mortalidade infantil $-1941-1970$

Ano \begin{tabular}{c|c|c} 
Mortalidade & $\begin{array}{c}\text { Mortalidade } \\
\text { groporcio- } \\
\text { nal * } \\
\text { (por mil } \\
\text { habitantes) }\end{array}$ & $\begin{array}{c}\text { Mortalidade } \\
\text { infantil } \\
\text { (por mil } \\
\text { nascidos } \\
\text { vivos) }\end{array}$ \\
\hline
\end{tabular}

\begin{tabular}{llll}
1941 & 26,57 & 29,0 & 293,0 \\
1942 & 28,42 & 26,9 & 306,9 \\
1943 & 28,31 & 27,6 & 366,5 \\
1944 & 31,19 & 25,2 & 495,1 \\
1945 & 33,18 & 26,8 & 429,8 \\
1946 & 34,52 & 29,4 & 513,0 \\
1947 & 33,60 & 26,0 & 217,1 \\
1948 & 38,07 & 25,7 & 248,7 \\
1949 & 38,31 & 26,8 & 237,9 \\
1950 & 37,43 & 23,5 & 230,4 \\
1951 & 39,41 & 23,8 & 218,8 \\
1952 & 38,84 & 21,5 & 197,4 \\
1953 & 40,75 & 22,0 & 221,5 \\
1954 & 42,82 & 21,2 & 198,0 \\
1955 & 41,56 & 19,6 & 204,1 \\
1956 & 40,04 & 22,0 & 213,6 \\
1957 & 42,18 & 21,5 & 209,0 \\
1958 & 42,60 & 22,3 & 276,0 \\
1959 & 42,94 & 16,9 & 230,1 \\
1960 & 41,63 & 16,3 & 151,7 \\
1961 & 39,63 & 16,0 & 179,4 \\
1962 & 36,00 & 15,7 & 166,1 \\
1963 & 33,91 & 14,6 & 147,2 \\
1964 & 29,89 & 14,5 & 125,6 \\
1965 & 33,13 & 14,4 & 148,8 \\
1966 & 31,66 & 13,5 & 149,4 \\
1967 & 29,85 & 12,3 & 142,4 \\
1968 & 30,37 & 13,0 & 153,9 \\
1969 & 31,06 & 12,7 & 165,3 \\
1970 & 32,68 & 13,0 & 205,7 \\
& & & \\
\hline & & &
\end{tabular}

* n.o de óbitos de menores de um ano n.o total de obitos $\times 100$

Fontes: IBGE

Anuário Estatístico do Brasil (IBGE). Rio de Janeiro. 1950-1972. 
IUNES, J. \& RONCHEZEL, V. S. C. - Evolução da mortalidade geral, infantil e proporcional no Brasil. Rev. Saúde puibl., S. Paulo, 8(supl.):3-48, 1974.

T A B E I A 22

Região Nordeste - Salvador - Evolução da mortalidade proporcional, mortalidade geral e mortalidade infantil - 1941-1970

\begin{tabular}{c|c|c|c}
\hline Ano & $\begin{array}{c}\text { Mortalidade } \\
\text { proporcio- } \\
\text { nal * }\end{array}$ & $\begin{array}{c}\text { Mortalidade } \\
\text { geral } \\
\text { (por mil } \\
\text { habitantes) }\end{array}$ & $\begin{array}{c}\text { Mortalidade } \\
\text { infantil } \\
\text { (por mil } \\
\text { nascidos } \\
\text { vivos) }\end{array}$ \\
\hline
\end{tabular}

\begin{tabular}{rrrr}
1941 & 78,02 & 27,0 & 249,8 \\
1942 & 24,87 & 26,5 & 267,7 \\
1943 & 23,60 & 25,5 & 250,2 \\
1944 & 23,37 & 26,1 & 285,4 \\
1945 & 22,55 & 27,9 & 225,9 \\
1946 & 25,25 & 28,0 & 260,4 \\
1947 & 26,87 & 25,4 & 257,3 \\
1948 & 26,87 & 24,7 & 240,8 \\
1949 & 26,43 & 26,7 & 205,0 \\
1950 & 27,25 & 18,3 & 210,7 \\
1951 & 26,37 & 18,6 & 228,3 \\
1952 & 32,28 & 17,6 & 289,1 \\
1953 & 30,64 & 17,1 & 286,5 \\
1954 & 33,06 & 17,4 & 330,4 \\
1955 & 34,92 & 16,6 & 353,5 \\
1956 & 33,13 & 16,6 & 215,7 \\
1957 & 33,64 & 18,4 & 115,6 \\
1958 & 32,89 & 16,0 & 223,8 \\
1959 & 34,49 & 13,8 & 145,9 \\
1960 & 35,39 & 14,7 & 147,0 \\
1961 & 35,03 & 13,6 & 140,4 \\
1962 & 35,30 & 13,9 & 139,5 \\
1963 & 31,02 & 11,6 & 101,8 \\
1964 & 31,29 & 11,4 & 101,2 \\
1965 & 27,26 & 10,5 & 81,0 \\
1966 & 29,49 & 10,8 & 124,2 \\
1967 & 29,64 & 11,0 & 83,8 \\
1968 & 28,18 & 13,0 & 154,3 \\
1969 & 26,33 & 11,2 & 83,8 \\
1970 & 28,58 & 10,9 & 87,6 \\
& & & \\
\hline & & &
\end{tabular}

* n.o de óbitos de menores de um ano total de óbitos $\times 100$

Fontes: IBGE

Anuário Estatístico do Brasil (IBGE). Rio de Janeiro. 1950-1972.
TA B E I A 23

Regiāo Nordeste - São Luiz - Evolução da mortalidade proporcional, mortalidade geral e mortalidade infantil - 1941-1970

\begin{tabular}{|c|c|c|c|}
\hline Ano & $\begin{array}{l}\text { Mortalidade } \\
\text { proporcio- } \\
\text { nal * }\end{array}$ & $\begin{array}{l}\text { Mortalidade } \\
\text { geral } \\
\text { (por mil } \\
\text { habitantes) }\end{array}$ & $\begin{array}{l}\text { Mortalldade } \\
\text { infantil } \\
\text { (por mil } \\
\text { nascidos } \\
\text { vivos) }\end{array}$ \\
\hline
\end{tabular}

\begin{tabular}{lrrr}
1941 & 21,92 & 20,0 & 230,8 \\
1942 & 21,63 & 19,5 & 211,9 \\
1943 & 24,89 & 21,3 & 246,8 \\
1944 & 25,10 & 21,5 & 220,8 \\
1945 & 24,62 & 21,3 & 244,3 \\
1946 & 23,36 & 19,2 & 212,3 \\
1947 & 24,38 & 22,0 & 226,3 \\
1948 & 21,06 & 18,4 & 127,0 \\
1949 & 25,36 & 17,6 & 176,1 \\
1950 & 24,59 & 17,0 & 164,9 \\
1951 & 53,12 & 17,6 & 186,3 \\
1952 & 27,05 & 16,1 & 147,5 \\
1953 & 28,69 & 15,5 & 136,7 \\
1954 & 26,25 & 18,0 & 147,3 \\
1955 & 31,07 & 17,7 & 209,1 \\
1956 & 30,80 & 18,3 & 211,2 \\
1957 & 29,79 & 17,4 & 214,6 \\
1958 & 31,30 & 16,4 & 183,3 \\
1959 & 29,83 & 12,7 & 168,8 \\
1960 & 31,96 & 11,2 & 145,9 \\
1961 & 30,84 & 13,4 & 76,7 \\
1962 & 34,50 & 11,6 & 79,5 \\
1963 & 31,98 & 10,4 & 89,8 \\
1964 & 29,90 & 11,8 & 79,1 \\
1965 & 31,11 & 11,0 & 59,2 \\
1966 & 31,57 & 10,8 & 127,0 \\
1967 & 16,91 & 11,6 & 104,6 \\
1968 & 28,85 & 10,6 & 109,6 \\
1969 & 38,35 & 12,0 & 102,9 \\
1970 & 30,07 & 9,7 & 92,4 \\
& & & \\
\hline & & & \\
\hline
\end{tabular}

* n.o de óbitos de menores de um ano n.० total de óbitos $\times 100$

Fontes: IBGE

Anuário Estatístico do Brasil (IBGE). Rio de Janeiro. 1950-1972. 
YUNES, J. \& RONCHEZEL, V. S. C. - Evoluçāo da mortalidade geral, infantil e proporclonal no Brasil. Rev. Saúde públ., S. Paulo, 8(supl.):3-48, 1974.

TA B E I A 24

Regiăo Nordeste - Terezina - Evolução da mortalidade proporcional, mortalidade geral e mortalidade infantil $-1941-1970$

\begin{tabular}{c|c|c|c}
\hline Ano & $\begin{array}{c}\text { Mortalidade } \\
\text { proporcio- } \\
\text { nal * }\end{array}$ & $\begin{array}{c}\text { Mortalidade } \\
\text { geral } \\
\text { (por mil } \\
\text { habitantes) }\end{array}$ & $\begin{array}{c}\text { Mortalidade } \\
\text { infantil } \\
\text { (por mil } \\
\text { nascidos } \\
\text { vivos) }\end{array}$ \\
\hline
\end{tabular}

\begin{tabular}{rrrr}
1941 & 29,88 & 22,0 & 501,1 \\
1942 & 30,41 & 26,3 & 634,5 \\
1943 & 25,76 & 26,4 & 453,6 \\
1944 & 26,95 & 26,5 & 541,0 \\
1945 & 26,38 & 26,7 & 423,7 \\
1946 & 23,58 & 24,1 & 328,6 \\
1947 & 26,60 & 22,2 & 348,7 \\
1948 & 26,77 & 20,5 & 311,7 \\
1949 & 27,49 & 20,8 & 306,4 \\
1950 & 26,11 & 19,1 & 292,0 \\
1951 & 34,64 & 22,1 & 384,5 \\
1952 & 32,81 & 20,9 & 332,4 \\
1953 & 36,92 & 20,4 & 463,2 \\
1954 & 29,89 & 20,4 & 312,6 \\
1955 & 34,50 & 19,0 & 325,3 \\
1956 & 33,43 & 21,0 & 302,9 \\
1957 & 35,15 & 19,6 & 261,7 \\
1958 & 40,54 & 24,2 & 417,6 \\
1959 & 35,23 & 23,5 & 277,7 \\
1960 & 35,96 & 11,2 & 289,9 \\
1961 & 36,58 & 10,6 & 278,3 \\
1962 & 35,98 & 9,4 & 208,9 \\
1963 & 36,19 & 9,6 & 259,4 \\
1964 & 32,61 & 10,2 & 242,8 \\
1965 & 33,23 & 9,8 & 182,9 \\
1966 & 34,24 & 9,6 & 240,6 \\
1967 & 31,70 & 10,6 & 262,9 \\
1968 & 32,79 & 9,9 & 246,3 \\
1969 & 32,97 & 10,7 & 81,3 \\
1970 & 35,71 & 10,1 & 79,5 \\
& & & \\
\hline & & &
\end{tabular}

* n.o de óbitos de menores de um ano n.o total de obitos $\times 100$

Fontes: IBGE

Anuário Estatístico do Brasil (IBGE). Rio de Janeiro. 1950-1972.
T A B E L A 25

Região Centro-Oeste - Brasilia - Evolução da mortalidade proporcional, mortalidade geral e mortalidade infantil - 1961-1970

\begin{tabular}{c|c|c|c}
\hline Ano & $\begin{array}{c}\text { Mortalidade } \\
\text { proporcio- } \\
\text { nal * }\end{array}$ & $\begin{array}{c}\text { Mortalidade } \\
\text { geral } \\
\text { (por mil } \\
\text { habitantes) }\end{array}$ & $\begin{array}{c}\text { Mortalidade } \\
\text { infantil } \\
\text { (por mil } \\
\text { nascidos } \\
\text { vivos) }\end{array}$ \\
\hline
\end{tabular}

$\begin{array}{llll}1961 & \ldots & 7,8 & \ldots \\ 1962 & 48,61 & 9,2 & \ldots \\ 1963 & 53,01 & 8,3 & \ldots \\ 1964 & 53,78 & 7,9 & 94,0 \\ 1965 & 36,95 & 9,9 & 87,2 \\ 1966 & 43,19 & 7,3 & 66,7 \\ 1967 & 40,73 & 7,3 & 61,3 \\ 1968 & 41,96 & 8,7 & 62,6 \\ 1969 & 43,99 & 9,1 & 77,4 \\ 1970 & 46,59 & 8,8 & 72,3\end{array}$

* n.o de óbitos de menores de um ano n.o total de óbitos $\times 100$

Fontes: IBGE

Anuário Estatístico do Brasil (IBGE). Rio de Janeiro. 1961-1972. 
YUNES, J. \& RONCHEZEL, V. S. C. - Evolução da mortalidade geral, infantil e proporcional no Brasil. Rev. Saúde públ., S. Paulo, 8(supl.):3-48, 1974.

TA B E L A 26

Região Centro-Oeste - Cuiabá - Evolução da mortalidade proporcional, mortalidade geral e mortalidade infantil - 1941-1970

\begin{tabular}{c|c|c|c} 
Ano & $\begin{array}{c}\text { Mortalidade } \\
\text { proporcio- } \\
\text { nal* }\end{array}$ & $\begin{array}{c}\text { Mortalidade } \\
\text { geral } \\
\text { (por mil } \\
\text { habitantes) }\end{array}$ & $\begin{array}{c}\text { Mortalidade } \\
\text { infantil } \\
\text { (por mil } \\
\text { nascidos } \\
\text { vivos) }\end{array}$ \\
\hline
\end{tabular}

\begin{tabular}{|c|c|c|c|}
\hline 1941 & 23,28 & 20,8 & 282,7 \\
\hline 1942 & 19,03 & 17,8 & 139,6 \\
\hline 1943 & 16,57 & 16,7 & 97,9 \\
\hline 1944 & 19,07 & 18,4 & 100,3 \\
\hline 1945 & 16,17 & $\mathbf{1 9 , 6}$ & 70,8 \\
\hline 1946 & 14,70 & 18,7 & 59,1 \\
\hline 1947 & 18,96 & 20,1 & 75,6 \\
\hline 1948 & 19,73 & 19,7 & 123,7 \\
\hline 1949 & 21,25 & 17,2 & 135,9 \\
\hline 1950 & 22,34 & 13,3 & 148,3 \\
\hline 1951 & 15,38 & 18,9 & 119,6 \\
\hline 1952 & 24,51 & 19,9 & 124,8 \\
\hline 1953 & 20,41 & 19,0 & 102,5 \\
\hline 1954 & 27,14 & 17,0 & 133,6 \\
\hline 1955 & 20,51 & 19,5 & 104,5 \\
\hline 1956 & 23,66 & 18,3 & 115,3 \\
\hline 1957 & 35,48 & 18,2 & 121,4 \\
\hline 1958 & 31,81 & 20,8 & 144,9 \\
\hline 1959 & 22,43 & 10,4 & 93,1 \\
\hline 1960 & 28,05 & 14,8 & 91,8 \\
\hline 1961 & 23,90 & 12,9 & 78,5 \\
\hline 1962 & 29,98 & 12,7 & 150,4 \\
\hline 1963 & 36,71 & 14,5 & 219,8 \\
\hline 1964 & $\mathbf{3 1 , 3 2}$ & 13,7 & 105,4 \\
\hline 1965 & $\mathbf{3 0 , 5 2}$ & 13,2 & 93,8 \\
\hline 1966 & 27,75 & 7,8 & 57,2 \\
\hline 1967 & 25,17 & 7,8 & 67,8 \\
\hline 1968 & 30,09 & 10,0 & 114,3 \\
\hline 1969 & $\mathbf{3 1 , 5 8}$ & 10,8 & 90,7 \\
\hline 1970 & 24,91 & 10,7 & 70,2 \\
\hline
\end{tabular}

* n.o de obitos de menores de um ano n.o total de 6 bitos $\times 100$

Fontes: IBGE

Anuário Estatístico do Brasil (IBGE). Rlo de Janeiro. 1950-1972.
TA B E L A 27

Região Centro-Oeste - Goiânia - Evolução da mortalidade proporcional, mortalidade geral e mortalidade infantil $-1941-1970$

\begin{tabular}{c|c|c|c} 
Ano & $\begin{array}{c}\text { Mortalidade } \\
\text { proporcio- } \\
\text { nal * }\end{array}$ & $\begin{array}{c}\text { Mortalidade } \\
\text { geral } \\
\text { (por mil } \\
\text { nabitantes) }\end{array}$ & $\begin{array}{c}\text { Mortalidade } \\
\text { infantil } \\
\text { (por mil } \\
\text { nascidos } \\
\text { vivos) }\end{array}$ \\
\hline
\end{tabular}

\begin{tabular}{|c|c|c|c|}
\hline 1941 & 35,71 & 36,1 & 278,8 \\
\hline 1942 & 35,44 & 41,9 & 510,8 \\
\hline 1943 & 27,25 & 25,5 & 195,7 \\
\hline 1944 & 22,06 & 25,3 & 132,8 \\
\hline 1945 & 24,27 & 24,2 & 158,9 \\
\hline 1946 & 24,96 & 30,3 & 120,9 \\
\hline 1947 & 23,21 & 28,2 & 108,2 \\
\hline 1948 & 17,86 & $\mathbf{3 1 , 1}$ & 133,6 \\
\hline 1949 & 33,67 & 26,7 & 163,0 \\
\hline 1950 & 26,95 & 17,1 & 117,5 \\
\hline 1951 & 37,76 & 20,6 & 138,0 \\
\hline 1952 & 27,22 & 21,3 & 123,7 \\
\hline 1953 & 28,81 & 21,2 & 117,1 \\
\hline 1954 & 37,63 & 23,3 & 130,6 \\
\hline 1955 & 36,11 & 23,6 & 175,9 \\
\hline 1956 & 31,31 & 25,0 & 119,3 \\
\hline 1957 & 30,00 & 25,7 & 185,3 \\
\hline 1958 & 31,97 & 26,6 & 111,5 \\
\hline 1959 & 34,86 & 11,4 & 96,2 \\
\hline 1960 & 26,26 & 11,9 & 110,1 \\
\hline 1961 & 30,56 & 9,6 & 78,5 \\
\hline 1962 & 22,47 & 11,6 & 69,6 \\
\hline 1963 & 16,17 & 11,9 & 71,8 \\
\hline 1964 & 29,84 & 9,3 & 87,0 \\
\hline 1965 & 29,13 & 9,0 & 90,0 \\
\hline 1966 & 24,55 & 11,4 & 84,0 \\
\hline 1967 & 27,23 & 11,4 & 92,7 \\
\hline 1968 & 23,73 & 6,5 & 46,6 \\
\hline 1969 & 40,58 & 10,9 & 123,1 \\
\hline 1970 & & & \\
\hline
\end{tabular}

* n.o de obitos de menores de um ano n.o total de ób1tos $\times 100$

Fontes: IBGE

Anuário Estatístico do Brasil (IBGE). Rio de Janeiro. 1950-1972. 
YUNES, J. \& RONCHEZEL, V. S. C. - Evoluçåo da mortalidade geral, infantil e proporcional no Brasil. Rev. Saúde públ., S. Paulo, 8(supl.):3-48, 1974.

TA B E L A 28

Região Sudeste - Belo Horizonte - Evolução da mortalidade proporcional, mortalldade geral e mortalidade infantil - 1941-1970

\begin{tabular}{c|c|c|c}
\hline Ano & $\begin{array}{c}\text { Mortalidade } \\
\text { proporcio- } \\
\text { nal * }\end{array}$ & $\begin{array}{c}\text { Mortalidade } \\
\text { geral } \\
\text { (por mil } \\
\text { habitantes) }\end{array}$ & $\begin{array}{c}\text { Mortalidade } \\
\text { Infantil } \\
\text { (por mil } \\
\text { nascidos } \\
\text { vivos) }\end{array}$ \\
\hline
\end{tabular}

\begin{tabular}{llrr}
1941 & 23,03 & 19,1 & 153,5 \\
1942 & 23,14 & 17,6 & 132,6 \\
1943 & 20,81 & 17,3 & 126,1 \\
1944 & 20,84 & 18,2 & 127,9 \\
1945 & 20,59 & 17,7 & 110,6 \\
1946 & 21,69 & 19,3 & 106,3 \\
1947 & 21,85 & 17,1 & 100,4 \\
1948 & 24,28 & 18,2 & 103,4 \\
1949 & 25,48 & 17,8 & 126,4 \\
1950 & 23,99 & 14,5 & 103,8 \\
1951 & 25,45 & 16,0 & 111,2 \\
1952 & 28,84 & 14,7 & 116,3 \\
1953 & 29,23 & 14,8 & 117,2 \\
1954 & 32,38 & 15,6 & 123,2 \\
1955 & 29,86 & 14,3 & 101,3 \\
1956 & 31,77 & 15,3 & 104,6 \\
1957 & 27,23 & 15,1 & 92,1 \\
1958 & 34,75 & 15,2 & 95,8 \\
1959 & 29,05 & 12,5 & 96,1 \\
1960 & 24,64 & 11,4 & 74,2 \\
1961 & 26,77 & 12,1 & 86,4 \\
1962 & 26,47 & 11,1 & 76,7 \\
1963 & 28,40 & 13,4 & 99,8 \\
1964 & 28,26 & 11,6 & 86,3 \\
1965 & 28,42 & 12,2 & 92,3 \\
1966 & 25,97 & 12,1 & 87,2 \\
1967 & 27,02 & 12,4 & 98,3 \\
1968 & 27,99 & 12,5 & 102,3 \\
1969 & 28,67 & 12,4 & 107,3 \\
1970 & 30,30 & 12,1 & 97,4 \\
& & & \\
\hline & & &
\end{tabular}

* n.o de obitos de menores de um ano n.o total de óbitos $\times 100$

Fontes: IBGE

Anuário Estatistico do Brasil (IBGE). Rio de Janeiro. 1950-1972.
TA B E L A 29

Regiåo Sudeste - Niteró1 - Evoluçáo da mortalldade proporcional, mortalidade geral e mortalidade infantil - 1941-1970

\begin{tabular}{|c|c|c|c|}
\hline Ano & $\begin{array}{c}\text { Mortalidade } \\
\text { proporclo- } \\
\text { nal * }\end{array}$ & $\begin{array}{c}\text { Mortalldade } \\
\text { geral } \\
\text { (por mil } \\
\text { habitantes) }\end{array}$ & $\begin{array}{c}\text { Mortalidade } \\
\text { Infantil } \\
\text { (por mil } \\
\text { nascidos } \\
\text { vivos) }\end{array}$ \\
\hline
\end{tabular}

\begin{tabular}{lrrr}
1941 & 19,38 & 21,3 & 185,1 \\
1942 & 20,53 & 20,3 & 168,9 \\
1943 & 20,24 & 19,8 & 152,7 \\
1944 & 19,98 & 18,9 & 166,3 \\
1945 & 18,74 & 20,7 & 142,0 \\
1946 & 21,51 & 21,1 & 153,4 \\
1947 & 19,80 & 20,9 & 127,0 \\
1948 & 18,30 & 20,7 & 133,2 \\
1949 & 18,43 & 18,7 & 113,3 \\
1950 & 19,39 & 14,0 & 107,6 \\
1951 & 24,52 & 15,2 & 128,5 \\
1952 & 19,74 & 13,5 & 143,3 \\
1953 & 22,45 & 13,9 & 109,0 \\
1954 & 23,85 & 15,5 & 116,7 \\
1955 & 21,65 & 13,7 & 96,6 \\
1956 & 20,38 & 14,5 & 95,6 \\
1957 & 23,91 & 13,9 & 103,3 \\
1958 & 22,83 & 10,9 & 86,4 \\
1959 & 20,68 & 12,1 & 84,1 \\
1960 & 20,05 & 11,3 & 95,7 \\
1961 & 31,57 & 11,9 & 96,2 \\
1962 & 20,73 & 11,1 & 91,5 \\
1963 & 23,14 & 11,7 & 113,1 \\
1964 & 21,69 & 9,8 & 90,1 \\
1965 & 20,34 & 10,6 & 101,7 \\
1966 & 15,82 & 10,7 & 110,5 \\
1967 & 18,43 & 11,0 & 131,6 \\
1968 & 18,18 & 11,3 & 89,4 \\
1969 & 19,52 & 11,5 & 67,0 \\
1970 & 18,19 & 11,0 & 64,0 \\
& & & \\
\hline & & &
\end{tabular}

- n.o de óbitos de menores de um ano: n.o total de 6 bitos $\times 100$

Fontes: IBGE

Anuário Estatístico do Brastl (IBGE). Rlo de Janeiro. 1950-1972. 
YUNES, J. \& RONCHEZEL, V. S. C. - Evolucão da mortalidade geral, infantil e proporcional no Brasll. Rev. Saúde públ., S. Paulo, 8(supl.):3-48, 1974.

TA B E L A 30

Regiăo Sudeste - Rio de Janeiro - Evolução da mortalidade proporcional, mortalidade geral e mortalidade infantil - 1941-1970

Ano \begin{tabular}{c|c|c}
$\begin{array}{c}\text { Mortalidade } \\
\text { proporclo- } \\
\text { nal * }\end{array}$ & $\begin{array}{c}\text { Mortalidade } \\
\text { geral } \\
\text { (por mil } \\
\text { habltantes) }\end{array}$ & $\begin{array}{c}\text { Mortalidade } \\
\text { infantil } \\
\text { (por mil } \\
\text { nascidos } \\
\text { vivos) }\end{array}$ \\
\hline
\end{tabular}

\begin{tabular}{rrrr}
1941 & 19,41 & 18,0 & 182,2 \\
1942 & 18,67 & 17,3 & 150,7 \\
1943 & 18,63 & 17,1 & 163,3 \\
1944 & 18,95 & 19,2 & 125,7 \\
1945 & 16,08 & 17,8 & 127,1 \\
1946 & 17,08 & 17,1 & 111,3 \\
1947 & 16,22 & 18,5 & 115,9 \\
1948 & 17,18 & 18,3 & 155,6 \\
1949 & 17,96 & 17,4 & 108,6 \\
1950 & 18,79 & 13,0 & 109,1 \\
1951 & 19,12 & 12,8 & 107,5 \\
1952 & 19,76 & 12,0 & 104,9 \\
1953 & 20,95 & 11,9 & 110,1 \\
1954 & 25,34 & 12,3 & 73,9 \\
1955 & 22,57 & 11,3 & 112,5 \\
1956 & 22,62 & 12,1 & 120,5 \\
1957 & 21,00 & 12,1 & 107,5 \\
1958 & 21,64 & 11,7 & 105,0 \\
1959 & 20,50 & 10,6 & 94,4 \\
1960 & 18,26 & 10,2 & 70,0 \\
1961 & 18,24 & 10,1 & 70,3 \\
1962 & 16,90 & 9,8 & 65,3 \\
1963 & $\ldots$ & $\ldots$ & $\ldots$ \\
1964 & $\ldots$ & $\ldots$ & $\ldots$ \\
1965 & $\ldots$ & $\ldots$. & $\ldots$ \\
1966 & $\ldots$ & $\ldots$ & $\ldots$ \\
1967 & $\ldots$ & $\ldots$ & $\ldots$ \\
1968 & 13,59 & 9,3 & 48,6 \\
1969 & 14,90 & 9,2 & 52,9 \\
1970 & & & \\
& & & \\
\hline & & &
\end{tabular}

* n.o de obitos de menores de um ano n.o total de óbitos $\times 100$

Fontes: IBGE

Anuário Estatístico do Brasil (IBGE). Rio de Janeiro. 1950-1972.
TA B E I A 31

Regiāo Sudeste - São Paulo - Evolução da mortalidade proporcional, mortalidade geral e mortalidade infantil - 1941-1971

\begin{tabular}{c|c|c|c}
\hline Ano & $\begin{array}{c}\text { Mortalidade } \\
\text { proporcio- } \\
\text { nal * }\end{array}$ & $\begin{array}{c}\text { Mortalidade } \\
\text { geral } \\
\text { (por mil } \\
\text { habitantes) }\end{array}$ & $\begin{array}{c}\text { Mortalidade } \\
\text { infantil } \\
\text { (por mil } \\
\text { nascidos } \\
\text { vivos) }\end{array}$ \\
\hline
\end{tabular}

\begin{tabular}{llrr}
1941 & 24,05 & 13,8 & 135,1 \\
1942 & 23,16 & 12,9 & 121,5 \\
1943 & 22,57 & 11,8 & 115,4 \\
1944 & 22,48 & 12,3 & 113,8 \\
1945 & 20,01 & 11,5 & 101,5 \\
1946 & 19,62 & 10,7 & $\mathbf{7 9 , 8}$ \\
1947 & 20,38 & 9,8 & 80,1 \\
1948 & 23,03 & 10,2 & 87,8 \\
1949 & 24,33 & 9,7 & 90,6 \\
1950 & 24,87 & 10,1 & 89,7 \\
1951 & 24,69 & 10,4 & 31,5 \\
1952 & 22,83 & 9,5 & $\mathbf{7 1 , 0}$ \\
1953 & 27,88 & 9,8 & $\mathbf{7 9 , 2}$ \\
1954 & 26,22 & 10,0 & $\mathbf{7 4 , 7}$ \\
1955 & 29,16 & 9,3 & 86,5 \\
1956 & $\mathbf{2 8 , 3 5}$ & 10,5 & $\mathbf{8 6 , 4}$ \\
1957 & 26,52 & 10,6 & $\mathbf{7 5 , 5}$ \\
1958 & $\mathbf{2 5 , 7 9}$ & $\mathbf{9 , 7}$ & $\mathbf{6 9 , 2}$ \\
1959 & $\mathbf{2 4 , 5 1}$ & $\mathbf{9 , 3}$ & $\mathbf{6 5 , 8}$ \\
1960 & $\mathbf{2 4 , 0 4}$ & 8,3 & $\mathbf{6 2 , 9}$ \\
1961 & $\mathbf{2 3 , 2 2}$ & $\mathbf{8 , 1}$ & $\mathbf{6 0 , 2}$ \\
1962 & $\mathbf{2 3 , 7 1}$ & $\mathbf{8 , 7}$ & $\mathbf{6 4 , 4}$ \\
1963 & $\mathbf{2 5 , 1 5}$ & $\mathbf{9 , 0}$ & $\mathbf{6 9 , 9}$ \\
1964 & $\mathbf{2 4 , 8 9}$ & $\mathbf{8 , 7}$ & $\mathbf{6 7 , 7}$ \\
1965 & $\mathbf{2 5 , 4 1}$ & $\mathbf{8 , 6}$ & $\mathbf{6 9 , 4}$ \\
1966 & $\mathbf{2 4 , 1 8}$ & $\mathbf{8 , 8}$ & $\mathbf{7 3 , 8}$ \\
1967 & $\mathbf{2 3 , 8 3}$ & $\mathbf{8 , 7}$ & $\mathbf{7 4 , 4}$ \\
1968 & $\mathbf{2 2 , 9 1}$ & $\mathbf{9 , 1}$ & $\mathbf{7 5 , 1}$ \\
1969 & $\mathbf{2 4 , 9 4}$ & $\mathbf{9 , 3}$ & $\mathbf{8 3 , 8}$ \\
1970 & & & \\
& & & \\
\hline & & &
\end{tabular}

- n.o de óbitos de menores de um ano n.o total de óbitos $\times 100$

Fontes: IBGE

Anuário Estatistico do Brasil (IBGE). Rio de Janeiro. 1950-1972. 
YUNES, 'J. \& RONCHEZEL, V. S. C. - Evoluçāo da mortalidade geral, infantil e proporcional no Brasil. Rev. Saúde públ., S. Paulo, 8(supl.):3-48, 1974.

T A B E L 32

Região Sudeste - Vitóría - Evolução da mortalidade proporcional, mortalidade geral e mortalidade infantil $-1941-1970$

\begin{tabular}{c|c|c|c}
\hline Ano & $\begin{array}{c}\text { Mortalidade } \\
\text { proporclo- } \\
\text { nal * }\end{array}$ & $\begin{array}{c}\text { Mortalidade } \\
\text { geral } \\
\text { (por mil } \\
\text { habitantes) }\end{array}$ & $\begin{array}{c}\text { Mortalidade } \\
\text { infantil } \\
\text { (por mil } \\
\text { nascidos } \\
\text { vivos) }\end{array}$ \\
\hline
\end{tabular}

$\begin{array}{llrr}1941 & 17,06 & 25,6 & 211,6 \\ 1942 & 17,73 & 25,0 & 239,5 \\ 1943 & 17,16 & 30,2 & 237,1 \\ 1944 & 14,52 & 26,4 & 167,1 \\ 1945 & 12,76 & 29,1 & 156,0 \\ 1946 & 14,40 & 28,7 & 144,2 \\ 1947 & 15,73 & 27,2 & 160,9 \\ 1948 & 16,78 & 27,8 & 144,2 \\ 1949 & 11,07 & 26,2 & 117,6 \\ 1950 & 17,44 & 21,5 & 137,2 \\ 1951 & 11,65 & 21,3 & 108,3 \\ 1952 & 17,42 & 19,9 & 115,3 \\ 1953 & 19,94 & 20,0 & 111,2 \\ 1954 & 20,97 & 19,2 & 105,2 \\ 1955 & 24,37 & 16,4 & 118,1 \\ 1956 & 28,18 & 22,0 & 131,2 \\ 1957 & 23,36 & 21,9 & 95,6 \\ 1958 & 24,27 & 20,6 & 96,7 \\ 1959 & 24,42 & 15,0 & 91,6 \\ 1960 & 20,37 & 15,3 & 77,9 \\ 1961 & 21,38 & 13,8 & 73,5 \\ 1962 & 25,32 & 17,0 & 101,4 \\ 1963 & 26,48 & 15,7 & 100,2 \\ 1964 & 27,81 & 16,2 & 103,1 \\ 1965 & 27,68 & 17,9 & 115,4 \\ 1966 & 27,64 & 18,5 & 124,3 \\ 1967 & 30,08 & 19,9 & 132,8 \\ 1968 & 29,26 & 19,7 & 107,8 \\ 1969 & 29,97 & 20,8 & 117,3 \\ 1970 & 31,10 & 21,7 & 121,9\end{array}$

* n.o de óbitos de menores de um ano n.o total de 6 bitos $\times 100$

Fontes: IBGE

Anuário Estatistico do Brasil (IBGE). Rio de Janeiro. 1950-1972.
TA B E L A 33

Região Sul - Curitiba - Evolucão da mortalidade proporcional, mortalidade geral e mortalidade infantil - 1941-1970

\begin{tabular}{c|c|c|c}
\hline Ano & $\begin{array}{c}\text { Mortalidade } \\
\text { proporcio- } \\
\text { nal * }\end{array}$ & $\begin{array}{c}\text { Mortalidade } \\
\text { geral } \\
\text { (por mil } \\
\text { habitantes) }\end{array}$ & $\begin{array}{c}\text { Mortalfdade } \\
\text { infantil } \\
\text { (por mil } \\
\text { nascidos } \\
\text { vivos) }\end{array}$ \\
\hline
\end{tabular}

\begin{tabular}{rrrr}
1941 & 20,87 & 14,7 & 124,2 \\
1942 & 21,63 & 15,3 & 137,2 \\
1943 & 22,68 & 13,8 & 128,8 \\
1944 & 20,07 & 15,3 & 124,2 \\
1945 & 22,29 & 14,8 & 104,3 \\
1946 & 20,53 & 14,1 & 79,7 \\
1947 & 18,54 & 15,0 & 80,0 \\
1948 & 21,28 & 13,6 & 90,0 \\
1949 & 21,82 & 14,3 & 94,9 \\
1950 & 23,65 & 12,9 & 131,4 \\
1951 & 28,14 & 14,8 & 132,1 \\
1952 & 24,82 & 14,8 & 133,4 \\
1953 & 26,89 & 14,5 & 114,3 \\
1954 & 27,53 & 14,4 & 128,7 \\
1955 & 30,21 & 12,1 & 143,3 \\
1956 & 28,88 & 15,1 & 140,7 \\
1957 & 29,67 & 15,3 & 130,4 \\
1958 & 29,18 & 16,5 & 147,2 \\
1959 & 28,13 & 11,6 & 135,3 \\
1960 & 27,25 & 11,8 & 115,9 \\
1961 & 37,06 & 11,2 & 118,6 \\
1962 & 26,04 & 11,3 & 106,3 \\
1963 & 29,31 & 12,0 & 103,8 \\
1964 & 25,92 & 11,1 & 82,0 \\
1965 & 25,97 & 11,6 & 89,9 \\
1966 & 21,99 & 11,3 & 73,2 \\
1967 & $2 .$, & 12,4 & 81,3 \\
1968 & 25,50 & 12,5 & 91,0 \\
1969 & 24,82 & 12,1 & 85,7 \\
1970 & 26,43 & 12,6 & 82,9 \\
& & & \\
\hline & & &
\end{tabular}

* n.o de óbitos de menores de um ano n. total de óbitos $\times 100$

Fontes: IBGE

Anuário Estatístico do Brasil (IBGE). Rio de Janeiro. 1950-1972. 
YUNES, J. \& RONCHEZEL, V. S. C. - Evolução da mortalidade geral, infantil e proporcional no Brasil. Rev. Saúde puibl., S. Paulo, 8(supl.):3-48, 1974.

T A B E L A 34

Região Sul - Florianópolis - Evolução da mortalidade proporcional, mortalidade geral e mortalidade infantil - 1941-1970

\begin{tabular}{c|c|c|c}
\hline Ano & $\begin{array}{c}\text { Mortalidade } \\
\text { proporcio- } \\
\text { nal * }\end{array}$ & $\begin{array}{c}\text { Mortalidade } \\
\text { geral } \\
\text { (por mil } \\
\text { habitantes) }\end{array}$ & $\begin{array}{c}\text { Mortalidade } \\
\text { infantil } \\
\text { (por mil } \\
\text { nascidos } \\
\text { vivos) }\end{array}$ \\
\hline
\end{tabular}

\begin{tabular}{lrrr}
1941 & 28,34 & 27,2 & 303,7 \\
1942 & 27,57 & 21,6 & 208,6 \\
1943 & 25,65 & 20,5 & 187,5 \\
1944 & 26,17 & 22,7 & 132,9 \\
1945 & 29,53 & 26,5 & 235,7 \\
1946 & 29,68 & 23,2 & 193,1 \\
1947 & 28,72 & 24,1 & 191,4 \\
1948 & 31,97 & 22,8 & 170,6 \\
1949 & 31,81 & 21,9 & 145,2 \\
1950 & 21,66 & 16,0 & 139,1 \\
1951 & 30,98 & 12,7 & 136,4 \\
1952 & 32,39 & 15,3 & 130,8 \\
1953 & 31,77 & 13,8 & 109,9 \\
1954 & 30,60 & 15,5 & 113,5 \\
1955 & 31,33 & 12,9 & 113,3 \\
1956 & 30,95 & 13,6 & 123,3 \\
1957 & 35,72 & 13,3 & 130,2 \\
1958 & 33,30 & 11,8 & 113,6 \\
1959 & 35,41 & 13,7 & 130,8 \\
1960 & 33,68 & 10,8 & $\ldots$ \\
1961 & 40,65 & 11,1 & $\ldots$ \\
1962 & 30,55 & 10,5 & $\ldots$ \\
1963 & 34,51 & 10,2 & 93,9 \\
1964 & 30,78 & 10,3 & 72,1 \\
1965 & 35,08 & 9,6 & 94,9 \\
1966 & 25,98 & 9,0 & 26,0 \\
1967 & 28,54 & 9,9 & 28,5 \\
1968 & $\ldots$ & $\ldots$ & $\ldots$ \\
1969 & $\ldots$ & $\ldots$ & $\ldots$ \\
1970 & $\ldots$ & $\ldots$ & $\ldots$ \\
& & & \\
\hline & & & \\
\hline
\end{tabular}

* n.o de óbitos de menores de um ano n.o total de 6 bitos $\times 100$

Fontes: IBGE

Anuário Estatístico do Brasil (IBGE). Rio de Janeiro, 1950-1972.
TA B E L A 35

Região Sul - Porto Alegre - Evolucão da mortalidade proporcional, mortalidade geral e mortalidade infantil $-1941-1970$

\begin{tabular}{c|c|c|c} 
Ano & $\begin{array}{c}\text { Mortalidade } \\
\text { proporcio- } \\
\text { nal * }\end{array}$ & $\begin{array}{c}\text { Mortalidade } \\
\text { geral } \\
\text { (por mil } \\
\text { nabitantes) }\end{array}$ & $\begin{array}{c}\text { Mortalidade } \\
\text { infantil } \\
\text { (por mil } \\
\text { nascidos } \\
\text { vivos) }\end{array}$ \\
\hline
\end{tabular}

\begin{tabular}{rrrr}
1941 & 23,49 & 21,2 & 230,3 \\
1942 & 22,91 & 20,3 & 219,7 \\
1943 & 21,46 & 17,8 & 185,4 \\
1944 & 17,58 & 19,9 & 142,4 \\
1945 & 17,20 & 17,6 & 143,7 \\
1946 & 17,49 & 20,4 & 127,2 \\
1947 & 17,06 & 19,5 & 109,3 \\
1948 & 22,84 & 20,7 & 133,9 \\
1949 & 20,62 & 18,7 & 123,9 \\
1950 & 21,75 & 14,2 & 128,8 \\
1951 & 23,07 & 14,5 & 136,2 \\
1952 & 23,27 & 13,9 & 119,3 \\
1953 & 22,42 & 12,7 & 105,8 \\
1954 & 23,61 & 13,1 & 107,5 \\
1955 & 21,84 & 12,3 & 100,9 \\
1956 & 28,20 & 14,7 & 102,4 \\
1957 & 28,08 & 16,0 & 127,7 \\
1958 & 26,63 & 13,6 & 141,7 \\
1959 & 21,26 & 13,7 & 130,8 \\
1960 & 23,90 & 11,1 & 102,8 \\
1961 & 23,21 & 10,8 & 94,5 \\
1962 & 22,10 & 10,1 & 90,7 \\
1963 & 23,59 & 10,6 & 100,8 \\
1964 & $\ldots$ & $\ldots$ & $\ldots$ \\
1965 & $\ldots$ & $\ldots$ & $\ldots$ \\
1966 & $\ldots$ & $\ldots$ & $\ldots$ \\
1967 & $\ldots$ & $\ldots$. & $\ldots$ \\
1968 & 17,64 & 7,8 & 50,5 \\
1969 & 16,55 & 8,0 & 46,7 \\
1970 & 18,28 & 8,0 & 49,4 \\
& & & \\
\hline & & &
\end{tabular}

- n.o de óbitos de menores de um ano n.o total de óbitos $\times 100$

Fontes: IBGE

Anuário Estatístico do Brasil (IBGE). Rio de Janeiro. 1950-1972. 